\title{
ANFIBIOS COLECTADOS POR LA COMISIÓN CIENTÍFICA DEL PACÍFICO (ENTRE 1862 Y 1865) CONSERVADOS EN EL MUSEO NACIONAL DE CIENCIAS NATURALES DE MADRID
}

\author{
J. E. González Fernández *
}

\begin{abstract}
RESUMEN
La Comisión Científica del Pacífico (CCP) es considerada como la mayor expedición científica realizada por España al continente americano durante el siglo XIX. En poco más de tres años (agosto de 1862 a diciembre de 1865) se colectaron y enviaron a España más de 80.000 ejemplares de fauna y flora correspondientes a cerca de 10.000 especies diferentes. La expedición probablemente remitió a Madrid 786 anfibios pertenecientes a 139 especies, que sufrieron los avatares por los que pasó la colección herpetológica del Museo Nacional de Ciencias Naturales en los años siguientes. El presente trabajo recoge los resultados de las labores de rescate y documentación museológica de los ejemplares de anfibios colectados por esa expedición, incorporando información de archivos, antiguos catálogos, viejas fichas de colección, etiquetas antiguas y frascos donde se encontraban. Se reconstruye parte del itinerario de la expedición, a través de los diarios de campo, a fin de documentar los lugares y fechas de colecta. Por medio de un catálogo museológico se proporciona detallada información del estatus taxonómico vigente y de la información asociada de los ejemplares que aún se conservan procedentes de esta expedición. Actualmente éstos son 643 ejemplares -que representan el 81 ' $8 \%$ de los 786 anfibios atribuidos de forma histórica a la CCP por Almagro (1866) - pertenecientes a 61 táxones del nivel especie, 17 de los cuales se citan por primera vez en este trabajo como colectados por la CCP. Durante la realización de este trabajo, de los 672 anfibios (pertenecientes a 59 táxones menores) empleados por Jiménez de la Espada en sus publicaciones, han sido localizados un total de 522 ejemplares (lo que supone el 77'67\% de todos ellos), pertenecientes a 43 táxones (el $74{ }^{\prime} 13 \%$ de los empleados por Jiménez de la Espada). Dado el desconocimiento de la fauna batracológica sudamericana en la segunda mitad del siglo XIX, las publicaciones basadas en parte de ese material que realizó entonces Marcos Jiménez de la Espada han devenido en clásicos taxonómicos. Son así de destacar muchos de los tipos nomenclaturales empleados por Jiménez de la Espada entre 1871 y 1875 para la descripción de una familia, 14 géneros y 36 especies y subespecies de anfibios neotropicales, algunos de los cuales se habían dado por perdidos en la literatura taxonómica.
\end{abstract}

Palabras clave: Batracología; Catálogo museológico; Colecciones científicas; Anfibios neotropicales; Comisión Científica del Pacífico; Jiménez de la Espada.

\section{ABSTRACT}

Amphibians collected by the Pacific Scientific Comission (between 1862 and 1865), preserved in the Museo Nacional de Ciencias Naturales de Madrid

The Pacific Scientific Commission (CCP) is considered to be the most important scientific expedition carried out by Spain to the American continent in the nineteenth cen- 
tury. In a little more than three years (August 1862 to December 1865), over eighty thousand specimens of fauna and flora, corresponding to nearly ten thousand different species, were collected and sent to Spain. The expedition probably sent to Madrid 786 amphibians belonging to 139 species, which suffered the vicissitudes to which the herpetological collection of the Natural History Museum was subjected in subsequent years. This work contains the results of the recovery and museological documentation tasks carried out on the amphibian specimens collected by the expedition, including information from archives, old catalogues, old collection records, old labels, and jars where they were kept. In order to document the places and dates of collection, part of the itinerary of the expedition is reconstructed by means of field diaries. By means of a museological catalogue, detailed information is given on the current taxonomic status and information associated with the extant specimens from this expedition, which currently amount to 643 specimens $-81{ }^{\prime} 8 \%$ of the 786 amphibians historically ascribed to CCP by Almagro (1866)- belonging to 61 taxa at species level, 17 of which are cited for the first time as having been collected by the CCP. 672 amphibians (included in 58 minor taxa) were used by Jiménez de la Espada; of these, 522 (77'67\% of the total) included in 43 taxa (74'13\% of total taxa) have been located during this research. Given our lack of knowledge of the SouthAmerican batracological fauna during the second half of the nineteenth century, publications by Marcos Jiménez de la Espada based on part of this material have become taxonomic classics. In this regard, there are many nomenclatural types used by Jiménez de la Espada between 1871 and 1875 for the description of one family, thirteen genera, and 36 species and sub-species of neontropical amphibians, some of which were regarded as lost in taxonomic literature.

Keywords: Batracology, Museological catalogue; Scientific collections; Neotropical amphibians, Pacific Scientific Commission, Jiménez de la Espada.

\section{Introducción}

La importancia de la Comisión Científica del Pacífico (CCP), a los 140 años de su realización, se manifiesta claramente por la relevancia que para los estudiosos de la fauna batracológica neotropical sigue teniendo el material colectado en esa expedición (1862-1865). Varios han sido los trabajos que tratan sobre la CCP, sobre su historia, integrantes, sobre el material colectado por ésta, y particularmente sobre la figura de Marcos Jiménez de la Espada (ver bibliografía en www.pacifico.csic.es). Sin embargo, hasta ahora no se había realizado un catálogo de los anfibios colectados por la misma.

Muy probablemente por falta material de tiempo, y sobre todo de medios, ni siquiera el propio Jiménez de la Espada, bajo cuya responsabilidad se recolectaron estos ejemplares y quien empleó bastantes de ellos en sus trabajos, nunca realizó un inventario completo de los mismos. Así pues, nunca existió ningún listado oficial completo de los ejemplares colectados, sólo las cifras de 786 ejemplares pertenecientes a 139 especies, indicadas en la Enumeración de las colecciones expuestas recogida por Almagro (1866). Estas cifras coinciden con las manejadas por Martínez (1898), aunque seguramente éste se basó en los números aportados por Almagro (1866) y no debió actualizarlos en esa fecha, pues por entonces ya se habían trasladado los fondos del Museo Nacional de Ciencias Naturales $(\mathrm{MNCN})$ a los sótanos de la actual Biblioteca Nacional, con la consiguiente pérdida y deterioro de material.

Antonio de Zulueta, insigne genetista que entre los años 1911 y 1913 realizó una revisión completa de la colección de anfibios y reptiles del MNCN, tampoco confeccionó ningún inventario global, o al menos no se conserva en el archivo del MNCN. Nos dejó, eso sí, unas fichas revisadas por él, aunque tampoco sabemos si las confeccionó en su totalidad, o si añadió su sello de revisión a las ya existentes con anterioridad. Sí hemos podido constatar que las etiquetas más antiguas que portan los ejemplares, con muy pocas excepciones que retienen las originales de la CCP, fueron confeccionadas por Zulueta. Se desconoce, por no existir ningún documento explicativo de esta labor de revisión a principios del siglo XX, si también fueron copiadas y reemplazadas por Zulueta las etiquetas y fichas anteriores.

Aunque la Guerra Civil (1936-1939) afortunadamente no afectó físicamente a las colecciones del MNCN, el posterior exilio de una parte importante de su personal técnico y científico contribuyó no poco a que todas las colecciones, incluidos los anfibios de la CCP, sufrieran un largo periodo de desidia y abandono.

Durante los siguientes 50 años el estudio de la colección del Pacífico (como del resto de la colec- 
ción) es prácticamente inexistente, siendo utilizada de forma puntual y parcialmente por unos pocos investigadores. A finales de los años sesenta Jay M. Savage estudia los sintipos de Hyloxalus fuliginosus Jiménez de la Espada, 1871, designando un lectotipo. Creemos que en torno a 1969, William E. Duellman visita la propia colección de anfibios y reptiles del MNCN (Lynch, 1975: 31); especialmente busca material colectado por la CCP y estudiado por Jiménez de la Espada, logrando localizar algunos de los ejemplares tipo nomenclaturales descritos por éste. Posteriormente, W. Ronald Heyer visita el MNCN, estudiando algunos leptodactílidos y publica los resultados en años posteriores (Heyer, 1969, 1979; Heyer \& Peters, 1971). Linda Trueb estudia algunos hílidos del grupo de los Hemiphractus (Trueb, 1974). Tendrán que pasar más de veinte años para que de nuevo una parte del material tipo empleado por Jiménez de la Espada vuelva a ser utilizado. Luis A. Coloma, a principios de los noventa, solicita en préstamo el lectotipo y paratipo de Hyloxalus fuliginosus (Jiménez de la Espada, 1871) y los sintipos de Hyloxalus bocagei (Jiménez de la Espada, 1871) y tiempo después designa un lectotipo para la especie (Coloma, 1995).

Con arreglo a todo lo anterior, antes de iniciar este trabajo, el conocimiento contrastado que teníamos (desde las publicaciones de Jiménez de la Espada) sobre la permanencia en las colecciones del MNCN, tanto de los ejemplares tipo nomenclaturales empleados por éste como de los que no tenían esa categoría, se reducía a unos pocos ejemplares pertenecientes a 18 especies, que seguidamente indicamos: (1) Leptodactylus latinasus Jiménez de la Espada, 1875; estudiado por W. Ronald Heyer el ejemplar contenido en el bote $\mathrm{n}^{\mathrm{o}} 335$ (actual MNCN 1695), describió su estado como muy deteriorado, pero aún así, reconoció el holotipo como el descrito por Jiménez de la Espada; de igual forma, reconoció la validez de la especie (Heyer, 1969: 1-3). (2) Leptodactylus wuchereri Jiménez de la Espada, 1875; también fue estudiado por W. Ronald Heyer el ejemplar conservado en el bote $\mathrm{n}^{\mathrm{o}} 163$ (actual MNCN 1694), pese a las aparentes diferencias encontradas en alguna medida y carácter descriptivo del ejemplar con respecto a lo indicado por Jiménez de la Espada, el ejemplar es reconocido como el estudiado por Jiménez de la Espada, aunque considerado un juvenil de Leptodactylus pentadactylus (Laurenti, 1768) y por tanto pone la especie en sinonimia de ésta (Heyer, 1969: 6-8); posteriormente, Heyer (1979: 15) considera que de quien realmente es sinónimo L. wuchereri, es de L. labyrinthicus (Spix, 1824). (3) Leptodactylus goliath Jiménez de la Espada, 1875; estudiado por Heyer el ejemplar contenido en el bote $\mathrm{n}^{\mathrm{o}} 328$ (actual MNCN 1691) -único individuo encontrado en la colección del MNCN, en ese momento, de los cuatro sintipos empleados por Jiménez de la Espada en la descripción de la especie- es designado lectotipo de $L$. goliath y confirmada la sinonimia propuesta por Boulenger (1882: 240) con L. pentadactylus (Heyer \& Peters, 1971: 167; Heyer, 1979: 15, 26). (4) Leptodactylus labrosus Jiménez de la Espada, 1875; también por Heyer, fue estudiado un espécimen hembra de 50'5 mm de longitud total, sin número de bote o ejemplar (Heyer \& Peters, 1971: 164-165), el actual MNCN 3524; único sintipo de los dos empleados por Jiménez de la Espada en la descripción de la especie que fue localizado, en ese momento, en la colección del MNCN; tras su análisis (Heyer \& Peters, op. cit.), confirman la validez de la especie y designan a este individuo como lectotipo de $L$. labrosus. (5) Leptodactylus stenodema Jiménez de la Espada, 1875; Heyer también estudió los ejemplares contenidos en los botes $n^{\text {os }} 190$ y 189 (actuales MNCN 1687 y 1688), confirmando la validez de la especie y designando lectotipo de la misma al ejemplar MNCN $1687 \mathrm{y}$, consecuentemente, paralectotipo al MNCN 1688 (Heyer \& Peters, 1971: 164-165; Heyer, 1979: 15, 34-36) (6) Rhinella iserni (Jiménez de la Espada, 1875); aunque poco después de su descripción fue sinonimizado con $B$. typhonius Schneider, 1799. Savage (1978) lo consideró especie válida, aunque sin estudiar el ejemplar. Posteriormente, Hoogmoed, tras estudiar detenidamente el ejemplar, lo separó del grupo "margaritifer y confirmó la validez de la especie (Hoogmoed, 1986). (7) Hyloxalus bocagei; estudiados por Luis A. Coloma los ejemplares MNCN 1583-1584, reafirma la validez de la especie y el primero de ellos es designado lectotipo y el segundo se convierte en paralectotipo (Coloma, 1995: 21). (8) Hyloxalus fuliginosus: estudiados por Jay M. Savage los ejemplares contenidos en el bote $\mathrm{n}^{\circ} 276$ (actuales MNCN 1585-1586), confirma la validez de la especie y designa al primero de ellos como lectotipo y consecuentemente el segundo se convierte en paralectotipo (Savage, 1968: 753), Frost $(2004,2006)$ recoge erróneamente -probablemente del trabajo de Coloma (1995: 31), quien también revisó los tiposque el número de catálogo actual del lectotipo es el MNCN 1584, cuando el correcto y realmente indicado por Coloma es el MNCN 1585. (9) Gastrotheca testudinea Jiménez de la Espada, 1871, estudiado por William E. Duellman el ejemplar guardado en el bote $\mathrm{n}^{\mathrm{o}} 155$ (actual MNCN 3510), éste es confirmado como el holotipo descrito por 
Jiménez de la Espada y la especie reafirmada como válida (Duellman, 1974: 4-5; 1977: 20). (10) Hemiphractus bubalus (Jiménez de la Espada, 1871); revisado por Linda Trueb el ejemplar contenido en el frasco 176, actual MNCN 1736, lo designa como holotipo de la especie (Trueb, 1974: 23). Este dato queda también recogido en Duellman (1977: 2122). (11) Cerathyla braconnieri (Jiménez de la Espada, 1871); igualmente revisado por Linda Trueb el ejemplar contenido en el bote $\mathrm{n}^{\mathrm{o}} 174$ (actual MNCN 1735), la especie fue sinonimizada con Hemiphractus bubalus (Trueb, 1974: 23). Este dato queda también recogido en Duellman (1977: 21-22). (12) Cerathyla palmarum (Jiménez de la Espada, 1871); estudiado en este caso el ejemplar contenido en el bote $\mathrm{n}^{\mathrm{o}} 175$ (actual MNCN 1735) también por Linda Trueb, sinonimizó la especie con Hemiphractus bubalus (Trueb, 1974: 23), dato que queda también recogido en Duellman (1977: 2122). (13) Hemiphractus proboscideus (Jiménez de la Espada, 1871); estudiado el ejemplar contenido en el bote $n^{\circ} 173$ (actual MNCN 1737) por Linda Trueb, la especie fue considerada válida y designado dicho ejemplar como holotipo de la misma (Trueb, 1974: 38), lo que tambien es reconocido por Duellman (1977: 22-23). (14) Hyla reticulata Jiménez de la Espada, 1871; estudiado por William E. Duellman el ejemplar conservado en el bote $n^{\circ}$ 329 (actual MNCN 3473), es confirmado como el holotipo descrito por Jiménez de la Espada, pero la especie es puesta por Duellman (1974: 4-5) en la sinonimia de Dendropsophus triangulum (Günther, 1869).

Aunque después de Jiménez de la Espada, no habían sido estudiado por nadie hasta hoy en día, John Lynch y Albert Schwartz, basándose en las descripciones originales de Jiménez de la Espada, sinonimizan las especies (15) Hylodes philippi Jiménez de la Espada, 1875 y (16) Hylodes verrucosus Jiménez de la Espada, 1875 con (17) Oreobates quixensis; al mismo tiempo Lynch \& Schwartz (1971: 109) sinonimizan el género Oreobates (Jiménez de la Espada, 1872) con el género Ischnocnema Reinhardt \& Lütken, 1862. De los ejemplares tipo de las tres especies mencionadas, Duellman durante una visita anterior al MNCN, sólo localiza el holotipo de Hylodes philippi, siendo recogido en el trabajo de Lynch \& Schwartz (1971) con el número de frasco 202 (actual MNCN 1600) y da por perdidos los de las otras dos especies. Lo mismo ha ocurrido con (18) Cystignathus hidalgoi Jiménez de la Espada, 1875; fue sinonimizado primero por Gorham (1966: 119), con Eupsophus taeniatus (Girard, 1855) y posteriormente Lynch (1971: 129), al sinonimizar el género
Eupsophus Fitzinger, 1843 con el género Batrachyla Bell, 1843, acabó convirtiéndolo en sinónimo de Batrachyla taeniata (Girard, 1855).

No podemos dejar de comentar, en este apartado, dos trabajos que, aunque bibliográficos, son los únicos que de forma global consideran taxonómicamente el material estudiado por Jiménez de la Espada y sus conclusiones.

El primero de ellos (Savage, 1978) acompaña a una reimpresión en facsímil del trabajo de Jiménez de la Espada Vertebrados del Viaje al Pacífico (Jiménez de la Espada, 1975a) y trata sobre el viaje, itinerario, bibliografía de Jiménez de la Espada, etc. Además, y esta es la parte que más nos interesa, Savage (1978: xiii), presenta una tabla comparativa entre los nombres asignados por Jiménez de la Espada a los diferentes táxones descritos por él y la denominación admitida como válida en ese momento. Según esta tabla los táxones admitidos como válidos, en esa fecha, corresponden a 24 especies: Atelopus planispina, Bufo iserni, Centrolene geckoideum, Colostethus fuliginosus, C. bocagei, C. pulchelus, "Cystignathus" humilis, Dendrophryniscus brevipollicatus, Edalorhina perezi, Eleutherodactylus cornutus, E. diadematus, E. galdi, E. lacrimosus, E. rubicundus, Gastrotheca testudinea, Hemiprhactus proboscideus, $H$. bubalus, Ischnocnema quixensis, Leptodactylus labrosus, L. latinasus, L. stenodema, Engystomops petersi, P. stentor y "Pyxicephalus leyboldi"; igualmente recoge la puesta en sinonimia (efectuada con anterioridad por diferentes autores) de las otras 15 especies y subespecies descritas por Jiménez de la Espada.

El segundo de ellos (De la Riva, 2000) realiza un exhaustivo resumen de la validez taxonómica que ha merecido a los diferentes autores la consideración de los táxones descritos por Jiménez de la Espada, así como sus propios criterios al respecto, no sólo en el trabajo considerado por Savage (op. cit.) sino también en las otros cinco trabajos herpetológicos realizados por Jiménez de la Espada. En el trabajo que nos ocupa (De la Riva, 2000), el autor recoge la validez, en esa fecha de, 23 táxones: Atelopus planispina, Bufo iserni, Centrolene geckoideum, Colostethus fuliginosus, C. bocagei, C. pulchelus, "Cystignathus" humilis, Dendrophryniscus brevipollicatus, Edalorhina perezi, Eleutherodactylus cornutus, E. diadematus, E. galdi, E. lacrimosus, E. rubicundus, Ensatina platensis, Gastrotheca testudinea, Hemiprhactus proboscideus, H. bubalus, Ischnocnema quixensis, Leptodactylus labrosus, L. latinasus, L. stenodema y Engystomops petersi. También refleja la general consideración de 15 de los táxones descritos por 
Jiménez de la Espada como sinonimia de otros y hace especial consideración a la indeterminada situación taxonómica de Leptodactylus wuchereri. Finalmente, analiza también el estatus taxonómico de la Familia Dendrophryniscidae, hoy en la sinonimia de Bufonidae y de los 14 géneros descritos por Jiménez de la Espada, recogiendo la validez de tan sólo 2 de ellos: Edalorhina y Dendrophryniscus, ya que los 12 restantes eran considerados sinónimos.

Hacia 1985 el MNCN y sus colecciones comienzan a resurgir del práctico abandono de lustros (González-Fernández, 2000). Al iniciarse la década, Juan Pablo Martínez-Rica inicia una revisión de la colección de anfibios y reptiles, recogiendo muy sucintamente en una serie de libros-inventario la información que acompaña a los ejemplares, así como confeccionando algunas fichas y etiquetas nuevas. En torno a 1985, el profesor argentino José M. Cei, invitado a realizar la actualización taxonómica de los reptiles sudamericanos de la colección, visita varias veces el MNCN y realiza también una revisión rápida y visual de los anfibios sudamericanos, identificando y revisando la adscripción de algunos ejemplares. A finales de ese mismo año, se comienza un proyecto de recuperación global de todas las colecciones del MNCN y ha sido necesario llegar a un razonable final de esa labor para poder inventariar y evaluar, en un contexto global, tanto las muestras perdidas como las recuperadas, y su información aneja.

Todas estas circunstancias han complicado la determinación del punto de partida exacto de este trabajo; no obstante, hemos podido hacer una recopilación de los ejemplares que Jiménez de la Espada cita en sus trabajos, lo que nos ha permitido detectar la existencia en la colección de anfibios y reptiles del MNCN de otro material que, pese a haber sido colectado por la CCP, nunca fue estudiado ni citado por ningún autor previamente y que, por primera vez, relacionamos en el catálogo recogido en este trabajo.

Coincidiendo con el 140 aniversario del viaje hemos querido confeccionar el inventario de los anfibios colectados por la CCP que aún se conservan en el MNCN, para conocimiento de la comunidad herpetológica, ya que desde los trabajos de Jiménez de la Espada, se desconoce el estado y permanencia o no de la mayor parte de ellos. Por otra parte, algunos ejemplares tipo nomenclaturales, figuran como desaparecidos en algunas publicaciones especializadas (o no están especificados sus correctos números de catálogo en dichas publicaciones). Así las cosas, todas estas posibles dudas son aclaradas en el catálogo que recoge el inventario confeccionado y que se muestra más adelante.
Igualmente, ilustraciones de una parte importante de los ejemplares recogidos en este catálogo pueden consultarse en González-Fernández (2004).

Finalmente, por las excepcionales condiciones en las que fueron colectados los anfibios objeto del presente trabajo, y por su importancia histórica, hemos creído que podría ser interesante realizar una sucinta descripción de las circunstancias que rodearon a la CCP tanto durante su viaje exploratorio como después, así como una brevísima reseña biográfica de sus participantes más directos y que recogemos en el Apéndice 6.

\section{Material y Métodos}

El proceso de documentación de los ejemplares partió del estudio de la información recogida en las etiquetas originales confeccionadas por los colectores, así como de las fichas antiguas que había en la colección, los antiguos libros de entrada, catálogo, etc., y también de las publicaciones de Jiménez de la Espada y otros trabajos zoológicos. Como ya se ha mencionado, en un número importante de casos tanto etiquetas, fichas, como incluso los propios ejemplares, no se han conservado hasta nuestros días.

\section{(A) Aspectos taxonómicos}

Se ha actualizado taxonómicamente en todos los ejemplares su nombre genérico y específico, mediante comprobación de las identificaciones previas, verificando que la denominación es correcta actualmente, o bien identificado las sinonimias y nombres vigentes de los táxones en cuestión. Aunque como norma general para la asignación taxonómica se han seguido los criterios de Frost et al. (2006), nos ha sido de utilidad inconmensurable un trabajo reciente (De la Riva, 2000) que, por el lugar de su publicación, puede haber pasado desapercibido para muchos herpetólogos; como ya hemos indicado anteriormente, en dicho trabajo, De la Riva comenta el estatus taxonómico de los diferentes taxa descritos por Jiménez de la Espada, lo que nos ha servido de base para resolver no pocas dudas al respecto. También hemos empleado para el grupo de los Hylidae, la propuesta taxonómica de Faivovich et al. (2005), y alguna otra para casos concretos, que se indican al tratar cada especie en el catálogo.

\section{(B) Aspectos GeOgRÁficos}

Los datos no taxonómicos, especialmente geográficos, no incluidos en las fichas o etiquetas dispo- 
nibles y que se han deducido por otras fuentes de información (diarios, publicaciones, etc.), se añaden a la base de datos y fichas confeccionadas a partir de este trabajo. Para indicar esta circunstancia, estas adiciones se incluyen entre corchetes: [ ], como por ejemplo «San Miguel [de Chimbo]». Como las localizaciones geográficas antiguas eran en muchos casos poco precisas o ambiguas, se ha afinado lo más posible la situación geográfica exacta del lugar de colecta de los ejemplares. El proceso ha diferido según la información inicial con la que se contaba: a) Cuando la localidad indicada previamente era coincidente con la denominación actual, se ha situado ésta en los mapas modernos, anotándose provincia, distrito, departamento, estado, etc. b) Cuando no era coincidente se ha actualizado la denominación, indicándose a continuación de la denominación antigua entre paréntesis y precedida del signo " $=$ ". Por ejemplo: Pernambuco (= Recife). Asimismo, también se han añadido las entidades geográficas de mayor categoría a las que pertenece el lugar. c) En los pocos casos en los que las localidades de colecta indicadas en las etiquetas o fichas existentes no han podido ser localizadas en los mapas consultados, estas denominaciones se indican seguidas (como superíndice) de signos de interrogación entre paréntesis, como por ejemplo: El Jorge ${ }^{(i ?)}$.

La actualización geográfica de los lugares de colecta se ha realizado empleando los atlas TimesRialp (1993) y Microsoft (2001) de forma genérica, aunque también se han utilizado algunos mapas de Ecuador, Perú, Brasil, Uruguay, etc. como los disponibles vía Internet en www.multimap.com y www.calle.com/world. Para localizar poblaciones históricas, así como para delimitar las fronteras modificadas entre las repúblicas sudamericanas durante estos años, fundamentalmente EcuadorPerú y Perú-Bolivia-Chile, se ha empleado la Enciclopedia Universal Ilustrada de 1905.

\section{(C) Parámetros incluidos en los registros}

En cada registro se facilita, cuando se conoce, y en este orden, la información siguiente: (1) Antecedido por el acrónimo del Museo Nacional de Ciencias Naturales (MNCN), el número de catálogo del ejemplar. (2) Si el ejemplar es un tipo nomenclatural de una especie, se indica su clase (holotipo, lectotipo, sintipo, etc.), así como el autor y año de descripción de la misma. En ambos casos y sólo cuando el taxon es diferente de la denominación bajo la que se encuentra recogido, se menciona de qué especie o género es el tipo, así como el autor y el año de descripción del taxon. (3) Sexo, edad y número de los individuos (si se trata de un lote). (4) Tipo de conservación del ejemplar, mediante unas abreviaturas codificadas que se explican más detalladamente en un apartado posterior. (5) Los datos de colecta, de menor a mayor entidad geográfica, indicándose el paraje, accidente geográfico, pedanía, etc. donde se ha colectado el ejemplar, la localidad a la que éste pertenece administrativamente, provincia, departamento y país, por ejemplo: Orillas del Amazonas, Tabatinga, Amazonas, Brasil. (6) La fecha de colecta en formato de ocho dígitos (dd-mm-aaaa); en ocasiones, cuando la colecta del lote se realiza entre varios días, el formato varía ligeramente (vide infra). (7) El colector y el donante. (8) Finalmente, bajo el epígrafe de observaciones, se indican todas aquellas circunstancias dignas de mención no reflejadas con anterioridad. Todos los campos mencionados se separan mediante un punto y guión al final de cada uno de ellos. Aquellos datos que no se conocen, simplemente no aparecen, obviándose guiones o signos de interrogación para indicar su inexistencia. Como en el caso de las referencias geográficas, la información deducida (como algunas fechas de colecta) de otros datos conocidos (diarios, publicaciones, etc.), se indica también entre corchetes "[...]". Los datos que se suponen con un alto grado de seguridad, pero aún así se dudan, se facilitan entre signos de interrogación " ¿...?".

\section{(D) Claves y Códigos empleados}

A lo largo del catálogo se emplean los siguientes códigos abreviados:

(1) El sexo se indica por las abreviaturas M (macho) y H (hembra).

(2) La edad de los individuos se indica mediante las abreviaturas Lv (larva), Pm (posmetamórfico), Jv (juvenil) y Ad (adulto).

(3) La forma de conservación puede ser en fluido o en seco, y en ambos casos puede tratarse de ejemplares enteros o de alguna parte, como esqueletos, pieles, etc. Las claves que se emplean son las siguientes: (a) ECF (Ejemplar completo en fluido); es la forma más común de conservación, se guardan los ejemplares incluidos en una solución acuosa de etanol (65-70\%) o formol (5-10\%). (b) EDC (Esqueleto desarticulado completo); se guardan los huesos obtenidos de la desarticulación completa del ejemplar. Los esqueletos así obtenidos se conservan en seco.

(4) En las fechas, también se emplean claves aclaratorias: a) Cuando se desconoce la fecha exacta de colecta, pero se conoce la fecha de entrada 
al museo, o la fecha de donación, compra, etc., o está documentada en alguna publicación, se antecede a dicha fecha el símbolo " $<$ " indicativo de que la colecta fue anterior a esa fecha conocida, ej.: <1863 (anterior a 1863). b) Cuando algún factor de la fecha oscila entre varios valores, se indican separados por una barra (/), ej.: 16/30-09-1862 indicativo de que la colecta se realizó entre días 16 y 30 de septiembre de 1862. c) En todos los casos, cuando la fecha no figuraba en la información disponible y ha sido deducida por otros datos o información, ésta se presenta incluida entre corchetes, por ejemplo: [01-1865].

(E) CONSIDERACIONES SOBRE LAS REFERENCIAS TAXONÓMICAS EN EL CATÁLOGO

La información taxonómica facilitada en el catálogo para cada especie atiende a los siguientes criterios:

1 Tras la denominación actual incluyendo autor y año de descripción, se indican en líneas consecutivas las publicaciones que han supuesto algún cambio nomenclatural, desde su descripción original hasta la denominación actualmente aceptada. Por ejemplo:

Scinax ruber (Laurenti, 1768)

Hyla rubra Laurenti, 1768, Synops. Rept.: 5.

Scinax rubra, Duellman \& Wiens, 1992, Occas. Pap. Mus. Nat. Hist. Univ. Kansas, 151: 23.

Scinax ruber, Köhler \& Böhme, 1996, Rev. Fr. Aquariol., 23: 139.

2 Cuando la especie fue estudiada por Jiménez de la Espada, se recoge además toda la revisión taxonómica que él consideró y por tanto citó en sus publicaciones. Ejemplo:

\section{Rhinella proboscidea (Spix, 1824)}

Bufo (Oxyrhynchus) proboscideus Spix, 1824, Spec. Nov. Testud. Ran. Brasil.: 52.

Otilophus typhonius, Peters, 1871, Monatsber. Preuss. Akad. Wiss. Berlin, 1871: 403.

En la siguiente fila, se indica, resaltado en negrita, la denominación empleada por Jiménez de la Espada. En el mismo ejemplo anterior:

Oxyrhynchus proboscideus, Jiménez de la Espada, 1875, Vert. Viaj. Pacif., Batr.: 178.

En las filas siguientes se recogen los cambios taxonómicos posteriores a Jiménez de la Espada, hasta la denominación aceptada en el momento de la finalización de este trabajo (30 de septiembre de 2006). En el ejemplo anterior

Bufo proboscideus, Hoogmoed, 1986, Stud. Herpetol., Prague: 147-150.
De tal forma que la relación definitiva resultante sería:

Rhinella proboscidea (Spix, 1824)

Bufo (Oxyrhynchus) proboscideus Spix, 1824, Spec. Nov. Testud. Ran. Brasil.: 52.

Otilophus typhonius, Peters, 1871, Monatsber. Preuss. Akad. Wiss. Berlin, 1871: 403.

Oxyrhynchus proboscideus, Jiménez de la Espada, 1875, Vert. Viaj. Pacif., Batr: 178.

Bufo proboscideus, Hoogmoed, 1986, Stud. Herpetol., Prague: $147-150$.

Rhinella proboscidea, Frost, Grant, Faivovich, Bain, Haas, Haddad, De Sá, Channing, Wilkinson, Donnellan, Raxworthy, Campbell, Blotto, Moler, Drewes, Nussbaum, Lynch, Green \& Wheeler, 2006, Bull. Am. Mus. Nat. Hist, 297: 366.

3 Si Jiménez de la Espada no estudió la especie en sus publicaciones, se indica en negrita este hecho en una nueva línea. Si además existe una ficha o etiqueta de bote antigua se indica dicha existencia, con la expresión también en negrita: "Figuraba en la ficha antigua como..." y la denominación y autor que recoge la ficha.

4 Cuando la especie en cuestión fue descrita por Jiménez de la Espada y posteriormente fue sinonimizada, se indica dicha circunstancia, el autor y la cita bibliográfica correspondiente. Ej.: Sinonimizado con Batrachyla taeniata por Gorham, 1966, Das Tierreich, 85: 119.

5 Si los ejemplares han sido revisados por algún especialista, se indica dicha circunstancia, empleándose el término determinado/s, cuando se clasificó por primera vez con la denominación actual y revisado/s, cuando se confirmó la determinación. Ej: Determinado como Hyla leucophylla por A. Zulueta en 1911 y revisado por J. M. Cei en 1985.

Por lo que respecta al tratamiento bibliográfico de todas las citas taxonómicas recogidas para cada especie en este epígrafe, sólo se reflejan específicamente en el apartado de bibliografía aquellas que afectan a los ejemplares tipo de la colección en uno de los dos supuestos siguientes: a) Si en ellas se designa un neotipo, lectotipo, etc., de ejemplares pertenecientes a la colección del MNCN. Ej. Leptodactylus labrosus, Heyer \& Peters, 1971. Proc. Biol. Soc. Washington, 84: 167 (designan lectotipo). b) Si la publicación establece la sinonimia del taxon descrito por Jiménez de la Espada con otro preferente según el Código Internacional de Nomenclatura Zoológica (ICZN). Ejemplo: Sinonimizado con Bufo arenarum por Boulenger, 1882, Cat. Batr. Sal. Brit. Mus.: 314. 


\section{Resultados y Discusión}

La revisión de los algo más de 3.500 anfibios de procedencia americana existentes en la colección del MNCN ha permitido, 140 años después de la finalización del viaje, determinar por primera vez de forma fehaciente cuáles de éstos fueron colectados por la CCP y aún se conservan. Con toda la información existente y la que se ha reunido mediante consultas documentales diversas, se ha confeccionado una base de datos que en su núcleo fundamental se muestra en el catálogo aquí presentado. Este catálogo incluye 643 ejemplares, de los cuales 628 están adscritos a 59 táxones menores, mientras que los 15 ejemplares restantes sólo han podido ser identificados a nivel de género. Por tanto, se ha logrado localizar el $81^{\prime} 8 \%$ de los 786 anfibios atribuidos de forma histórica a las colectas de la CCP por Almagro (1866). Entre los anfibios localizados se encuentran 522 ejemplares (el $77^{\prime} 67 \%$ ) de los de 672 empleados por Jiménez de la Espada en sus trabajos. Éstos pertenecen a 42 táxones, lo que representa el $722^{\prime} 43 \%$ de los 58 táxones menores (especies y "variedades") estudiados por él. Queremos destacar que, salvo el de $C$. caudiverbera (MNCN 1734), se han perdido todos los esqueletos que Jiménez de la Espada estudió.

Como consecuencia de la investigación desarrollada, por primera vez se proporciona información inédita sobre 19 especies colectadas por la CCP, y no citadas nunca ni por Jiménez de la Espada ni por ningún otro investigador posterior.

También se ha constatado la desaparición, a lo largo de estos años, de al menos 63 ejemplares, ya que algunas fichas antiguas estudiadas se refieren a más de un ejemplar, pero sin especificar cuántos, cuya documentación sí ha podido ser localizada y cuya correspondiente información también se facilita en el presente trabajo.

Toda esta información nos permite deducir que si a los ejemplares ya localizados (643) añadimos todos aquellos para los que, de una u otra forma, se ha podido constatar su desaparición, la cifra obtenida es de 705 ejemplares, que ya se aproxima bastante a los 786 indicados por Almagro (1866). Donde parece existir más discrepancia es en el número de especies, ya que las 139 indicadas por Almagro (1866) distan mucho de las 64 (61 a nivel de especie, 3 más identificadas únicamente a nivel de género) constatadas en este trabajo. Aunque añadamos aquellas correspondientes a los ejemplares que sabemos con seguridad que se han perdido a lo largo de estos 140 años (16 especies), la cifra total de 80 especies es aún muy distante de la indicada por Almagro (1866). Todo ello nos inclina a pensar que en la cifra de 139 especies de anfibios mencionada por Almagro, éste no se refería a especies biológicas diferentes. En la Enumeración de las Colecciones Expuestas (para la exposición en el Jardín Botánico), en los apartados referentes a otros grupos como crustáceos, Almagro (1866: 168) indica textualmente: “... consta esta colección de 179 especies distintas, ó de diferente localidad y ...”, y en la relación de peces igualmente afirma "...consta esta colección de 677 especies distintas, ó de diferente localidad..." (Almagro, 1866: 169). Parece claro que Almagro habla de especies distintas o de distintas localidades indistintamente. Aunque junto a los cuadros con los datos de especies y número de individuos de cada una referentes a reptiles, anfibios, aves y mamíferos de ese inventario no existe ninguna anotación en este sentido, nos inclinamos a pensar que se está refiriendo al conjunto de especies distintas, o de diferente localidad. Por lo que respecta a la afirmación por parte de Martínez en el obituario de Marcos Jiménez de la Espada (Martínez, 1898) de ese mismo número de 139 especies, creemos que Martínez debió de recoger la información facilitada por Almagro en 1866, pero no la comprobó ni actualizó a esa fecha de 1898 .

Por otra parte, durante la elaboración del presente trabajo se ha podido constatar la existencia en la colección del MNCN de 138 anfibios colectados por la CCP que son ejemplares tipo nomenclaturales. Están adscritos a 28 especies y subespecies diferentes, de las que 14 de ellas son unánimemente admitidas como válidas, 12 son consideradas sinonimia de otras y en la última de ellas (Leptodactilus wuchereri) no existe acuerdo definitivo al respecto. En la actualidad se considera, que la Familia Dendrophryniscidae (Jiménez de la Espada, 1871) es sinónimo de Bufonidae. Por lo que respecta a los 14 géneros, 36 especies y 3 subespecies (o variedades) descritas por Jiménez de la Espada (González-Fernández, 2000: 73), 6 géneros y 22 especies se aceptan como válidas, mientras que otros 8 géneros, 14 especies y 3 subespecies son consideradas sinonimias. En el Apéndice 1, se comentan y recogen pormenorizadamente todas estas circunstancias.

Este trabajo también ha permitido confirmar la presencia en la colección de ejemplares tipo considerados historicamente perdidos por diferentes autores, o de los que se desconocían sus actuales números de catálogo. Éstos pertenencen a los siguientes táxones descritos por Jiménez de la Espada: (1) Bufo marinus platensis, (2) Bufo mari- 
nus napensis, (3) Bufo marinus fluminensis, (4) Centrolene geckoideum, (5) Edalorhina perezi, (6) Eleutherodactylus cornutus, (7) Eleutherodactylus galdi, (8) Eleutherodactylus napaeus, (9) Gastrotheca testudinea, (10) Hyla reticulata, (11) Hylodes verrucosus, (12) Oreobates quixensis, (13) Limnophys napaeus y (14) Pleurodema granulosum. Los datos particulares de cada uno de ellos se muestran también en el catálogo confeccionado. También se indican aquellos ejemplares tipo empleados por Jiménes de la Espada que, desgraciadamente, no han podico ser localizados durante el presente estudio, así como aquellos colectados por la CCP y que, empleados o no por Jiménez de la Espada, tampoco han podido ser localizados, aunque sí se ha encontrado alguna ficha de antigua colección que recoge su existencia en la colección, en tiempos pasados (Apéndices 2-5).

Además, queremos reseñar que entre el material conservado, y reseñado en el catálogo, se encuentran varios ejemplares de importancia científica especial, al pertenecer a especies consideradas actualmente extintas (Ron et al., 2002), como Atelopus guanujo Coloma, 2002 o Atelopus ignescens (Cornalia, 1849). También se ha ampliado el aéra de distribución de una especie (Caecilia gracilis) a Ecuador.

Al margen de todo lo anterior, a nuestro entender el principal resultado del presente trabajo es en sí mismo el catálogo que seguidamente se proporciona, en el cual se recoge por primera vez toda la información disponible, comentarios, referencias etc., de todos los anfibios que se colectaron durante los más de tres años que duró el viaje de la CCP por tierras americanas y que a 30 de septiembre de 2006 se conservan en el Museo Nacional de Ciencias Naturales (CSIC) de Madrid.

Como última consideración, nos hemos inclinado en esta ocasión por elegir (dentro de cada categoría taxonómica) una organización alfabética de todos los táxones contemplados en este catálogo, pese a ser hasta hace poco costumbre mayoritaria la confección de los catálogos en orden sistemático, por dos motivos: 1- Las directrices de publicaciones tan relevantes en el mundo de la Herpetología y más concretamente de la Batracología, como Amphibian Species of the World (Frost, 1985, 2006 y Frost et al., 2006) y 2- La disparidad existente, en algunos casos, en los criterios y organización taxonómica sugerida por diferentes autores, lo que supone una falta de coincidencia unánime a la hora de considerar qué grupos son más primitivos y cuáles más evolucionados (sobre todo en grupos menores).
Catálogo de los anfibios colectados por la CCP conservados en la colección de anfibios y reptiles del Museo Nacional de Ciencias Naturales (CSIC) de Madrid, a 30 de septiembre de 2006

\section{CLASE AMPHIBIA}

Orden ANURA

Familia AMPHignathodontidae

Gastrotheca riobambae (Fowler, 1913) ${ }^{(*)}$

Nototrema marsupiatum Günther, 1859 «1858», Cat. Batr. Sal. Coll. Brit. Mus.: 116.

Nototrema marsupiatum, Jiménez de la Espada, 1875, Vert. Viaj. Pacif., Batr.: Lam. 4, fig. 1.

Hyla riobambae Fowler, 1913. Proc. Acad. Nat. Sci. Philadelphia, 65: 157.

Gastrotheca riobambae Duellman \& Fritts, 1972. Occas. Pap. Mus. Nat. Hist. Univ. Kansas, 9: 11.

${ }^{(*)}$ : Aunque Jiménez de la Espada determinó los ejemplares como Nototrema marsupiatum, actualmente se sabe que estos no pueden pertenecer a dicha especie, ya que G. marsupiata se distribuye exclusivamente en el sur de Perú y Bolivia y por tanto de las posibles 16 especies que habitan Ecuador, lo más probable es que se trate de ejemplares de G. riobambae (De la Riva, comunicación personal).

MNCN 3490-3495.- ECF.- Quito, Pichincha, ECUADOR.- 1863/1865.- Colectó: M. Jiménez de la Espada. OBSERVACIONES: Quizás alguno pueda ser el ejemplar figurado en Jiménez de la Espada (1875a: Lam. 4, fig. 1) como «Nototrema marsupiatum».

MNCN 3496-3502.- 5H+1M.- 6Ad y 1Jv.- ECF.- Quito, Pichincha, ECUADOR.- [1863/1864].- Colectó: M. Jiménez de la Espada.

OBSERVACIONES: Quizás alguno pueda ser el ejemplar figurado en Jiménez de la Espada (1875a: Lam. 4, fig. 1) como «Nototrema marsupiatum».

MNCN 3503.- H.- Ad.- ECF.- Otavalo ${ }^{(*)}$ Imbabura, ECUADOR.- [01/03-11-1864].- Colectó: F. Martínez y Sáez ${ }^{(* *)}$.

ObSERVACIONES: ${ }^{*}$ Resulta curioso que tratándose de un ejemplar de Otavalo, no esté indicada tanto en la etiqueta como en la ficha antigua la denominación de variedad otavalensis y la indicación "cotipo", como ocurre en los ejemplares siguientes. Tal vez Jiménez de la Espada lo desechó por tener un menor tamaño. (**) Aun cuando la ficha antigua indica "Espada" en la casilla correspondiente al colector, fue Martínez quien visitó esta localidad y por tanto quien debió de colectar el ejemplar.

MNCN 3504-3505.- M y H.- 2Ad.- ECF.- [¿Otavalo?] ${ }^{(*)}$ ¿Imbabura? ECUADOR.- [01/03-11-1864].- Colectó: F. Martínez y Sáez ${ }^{(* *)}$. 


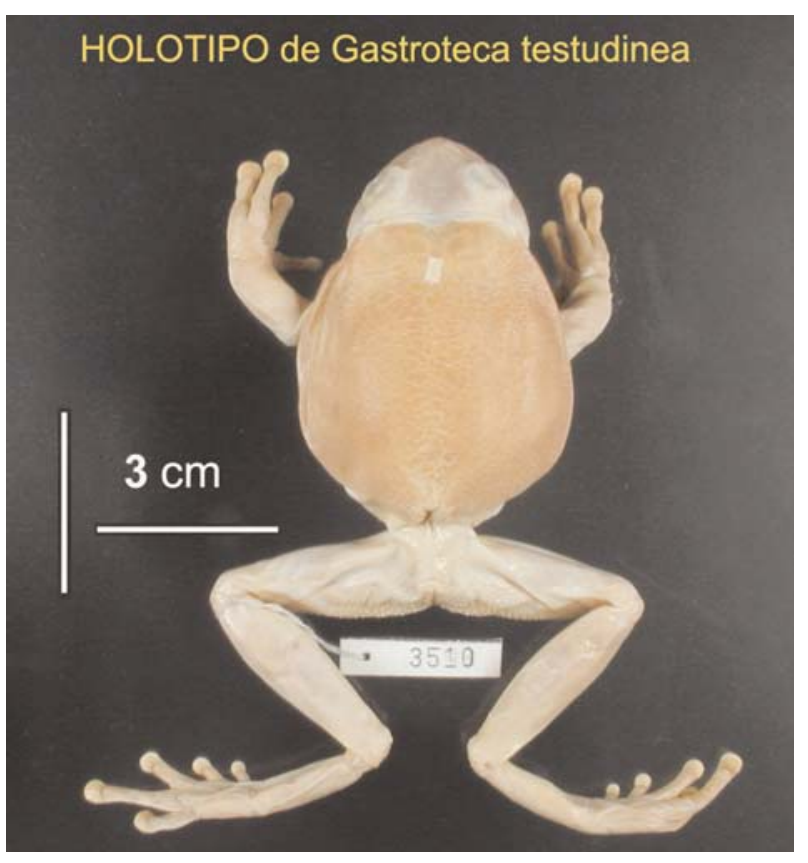

OBSERVACIONES: ${ }^{*}$ La etiqueta antigua indica: "Nototrema marsupiatum var. otavalensis Espada Cotitos". Probablemente Jiménez de la Espada pensó en describir una subespecie en base a estos ejemplares, pero nunca lo hizo. Quizás alguno pueda ser el ejemplar figurado en Jiménez de la Espada (1875a: Lam. 4, fig. 1) como «Nototrema marsupiatum».

(**) Aun cuando la ficha antigua indica "Espada" en la casilla correspondiente al colector, fue Martínez quien visitó esta localidad y por tanto quien debió de colectar el ejemplar.

MNCN 3506-3507.- 2Ad.- ECF.- Quito, Pichincha, ECUADOR.- 1863/1865.- Colectó: M. Jiménez de la Espada.

OBSERVACIONES: Quizás alguno pueda ser el ejemplar figurado en Jiménez de la Espada (1875a: Lam. 4, fig. 1) como «Nototrema marsupiatum».

MNCN 3508-3509.- M y H.- 2Ad.- ECF.- ¿Quito? ${ }^{(*)}$ ¿Pichincha?, ECUADOR.- 1863/1865.- Colectó: M. Jiménez de la Espada.

OBSERVACIONES: ${ }^{*}$ ) En la ficha antigua, Zulueta en 1911 indica: «Hallados con una etiqueta de otros ejemplares» y de ahí que dudemos de la exactitud de la localidad de colecta; de ser correcta, alguno pudiera ser el ejemplar figurado en Jiménez de la Espada (1875a: Lam. 4, fig. 1) como «Nototrema marsupiatum».

Gastrotheca testudinea (Jiménez de la Espada, 1871)

Nototrema testudineum Jiménez de la Espada, 1871 «1870» J. Sci. Math. Phys. Nat., Lis., 3: 62.
Gastrotheca testudinea, Duellman, 1974. Occas. Pap. Mus. Nat. Hist. Univ. Kansas, 27: 4.

Gastrotheca testudinea, Duellman, 1977. Das Tierreich, 95: 20. Gastrotheca (Opisthodelphys) testudinea, Dubois, 1987 «1986», Alytes, 5: 31

MNCN 3510.- HOLOTIPO.- [H].- Ad.- ECF.- Faldas del Volcán Sumaco, San José de Moti ${ }^{(*)}$, Napo, ECUADOR.- 06-1865.- Colectó: M. Jiménez de la Espada.

(*) Ver comentario al final de este catálogo.

OBSERVACIONES: Recogido en Jiménez de la Espada (1871: 62) y figurado en Jiménez de la Espada (1875a: Lam. 4, fig. 2, 2a, 2b), en ambos casos como «Nototrema testudineum». Recogido en Duellman (1974: 4-5; 1977: 20) como Gastrotheca testudinea.

\section{Familia BATRACHOPHRYNIDAE}

Caudiverbera caudiverbera (Linnaeus, 1758)

Lacerta caudiverbera Linnaeus, 1758, Syst. Nat., Ed. 10, 1: 200.

Calyptocephalus gayi Duméril \& Bibron, 1841, Erp. Gén., 8: 450.

Peltocephalus quoyi Tschudi, 1838, Classif. Batr.: 41, 81 .

Calyptocephalus gayi, Jiménez de la Espada, 1875, Vert. Viaje Pacifico, Batr.: 2-9.

Caudiverbera caudiverbera, Myers, 1962, Copeia, 1962: 195202.

MNCN 1703-1707.- 5Ad.- ECF.- Lago de Paine y Quillota, Valparaiso, CHILE.- [1863-1864].- Colectó: M. Jiménez de la Espada.

ObSERVACIONES: Recogidos en Jiménez de la Espada (1875: 2-9) como «Calyptocephalus gayi». Mezclados los ejemplares de Laguna de Paime y Quillota.

MNCN 1731.- Jv.- ECF.- , CHILE.- [<1911].- Donó: ¿CCP?.

OBSERVACIONES: Es cuando menos arriesgado asignar este ejemplar a la CCP, ya que el propio Zulueta al revisarlo en 1911 consignó este dato como dudoso. Nosotros creemos que tanto por la coloración parda (y no blanquecina) del ejemplar, su textura más consistente y no blanda o fofa, común a muchos ejemplares colectados por la CCP -incluidos los otros ejemplares de Caudiverbera caudiverbera conservados en el MNCN- Zulueta estaba en lo cierto y también nos inclinamos a poner en duda su colecta por parte de la CCP.

MNCN 1732-1733.- 2H.- 2Ad.- ECF.- CHILE.- [18631864].- Colectó: M. Jiménez de la Espada.

OBSERVACIONES: Recogidos en Jiménez de la Espada, 1875: 2-9 como «Calyptocephalus gayi».

MNCN 1734.- H.- Ad.- EDC.- CHILE.- [1863-1864].Colectó: M. Jiménez de la Espada.

ObSERVACIONES: Recogido en Jiménez de la Espada, 1875: 2-9 como «Calyptocephalus gayi». 


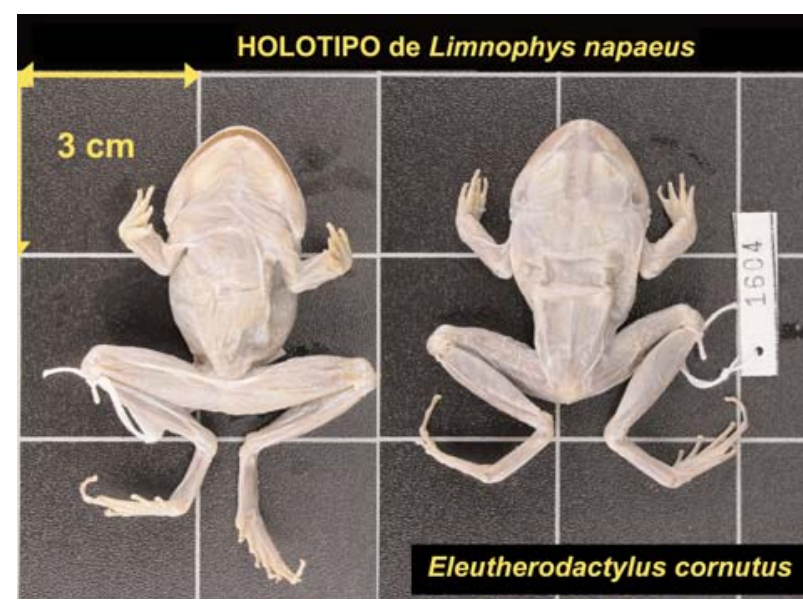

\section{Familia BRACHYCEPHALIDAE}

Eleutherodactylus sin determinar especie.

MNCN 4021-4024.- 2Ad / 2Jv.- ECF.- 1862/1865.

Eleutherodactylus conspicillatus (Günther, 1858)

Hylodes conspicillatus Günther, 1858, Arch. Naturgesch., 24: 326.

Eleutherodactylus conspicillatus, Stebbins \& Hendrickson, 1959, Univ. California Publ. Zool., 56: 528.

No empleado por Jiménez de la Espada es sus publicaciones.

Figuraba en la ficha antigua como Eleutherodactylus conspicillatus. Cope. Probablemente quería hacer referencia a (Lithodytes conspicillatus, Cope, 1868, Proc. Acad. Nat. Sci. Philadelphia, 20: 115).

MNCN 1606.- ECF.- Archidona de Quijos (=Archidona) Napo, ECUADOR.- [04/05-1865].- Colectó: M. Jiménez de la Espada.

Observaciones: Determinado por Jiménez de la Espada como «Hylodes conspicillatus» Cope (1862) en la etiqueta de frasco.

MNCN 1641-1672.- 32Ad+Jv.- ECF.- San José de Moti (*) Napo, ECUADOR.- [-06-1865].- Colectó: M. Jiménez de la Espada.

OBSERVACIONES: ${ }^{(*)}$ Ver comentario al final de este catálogo. Determinado por Jiménez de la Espada como «Hylodes conspicillatus» Cope (1862) en la etiqueta de frasco.

Eleutherodactylus cornutus (Jiménez de la Espada, 1871)

Limnophys cornutus Jiménez de la Espada, 1871»1870», $J$. Sci. Math. Phys. Nat., Lisboa, 3: 60.

Limnophys napaeus Jiménez de la Espada, 1871 «1870», $J$. Sci. Math. Phys. Nat., Lisboa, 3: 60.

Sinonimizado con Strabomantis biporcatus por Jiménez de la Espada, 1872, An. Soc. Esp. Hist. Nat., 1: 85

Eleutherodactylus cornutus cornutus, Rivero, 1961, Bull. Mus. Comp. Zool., 126: 55.

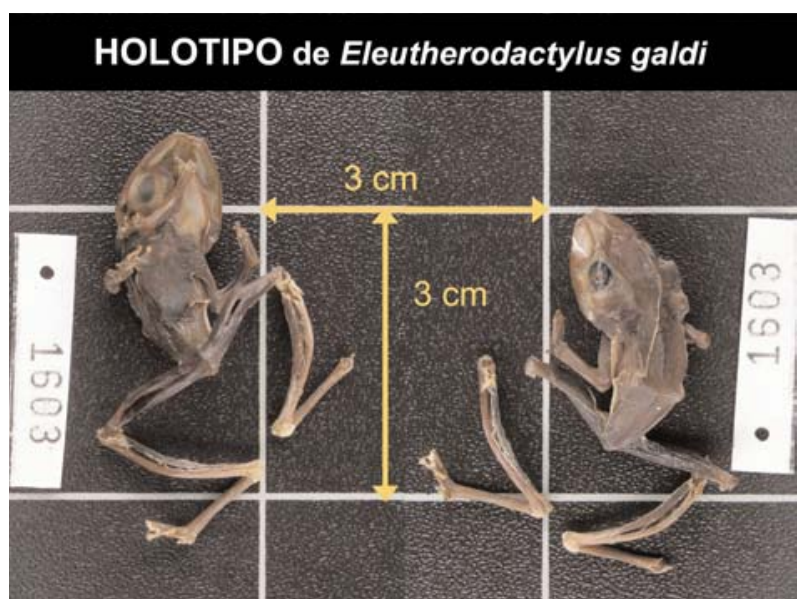

Eleutherodactylus cornutus, Gorham, 1966. Das Tierreich, 85: 222.

MNCN 1604.- HOLOTIPO de Limnophys napaeus, Jiménez de la Espada, 1871.-Ad.- ECF.- Orillas del río Suno, San José de Moti ${ }^{(*)}$ Napo, ECUADOR.- 061885.- Colectó: M. Jiménez de la Espada.

OBSERVACIONES: ${ }^{*}$ ) Ver comentario al final de este catálogo. Tanto el holotipo de Limnophys napaeus, como el de L. cornutus, no fueron encontrados por W.E. Duellman cuando visitó la colección del MNCN en 1969 (Linch, 1975: 31). Pero han sido encontrados un bote y una ficha correspondienten al ejemplar mencionado en este registro, probablemente localizado por Jesús Dorda hacia 1985.

Eleutherodactylus galdi (Jiménez de la Espada, 1871)

Pristimantis galdi Jiménez de la Espada, 1871 «1870», J. Sci. Math. Phys. Nat., Lisboa, 3: 61.

Eleutherodactylus galdi, Peters, 1955, Rev. Ecuat. Entomol. Parasitol., 3-4: 350.

MNCN 1601-1603.- SINTIPOS.- ECF.- Selvas próximas a San José de Moti ${ }^{*}$ N) Napo, ECUADOR.- 071885.- Colectó: M. Jiménez de la Espada.

OBSERVACIONES: ${ }^{*}$ ) Ver comentario al final de este catálogo. Recogido en Jiménez de la Espada (1871: 61) como «Pristimantis galdi», alguno podría ser el figurado en Jiménez de la Espada (1875a: Lam. III bis, fig. $6,6 a, 6 b, 6 c, 6 d, 6 e, 6 f)$, también como «Pristimantis galdi».

\section{Eleutherodactylus unistrigatus (Günther, 1859)}

Hylodes unistrigatus Günther, 1859, Proc. Zool. Soc. London, 1859: 416.

Eleutherodactylus unistrigatus, Barbour \& Noble, 1920, Bull. Mus. Comp. Zool., 63: 401.Gorham, 1966, Das Tierreich, 85: 80 .

Figuraba en la ficha antigua como Hylodes unistrigatus Günther. 


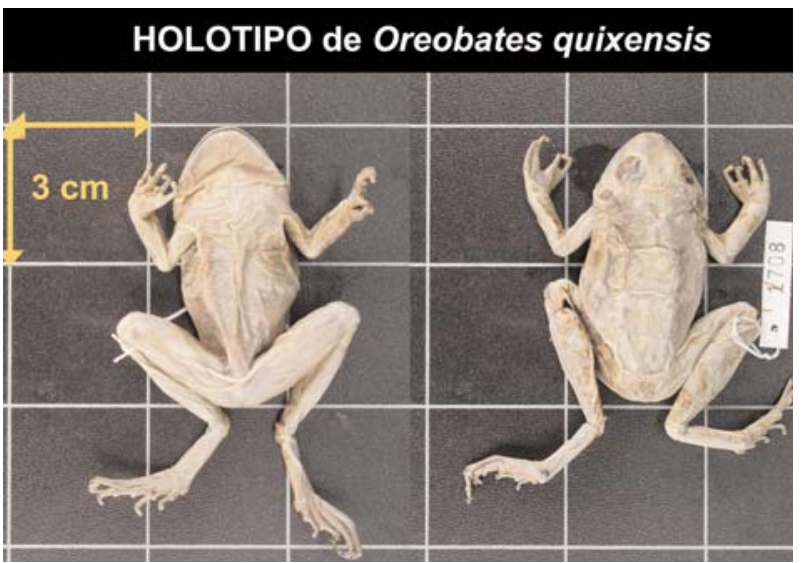

MNCN 1607-1636.- 30Ad+Jv.- ECF.- Otavalo.Imbabura, ECUADOR.- [01/03-12-1864].- Colectó: [F. Martínez y Sáez] ${ }^{(*)}$.

OBSERVACIONES: ${ }^{*}$ Aunque la ficha antigua indica que el colector fue [Jiménez de la] Espada, la etiqueta antigua del bote indica que el lugar de colecta fue Otavalo; como el único expedicionario que visitó Otavalo fue $\mathrm{F}$. Martínez y Sáez, éste debio ser quien realizó la colecta. Martínez-Rica aumentó de 29 a 30 el número de ejemplares, pero no indica si fue porque añadió alguno de otra procedencia, o porque estaban históricamente mal contados.

Oreobates quixensis Jiménez de la Espada, 1872

Oreobates quixensis Jiménez de la Espada, 1872, An. Soc. Esp. Hist. Nat., 1: 87.

Hylodes verrucosus Jiménez de la Espada, 1875, Vert. Viaje Pacifico, Batr: Lam. 3bis fig. 1.

Borborocoetes quixensis, Boulenger, 1882, Cat. Batr. Sal. Brit. Mus.: 256.

Sinonimizado con Eleutherodactylus verrucosus por Gorham, 1966, Das Tierreich, 85: 107

Sinonimizado con Ischnocnema quixensis por Lynch \& Schwartz, 1971, J. Herpetol., 5: 109.

Hylodes philippi Jiménez de la Espada, 1875, Vert. Viaje Pacifico, Batr.: Lam. 3bis fig. 2, $2^{\mathrm{a}}$.

Sinonimizado Eleutherodactylus philippi por Gorham, 1966, Das Tierreich, 85: 92

Sinonimizado con Ischnocnema quixensis por Lynch \& Schwartz, 1971, J. Herpetol., 5: 109.

Ischnocnema quixensis, Lynch \& Schwartz, 1971, J. Herpetol., 5: 109 .

Oreobates quixensis, rehabilitado por Caramaschi \& Canedo, 2006, Zootaxa, 1116: 43-54

NOTA: Un reciente trabajo (Caramaschi \& Canedo, 2006) aparecido durante la redacción de éste catálogo rehabilita la validez del género Oreobates Jiménez de la Espada, 1872 y por tanto la denominación original Oreobates quixensis Jiménez de la Espada, 1872 para la especie. La aparición de los tipos de Hylodes verru-

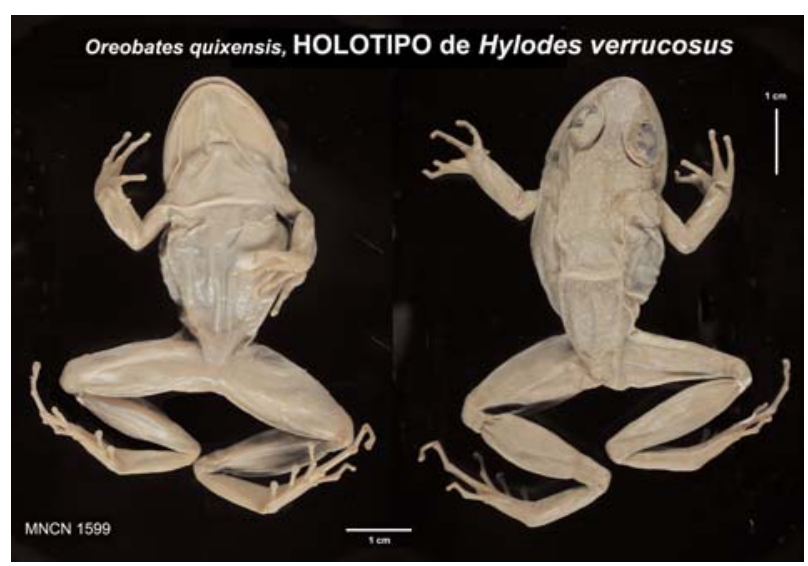

cosus e Ischnocnema quixensis podría permitir la continuación de los estudios sobre estas especies realizados por Lynch \& Schwartz (1971) exclusivamente en base a las descripciones de los mismos.

MNCN 1599.- HOLOTIPO de Hylodes verrucosus Jiménez de la Espada, 1875.- Ad.- ECF.- San José de Moti ${ }^{*}$ N) Napo, ECUADOR.- [06-1865].- Colectó: M. Jiménez de la Espada.

OBSERVACIONES: ${ }^{*}$ Ver comentario al final de este catálogo. Recogido en Jiménez de la Espada (1875a: Lam. 3bis, fig 1, $1^{\mathrm{a}}$ ).

MNCN 1600.- HOLOTIPO de Hylodes philippi Jiménez de la Espada, 1875.- ECF.- San José de Moti (*) Napo, ECUADOR.- [06-1865].- Colectó: M. Jiménez de la Espada.

OBSERVACIONES: ${ }^{*}$ ) Ver comentario al final de este catálogo. Recogido en Jiménez de la Espada (1875a, Lam. 3bis, fig 2, $2^{\mathrm{a}}$ ).

MNCN 1708.- SINTIPO de Oreobates quixensis (Jiménez de la Espada, 1872).- Ad.- ECF.- San José de

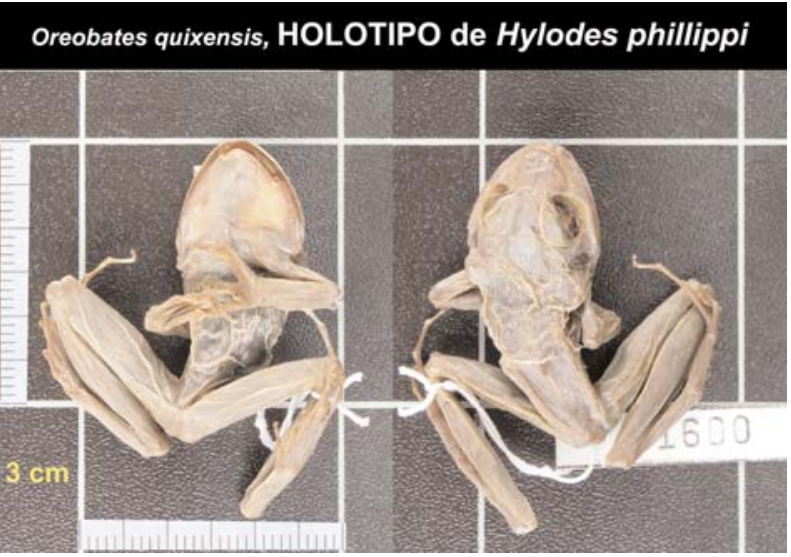


Moti ${ }^{*)}$ Napo, ECUADOR.- [06-1865].- Colectó: M. Jiménez de la Espada.

OBSERVACIONES: ${ }^{(*)}$ Ver comentario al final de este catálogo. Recogido en Jiménez de la Espada (1872a: 87) y en Jiménez de la Espada (1875a: 99-104) como «Oreobates quixensis».

MNCN 1709-1721.- SINTIPOS de Oreobates quixensis (Jiménez de la Espada, 1872).- 13Ad.- ECF.- Archidona de Quijos (=Archidona) Napo, ECUADOR.- [04/051865].- Colectó: M. Jiménez de la Espada.

OBSERVACIONES: Recogido en Jiménez de la Espada (1872a: 87) y en Jiménez de la Espada (1875a: 99104) como «Oreobates quixensis». Falta la ficha antigua; la confeccionada por Martínez-Rica en torno a 1980 recoge 13 ejemplares de esta procedencia, pero Jiménez de la Espada sólo cita 11 (4HH, 5MM y 2JJ); además, dos de los ejemplares tienen una coloración y textura diferente a los otros. No obstante, parecen pertenecer a Oreobates quixensis, aunque podrían ser ejemplares de Hylodes verrucosus o Hylodes philippi, ya que Jiménez de la Espada nunca hizo mención al número de ejemplares, estudiados por él, pertenecientes a estas dos especies.

\section{Familia BufonidAe}

Atelopus sin especificar

Phryniscus ignescens Cornalia, 1849, Vert. Syn. Mus. Mediolanense Extant.: 14.

Phryniscus laevis Günther, 1858, Arch. Naturgesch., 24: 321. Phrynidium laeve, Cope, 1867, J. Acad. Nat. Sci. Philadelphia, (2), 6: 196

Atelopus laevis, Cope, 1868, Proc. Acad. Nat. Sci. Philadelphia, 20: 117 .

Atelopus ignescens, Jiménez de la Espada, 1875, Vert. Viaj. Pacif., Batr: 139.

Determinados genéricamente como Atelopus por S. Lötters (2004), comunicación personal.

MNCN 1493.- H.- Ad.- ECF.- Nanegal [Pichincha] ECUADOR.- [1864/865].- Colectó: F. Martínez y Sáez. OBSERVACIONES: Recogidos en Jiménez de la Espada, 1875a: 139-148 como «Atelopus ignescens».

MNCN 1495-1498.- [M y 3H].- 4Ad.- ECF.- Ambato, Tungurahua, ECUADOR.- [11-1864].- Colectó: M. Jiménez de la Espada.

OBSERVACIONEs: Recogidos en Jiménez de la Espada, 1875a: 139-148.M como "Atelopus ignescens". Jiménez de la Espada, da como localidad Hambato, en lugar de Ambato, probablemente influenciado por la denominación indígena, ya que el vocablo significaría "la Colina de la Rana" pues Hambatu o Jambatu en la lengua de los indios quichua de Imbabura (Ecuador) designa a un renacuajo propio del río que cruza la urbe de Ambato.

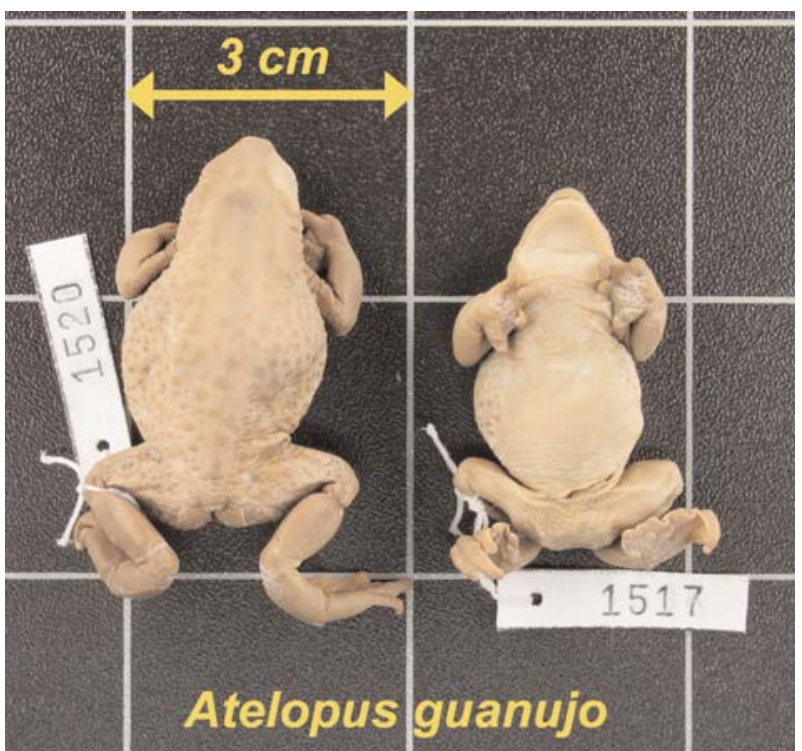

Atelopus guanujo Coloma, 2002

Phryniscus ignescens Cornalia, 1849 Vert. Syn. Mus. Mediolanense Extant: 14

Phryniscus laevis Günther, 1858, Arch. Naturgesch., 24: 321.

Phrynidium laeve, Cope, 1867, J. Acad. Nat. Sci. Philadelphia, (2)6: 196.

Atelopus laevis, Cope, 1868, Proc. Acad. Nat. Sci. Philadelphia, 20: 117.

Atelopus ignescens, Jiménez de la Espada, 1875, Vert. Viaj. Pacif., Batr.: 139.

Determinados como Atelopus guanujo Coloma, 2002 (Herpetologica, 58: 230) por S. Lötters (2003).

MNCN 1513-1520.- 5M y 3H.- 8Ad.- ECF.- [Páramos de las] faldas del Volcán Chimborazo, Chimborazo, ECUADOR.- 07-[1864].- Colectó: M. Jiménez de la Espada. OBSERVACIONES: Recogidos en Jiménez de la Espada, 1875a: 139-148 como «Atelopus ignescens».

Atelopus ignescens (Cornalia, 1849)

Phryniscus ignescens Cornalia, 1849, Vert. Syn. Mus. Mediolanense Extant.: 14.

Phryniscus laevis Günther, 1858, Arch. Naturgesch., 24: 321.

Phrynidium laeve, Cope, 1867, J. Acad. Nat. Sci. Philadelphia, (2)6: 196.

Atelopus laevis, Cope, 1868, Proc. Acad. Nat. Sci. Philadelphia, 20: 117.

Atelopus ignescens, Jiménez de la Espada, 1875, Vert. Viaj. Pacif., Batr.: 139.

Atelopus ignescens, Coloma, Lötters, \& Salas, 2000, Herpetologica, 56: 304 Designan neotipo.

Revisados por S. Lötters (2003)

MNCN 1418-1469.- MM y HH.- 52Ad.- ECF.- Quito ${ }^{(*)}$, Pichincha, ECUADOR.- [-11/12-1864].- Colectó: M. Jiménez de la Espada.

OBSERVACIONES: Recogidos en Jiménez de la Espada, 1875a: 139-148 como "Atelopus ignescens" Uno de 
ellos podría ser el figurado en Jiménez de la Espada (1875a: Lam. 1 fig 7, 7a) cómo «Phryniscus ignescens»». ${ }^{(*)}$ Seguramente son ejemplares de diferentes localidades de Ecuador (Moya de Pelileo, Páramo de Mojanda, Laguna de la Mica, etc.) mezclados históricamente, por causas desconocidas. Lo mismo sucede con la serie MNCN 3164-3245.

MNCN 1470-1492.- MM y HH.- 23Ad.- ECF.- [Valles próximos a] Quito, Pichincha, ECUADOR.- [11/121864].- Colectó: M. Jiménez de la Espada.

OBSERVACIONES: Recogidos en Jiménez de la Espada, 1875a: 139-148 como "Atelopus ignescens" Uno de ellos podría ser el figurado en Jiménez de la Espada (1875a: Lam. 1 fig 7, 7a) como "Phryniscus ignescens». Corresponden en parte a los $(15 \mathrm{MM}+22 \mathrm{HH})$ denominados "variedad" por Jiménez de la Espada (1875a: 148).

MNCN 1494.- 27Pm.- ECF.- [Hacienda de] Lisco [Volcán (=nevado) de] Antisana, Pichincha, ECUADOR.- 39004300 m.- [01-1865].- Colectó: M. Jiménez de la Espada. OBSERVACIONES: Recogidos en Jiménez de la Espada (1875a: 139-148) como "Atelopus ignescens" Podría ser el figurado en Jiménez de la Espada (1875a: Lam. 1 fig 7, 7a) como «Phryniscus ignescens».

MNCN 1499-1512.- 7MM y 7HH.- 14Ad.- ECF.- [Laguna de] la Mica [Volcán (=nevado) de] Antisana, Pichincha, ECUADOR.- [01-1865].- Colectó: M. Jiménez de la Espada.

OBSERVACIONES: Recogidos en Jiménez de la Espada (1875a: 139-148) como "Atelopus ignescens". Sin duda se trata de las seis parejas en amplexo que Jiménez de la Espada (1875a: 147) comenta que se conservan en la colección.

MNCN 1521-1582.- 36MM+26HH.- 62Ad.- ECF.[Valles próximos a] Quito, Pichincha, ECUADOR.[11/12-1864].- Colectó: M. Jiménez de la Espada.

OBSERVACIONES: Recogidos en Jiménez de la Espada (1875a: 139-148) como "Atelopus ignescens" Uno de ellos podría ser el figurado en Jiménez de la Espada (1875a: Lam. 1 fig 7, 7a) como «Phryniscus ignescens»).

MNCN 3164-3245.- MM y HH.- 82Ad.- ECF.- [Laguna de la Mica, Volcán (=nevado) de Antisana] [Pichincha] ECUADOR.- [-01-1865].- Colectó: [M. Jiménez de la Espada].- Donó: [CCP.].

OBSERVACIONES: Recogidos en Jiménez de la Espada (1875a: 139-148) como "Atelopus ignescens" Uno de ellos podría ser el figurado en Jiménez de la Espada (1875a: Lam. 1 fig 7, 7a) cómo «Phryniscus ignescens». Muchas HH están diseccionadas como indica Jiménez de la Espada (1875a: 147). Seguramente mezclados con ejemplares de otras localidades de Ecuador (ver comentario en MNCN 1418-1469).

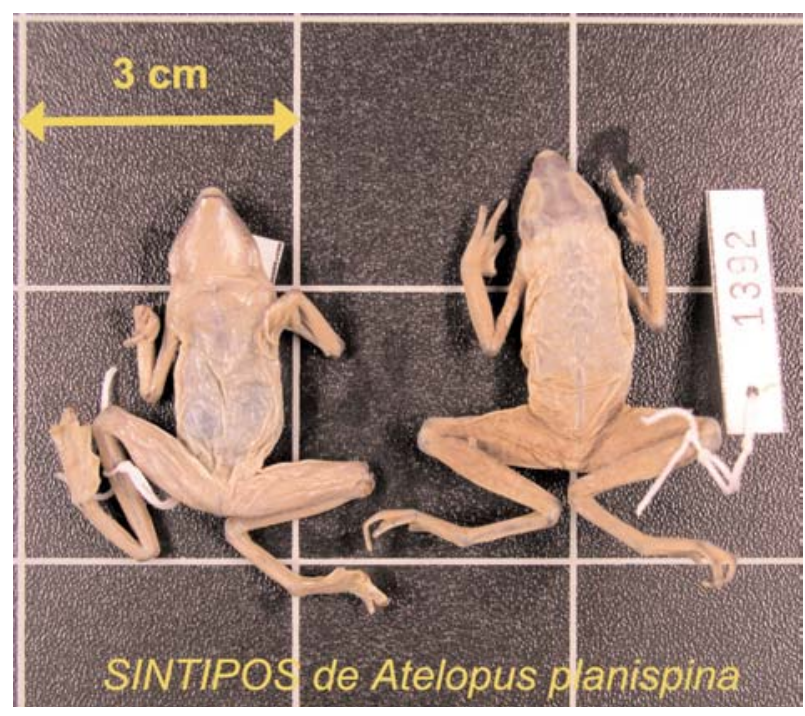

Atelopus planispina Jiménez de la Espada, 1875

Atelopus planispina Jiménez de la Espada, 1875, Vert. Viaj. Pacif., Batr: 148.

Revisados por S. Lötters (2003).

MNCN 1390-1417.- SINTIPOS .- 28(MM+HH).28(Ad+Jv).- ECF.- Pié del Volcán Sumaco, San José de Moti (*) Napo, ECUADOR.- 16/31-06-1865.Colectó: M. Jiménez de la Espada.

ObSERVACIONES: ${ }^{*}$ ) Ver comentario al final de este Catálogo.

\section{Chaunus arenarum (Hensel, 1867)}

Rana marina Linnaeus, 1758, Syst. Nat., Ed. 10, 1: 211. Bufo agua Latreille, 1801, In Sonnini \& Latreille, Hist. Nat. Rept., 2: 130.

Bombinator horridus Merrem, 1820, Tent. Syst. Amph.: 179.

Bufo humeralis Daudin, 1803, Hist. Nat. Gen. Part. Rept., 8: 205.

Bufo maculiventris Spix, 1824, Spec. Nov. Testud. Ran. Brasil.: 45.

Bufo lazarus Spix, 1824, Spec. Nov. Testud. Ran. Brasil.: 45.

Bufo arenarum Hensel, 1867, Arch. Naturgesch., 33: 143.

Bufo marinus var. platensis Jiménez de la Espada, 1875, Vert. Viaj. Pacif., Batr.: 202.

Sinonimizado con Bufo arenarum por Boulenger, 1882, Cat. Batr. Sal. Brit. Mus.: 314.

Bufo arenarum platensis, Gallardo, 1964, Neotropica, 10(31): 24; Gallardo, 1965, Pap. Avulsos, Dept. Zool., São Paulo, 17: 70 .

Chaunus arenarum, Frost, Grant, Faivovich, Bain, Haas, Haddad, De Sá, Channing, Wilkinson, Donnellan, Raxworthy, Campbell, Blotto, Moler, Drewes, Nussbaum, Lynch, Green \& Wheeler, 2006, Bull. Am. Mus. Nat. Hist, 297: 364

MNCN 3101-3113.- SINTIPOS de Bufo marinus var. platensis (Jiménez de la Espada, 1875).- 5Ad, 7Jv y 4Pm.- ECF.- Río Grande, Río Grande do Sul, BRASIL.- 
Chaunus arenarum,

SINTIPOS de B. marinus var. platensis

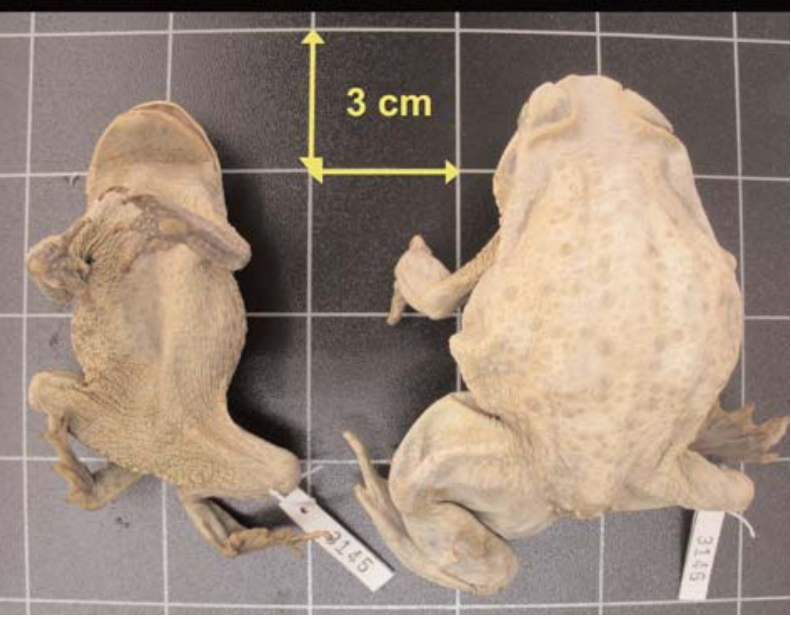

[11/12-1862].- Colectó: M. Jiménez de la Espada.Donó: [Comisión Científica del Pacífico].

OBSERVACIONES: Recogidos en Jiménez de la Espada (1875a: 202-203) como «Bufo marinus var. platensis». Probablemente, formaron serie con MNCN 3101-3113 e incluso con MNCN 3145-3150, de los que se separaron por motivos y en fecha desconocidos.

MNCN 3131-3134.- SINTIPOS de Bufo marinus var. platensis (Jiménez de la Espada, 1875a).- 3Ad y Jv.ECF.- [1862/1865].- Colectó: [M. Jiménez de la Espada].- Donó: [Comisión Científica del Pacífico]. OBSERVACIONES: Probablemente se trata de ejemplares recogidos por Jiménez de la Espada (1875a: 202-203), como «Bufo marinus var. platensis» procedentes de Uruguay y/o Argentina.

MNCN 3135-3143.- SINTIPOS de Bufo marinus var. platensis (Jiménez de la Espada, 1875).- 6Ad / JV / 2Ad.- ECF.- Río Grande, Río Grande do Sul, BRASIL.- [11/12-1862].- Colectó: [M. Jiménez de la Espada].- Donó: [Comisión Científica del Pacífico]. ObSERVACIONES: Recogidos en Jiménez de la Espada (1875a: 202-203) como «Bufo marinus var. platensis». Probablemente, formaron serie con MNCN 3101-3113 e incluso con MNCN 3145-3150, de los que se separaron por motivos y en fecha desconocidos.

MNCN 3144.- SINTIPO de Bufo marinus var. platensis (Jiménez de la Espada, 1875).- Ad.- ECF.- La Plata, ARGENTINA.- [ -01-1863].- Colectó: [F. Amor].- Donó: [Comisión Científica del Pacífico]. OBSERVACIONES: Recogidos en Jiménez de la Espada (1875a: 202-203) como «Bufo marinus var. platensis». $\mathrm{Su}$ adscripción a una localidad exacta es dudosa pues
Jiménez de la Espada habla de Córdoba de Tucumán, Campo de San Roque y de República Argentina; podría ser incluso de Montevideo (Uruguay).

MNCN 3145-3150.- SINTIPOS de Bufo marinus var. platensis (Jiménez de la Espada, 1875).- 6Ad.- ECF.Río Grande, Río Grande do Sul, BRASIL.- [11/121862].- Colectó: [M. Jiménez de la Espada].- Donó: [Comisión Científica del Pacífico].

ObSERVACIONES: Recogidos en Jiménez de la Espada (1875a: 202-203) como «Bufo marinus var. platensis». Probablemente, formaron serie con MNCN 3101-3113 e incluso con MNCN 3145-3150, de los que se separaron por motivos y en fecha desconocidos.

MNCN 15982.- SINTIPO de Bufo marinus var. platensis (Jiménez de la Espada, 1875).- H.- Jv.- EDC.La Plata, Buenos Aires, ARGENTINA.- [01-1863].Colectó: [F. Amor].- Donó: [Comisión Científica del Pacífico].

OBSERVACIONES: Dos individuos mezclados preparados en 1985, a partir de un bote estropeado en la colección. Seguramente también son Sintipos de «Bufo marinus var. platensis» recogidos en Jiménez de la Espada (1875a: 202-204), donde figuran como de la República Argentina y no de La Plata. Su adscripción a una localidad exacta es dudosa, pues Jiménez de la Espada habla de Córdoba de Tucumán, Campo de San Roque y de República Argentina; podrían ser incluso de Montevideo (Uruguay).

\section{Chaunus arunco (Molina, 1782)}

Rana arunco Molina, 1782, Saggio Stor. Nat. Chili: 216

Bufo chilensis Tschudi, 1838, Classif. Batr.: 88.

Bufo spinulosus 1835, Nova Acta Acad. Caes. Leop.-Carol. 17(1): 185-268.

Phryne chilensis, Fitzinger, 1861, Sitzungsber. Akad. Wiss. Wien, Math. Naturwiss. Kl., 42.

Bufo chilensis, Jiménez de la Espada, 1875, Vert. Viaj. Pacif., Batr.: 204.

Sinominizado con Bufo arunco por Ortiz \& Lescure, 1989, Mus. Natl. Hist. Nat. Paris, (4)11(A-3) Suppl.: 115.

Chaunus arunco, Frost, Grant, Faivovich, Bain, Haas, Haddad, De Sá, Channing, Wilkinson, Donnellan, Raxworthy, Campbell, Blotto, Moler, Drewes, Nussbaum, Lynch, Green \& Wheeler, 2006, Bull. Am. Mus. Nat. Hist., 297: 364.

MNCN 3123-3126.- 2Ad y 2Jv.- ECF.- CHILE.[1863/1865].- Colectó: [M. Jiménez de la Espada].Donó: [Comisión Científica del Pacífico].

OBSERVACIONES: Recogidos en Jiménez de la Espada (1875a: 204-208) como «Bufo chilensis», aunque el autor no hace mención específica a la localidad recogida en la etiqueta antigua (Concepción).

Chaunus crucifer Wied-Neuwied, 1821

Bufo crucifer Wied-Neuwied, 1821, Reise Brasil. Jahr. 18151817, 2: 132

Bufo ornatus Spix, 1824, Spec. Nov. Testud. Ran. Brasil.: 45. 
Bufo dorsalis Spix, 1824, Spec. Nov. Testud. Ran. Brasil.: 46. Bufo cinctus Wied, Beitr. Nat. Bras., I: 564.

Bufo melanotis Duméril \& Bibron, 1841, Erp. Gén., 8: 710.

Bufo ornatus, Jiménez de la Espada, 1875, Vert. Viaj. Pacif., Batr: 204.

Sinonimizado con Bufo crucifer por Peters, 1872, Monatsber. Preuss. Akad. Wiss. Berlin, 1872: 226.

Chaunus crucifer, Frost, Grant, Faivovich, Bain, Haas, Haddad, De Sá, Channing, Wilkinson, Donnellan, Raxworthy, Campbell, Blotto, Moler, Drewes, Nussbaum, Lynch, Green \& Wheeler, 2006, Bull. Am. Mus. Nat. Hist.., 297: 364.

MNCN 3077-3078.- M y H.- 2Ad.- ECF.- Río de Janeiro, Río de Janeiro, BRASIL.-10/11-1862.- Colectó: M. Jiménez de la Espada.

OBSERVACIONES: Probablemente sean dos de los cinco «Bufo ornatus» recogidos en Jiménez de la Espada (1875a: 204).

MNCN 3122.- M.- Ad.- ECF.- [Río de Janeiro, Río de Janeiro, BRASIL].- [10/11-1862].- Colectó: [M. Jiménez de la Espada].- Donó: [Comisión Científica del Pacífico]. OBSERVACIONES: Probablemente sea uno de los cinco «Bufo ornatus» recogidos en Jiménez de la Espada (1875a: 204).

MNCN 3127.- M.- Ad.- ECF.- [Río de Janeiro, Río de Janeiro, BRASIL].- [-10/11-1862].- Colectó: [M. Jiménez de la Espada].- Donó: [Comisión Científica del Pacífico]. OBSERVACIONES: Probablemente sea uno de los cinco «Bufo ornatus» recogidos en Jiménez de la Espada (1875a: 204).

Chaunus fernandezae (Gallardo, 1957)

Bufo d'Orbignyi Duméril \& Bibron, 1841, Erp. Gén., 8: 697

Chilophryne d'orbignyi, Fitzinger, 1843, Syst. Rept.: 32

Chilophryne d'orbignyi, Jiménez de la Espada, 1875, Vert. Viaj. Pacif., Batr.: 188

Bufo d'Orbignyi, Boulenger, 1882, Cat. Batr. Sal. Brit. Mus.: 322 Bufo granulosus fernandezae Gallardo, 1957, Rev. Mus. Argent. Cienc. Nat. Bernardino Rivadavia, Cienc. Zool., 3: 347.

Bufo fernandezae, Cei, 1964, Not. Biol. Fac. Cienc. Exact. Fis. Nat., Zool., 4: 18; Cei, 1972, Evol. Genus Bufo: 88; Cei, 1980, Monit. Zool. Ital., N.S., Monogr., 2: 193-195.

Determinados por J. M. Cei en 1985, como Bufo fernandezae.

Chaunus fernandezae, Frost, Grant, Faivovich, Bain, Haas, Haddad, De Sá, Channing, Wilkinson, Donnellan, Raxworthy, Campbell, Blotto, Moler, Drewes, Nussbaum, Lynch, Green \& Wheeler, 2006, Bull. Am. Mus. Nat. Hist., 297: 364.

MNCN 3079.- Ad.- ECF.- [Cuenca del Río de la Plata] ARGENTINA o URUGUAY.- 01-1863.- Colectó: F. Amor.

OBSERVACIONES: Recogido en Jiménez de la Espada (1875a: 188-194) como «Chilophryne d'orbignyi».

MNCN 3082-3083.- M y H.- 2Ad.- ECF.- Montevideo, Canelones, URUGUAY.- 12-1862.- Colectó: F. Martínez y Sáez.

OBSERVACIONES: Recogidos en Jiménez de la Espada (1875a: 188-194) como «Chilophryne d'orbignyi».
MNCN 3087-3093.- 6Ad y Pm.- ECF.- Río Grande, Río Grande do Sul, BRASIL.- 10/11-1862.- Colectó: M. Jiménez de la Espada.

OBSERVACIONES: Recogidos en Jiménez de la Espada (1875a: 188-194) como «Chilophryne d'orbignyi».

Chaunus marinus (Linnaeus, 1758)

Rana marina Linnaeus, 1758, Syst. Nat., Ed. 10, 1: 211.

Bufo agua Latreille, 1801, In Sonnini \& Latreille, Hist. Nat. Rept., 2: 130 .

Bombinator horridus Merrem, 1820, Tent. Syst. Amph.: 179.

Bufo humeralis Daudin, 1803, Hist. Nat. Gen. Part. Rept., 8: 205.

Bufo maculiventris Spix, 1824, Spec. Nov. Testud. Ran. Brasil.: 45.

Bufo lazarus Spix, 1824, Spec. Nov. Testud. Ran. Brasil.: 45

Bufo arenarum Hensel, 1867, Arch. Naturgesch., 33: 143.

Bufo marinus var. napensis Jiménez de la Espada, 1875, Vert. Viaje Pacif., Batrach.: 201.

Bufo marinus var. fluminensis Jiménez de la Espada, 1875, Vert. Viaje Pacif., Batrach.: 199.

Bufo marinus marinus, Schmidt, 1932, Zool. Ser., Field Mus. Nat. Hist., 18: 159.

Chaunus marinus, Frost, Grant, Faivovich, Bain, Haas, Haddad, De Sá, Channing, Wilkinson, Donnellan, Raxworthy, Campbell, Blotto, Moler, Drewes, Nussbaum, Lynch, Green \& Wheeler, 2006, Bull. Am. Mus. Nat. Hist., 297: 364.

NOTA: sobre los diferentes ejemplares englobados en esta especie, De la Riva (2000) llama la atención sobre la considerable distancia geográfica existente entre las diferentes localidades donde Jiménez de la Espada colectó Bufo marinus var. fluminensis (prácticamente todo el continente sudamericano), e indica: “...deben estar representadas al menos dos especies, B. marinus por un lado y otra del sudeste de Brasil, lo que podría afectar a la nomenclatura y/o sinonimia de alguna especie de sapo de esta región (B. rufus Garman, 1877 y B. paracnemis Lutz, 1925; fueron descritos con posterioridad a B. m. fluminensis). Lamentablemente, Luzt (1934), en su revisión de las especies de Bufo de Brasil, no mencionó en ningún momento el trabajo de Espada...".

MNCN 3058.- SINTIPO de Bufo marinus var. napensis (Jiménez de la Espada, 1875).- H.- Ad.- EPF ${ }^{(*)}$.Archidona de Quijos (=Archidona) Napo, ECUADOR.[04/05-1865].- Colectó: M. Jiménez de la Espada.

OBSERVACIONES: ${ }^{*}$ Le falta la cabeza. Recogido en Jiménez de la Espada (1875a: 201-202) como «Bufo marinus var. napensis».

MNCN 3059.- SINTIPO de Bufo marinus var. napensis (Jiménez de la Espada, 1875).- H.- Ad.- ECF.Archidona de Quijos (=Archidona), Napo, ECUADOR.[04/05-1865].- Colectó: M. Jiménez de la Espada. OBSERVACIONES: Recogido en Jiménez de la Espada (1875a: 201-202) como «Bufo marinus var. napensis».

MNCN 3060.- SINTIPO de Bufo marinus var. napensis (Jiménez de la Espada, 1875).- H.- Ad.- ECF.- 
Chaunus Marinus,

SINTIPOS de Bufo marinus var. napensis

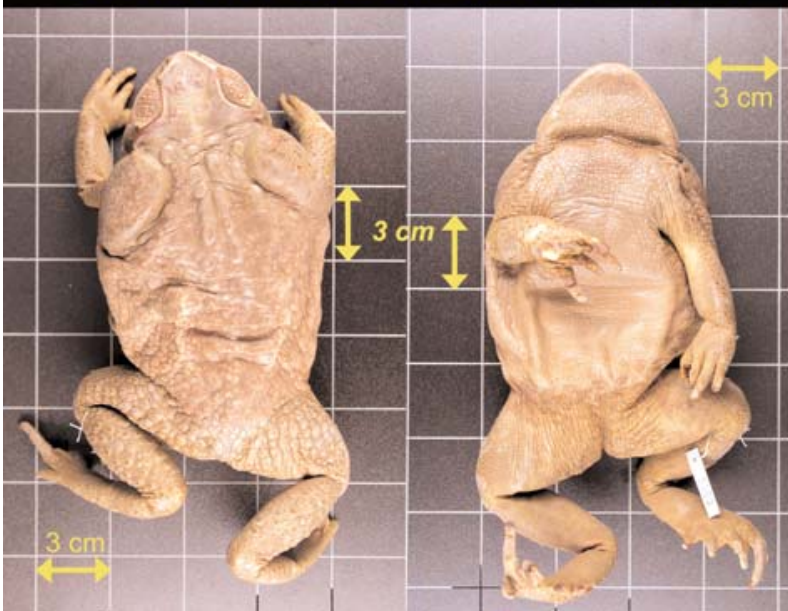

Archidona de Quijos (=Archidona) Napo, ECUADOR.[04/05-1865].- Colectó: M. Jiménez de la Espada. OBSERVACIONES: Recogido en Jiménez de la Espada (1875a: 201-202) como «Bufo marinus var. napensis».

MNCN 3061.- SINTIPO de Bufo marinus var. napensis (Jiménez de la Espada, 1875).- Ad.- ECF.- Frontera de Brasil y Perú, Tabatinga, Amazonas, BRASIL.[08/09-1865].- Colectó: M. Jiménez de la Espada.

OBSERVACIONES: La ficha antigua dice: «Bufo marinus var. napensis, Espada. Localidad: Tabatinga (Quito??)» Aunque Jiménez de la Espada (1875a: 200) al hablar de la var. fluminensis menciona: "cinco pequeñuelos de Tabatinga, orillas del Amazonas y frontera del Perú y Brasil", por su tamaño, no puede referirse al ejemplar en cuestión; por tanto, probablemente se trate de un error, bien de cambio de etiquetas o frascos, o bien que el ejemplar sea uno de los dos $(\mathrm{M}$ o $\mathrm{H})$ de Cotapino, cerca de Santa Rosa de Napo (Ecuador) Bufo marinus var. napensis Jiménez de la Espada (1875a: 202).

MNCN 3062-3063.- SINTIPOS de Bufo marinus var. fluminensis $^{(*)}$ (Jiménez de la Espada, 1875).- 2Ad.ECF.- 1862/1865.- Colectó: M. Jiménez de la Espada.

MNCN 3064.- SINTIPO de Bufo marinus var. fluminensis ${ }^{(*)}$ (Jiménez de la Espada, 1875).- Ad.- ECF.1862/1865.- Colectó: M. Jiménez de la Espada.

OBSERVACIONES: Datos de la etiqueta antigua: Zulueta1912, Concepción (Chile).

MNCN 3066- 3069, 3072.- SINTIPOS de Bufo marinus var. fluminensis ${ }^{(*)}$ (Jiménez de la Espada, 1875).- 5Ad.ECF.- 1862/1865.- Colectó: M. Jiménez de la Espada.

(*) Probablemente son sintipos de «Bufo marinus var. fluminensis» Jiménez de la Espada, 1875 procedentes

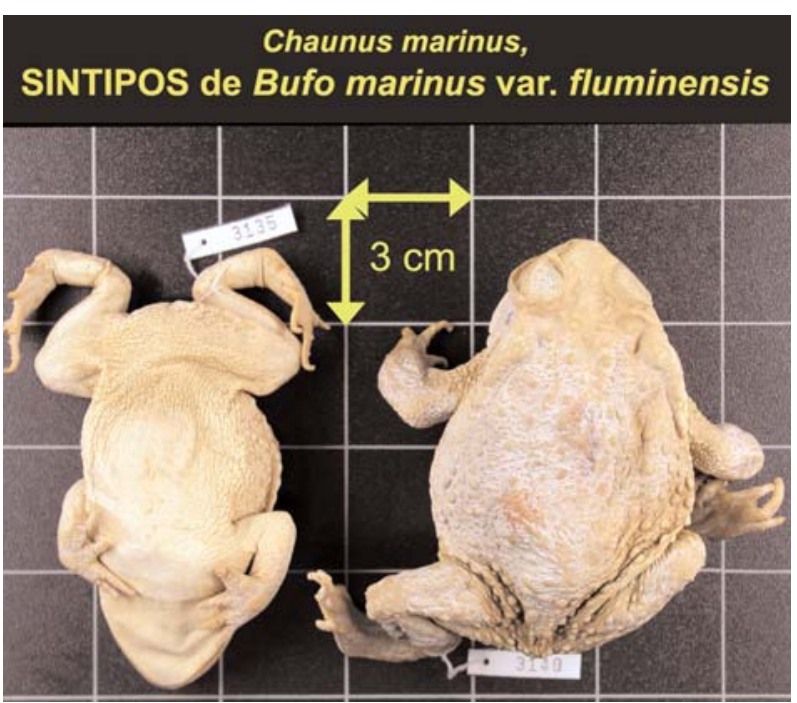

de Chonana (Guayas) o de Babahoyo (Los Ríos) en Ecuador, o bien de la Facenda Imperial [Hacienda que el emperador Pedro II de Brasil poseía en la localidad] de Santa Cruz, a 14 leguas (unos 67,5 km) de Río de Janeiro y en la cual colectaron los expedicionarios con autorización y por expreso deseo del emperador. Actualmente es imposible determinar la localidad exacta de todos estos ejemplares al carecer de más indicaciones tanto en la etiqueta como en las fichas que se conservan \{ver Jiménez de la Espada (1875a: 195-203)\}.

MNCN 3071.- SINTIPO de Bufo marinus var. fluminensis $^{(*)}$ (Jiménez de la Espada, 1875).- Jv.- ECF.- Río de Janeiro, Río de Janeiro, BRASIL.- 10/11-1862.Colectó: M. Jiménez de la Espada.

OBSERVACIONES: Recogido en Jiménez de la Espada (1875a: 199-200) como « Bufo marinus var. fluminensis».

MNCN 3074-3075.- SINTIPOS de Bufo marinus var. napensis (Jiménez de la Espada, 1875).- 2Jv.- ECF.San José de Moti ${ }^{(*)}$ Napo, ECUADOR.- [06-1865].Colectó: M. Jiménez de la Espada.

ObSERVACIONES: ${ }^{*}$ (Ver comentario al final de este catálogo). Recogidos en Jiménez de la Espada, (1875a: 201-202) como «Bufo marinus var. napensis»

MNCN 3076.- SINTIPO de Bufo marinus var. fluminensis (Jiménez de la Espada, 1875).- 5Pm.- ECF.Tabatinga, Amazonas, BRASIL.- 08/09-1865.- Colectó: M. Jiménez de la Espada.

OBSERVACIONES: Recogidos en Jiménez de la Espada (1875a: 199-200) como «Bufo marinus var. fluminensis», donde indica también que la localidad de origen es Tabatinga, orillas del Amazonas y la frontera de Perú con Brasil. 
Chaunus schneideri (Werner, 1894)

Bufo schneideri Werner, 1894, Zool. Anz., 17: 411.

No empleado por Jiménez de la espada en sus publicaciones. Chaunus schneideri, Frost, Grant, Faivovich, Bain, Haas, Haddad, de Sá, Channing, Wilkinson, Donnellan, Raxworthy, Campbell, Blotto, Moler, Drewes, Nussbaum, Lynch, Green, \& Wheeler, 2006, Bull. Am. Mus. Nat. Hist., 297: 364.

MNCN 3070.- Ad.- ECF.- Concepción ${ }^{(*)}$, Biobío, CHILE.[1863/1865].- Colectó: M. Jiménez de la Espada.

${ }^{(*)}$ Por algún error (antes de 1985) se cambió de frasco o de etiqueta con el ejemplar 3064 Chaunus marinus, especie que no se distribuye por Chile. Tampoco parece que se trate de Chaunus arunco (Molina, 1782) por la forma de las parótidas. La localidad incluso podría tratarse de Concepción (Uruguay), por lo que es necesaria la identificación definitiva por parte de un especialista; no obstante nosotros nos inclinamos por la especie indicada y procedente seguramente de Brasil, Uruguay o Argentina, nunca de Chile.

\section{Rhaebo guttatus Schneider, 1799}

Bufo guttatus Schneider, 1799, Hist. Amph. Nat.: 218 Bufo leschenaultii Duméril \& Bibron, 1841, Erp. Gén., 8: 662. Rhaebo leschenaultii, Cope, 1862, Proc. Acad. Nat. Sci. Philadelphia, 14: 357.

Rhaebo leschenaultii, Jiménez de la Espada, 1875, Vert. Viaj. Pacif., Batr.: 167.

Bufo guttatus, Rivero, 1961, Bull. Mus. Comp. Zool., 126: 21. Rhaebo guttatus, Frost, Grant, Faivovich, Bain, Haas, Haddad, De Sá, Channing, Wilkinson, Donnellan, Raxworthy, Campbell, Blotto, Moler, Drewes, Nussbaum, Lynch, Green \& Wheeler, 2006, Bull. Am. Mus. Nat. Hist., 297: 365.

MNCN 3095-3096.- M y H.- Ad y Jv.- ECF.- Provincia de Quijos, [Napo] ECUADOR.- [10-06-1865].- Colectó: M. Jiménez de la Espada.

Observaciones: Recogidos en Jiménez de la Espada (1875a: 167-170), como «Raebo leschenaultii». El macho adulto, bien podría tratarse del otro macho de Ávila de Quijos, del que también habla Jiménez de la Espada (1875a: 170). En cualquier caso, el ejemplar macho que describe Jiménez de la Espada en dicha página, coincide plenamente en sus medidas con las del que se conserva.

Rhinella iserni (Jiménez de la Espada, 1875)

Oxyrhynchus iserni Jiménez de la Espada, 1875, Vert. Viaje Pacif., Batr.: 185.

Bufo iserni, Savage, 1978, Intr. Vert. Viaje Pacif.: xiii.

Rhinella iserni, Frost, Grant, Faivovich, Bain, Haas, Haddad, De Sá, Channing, Wilkinson, Donnellan, Raxworthy, Campbell, Blotto, Moler, Drewes, Nussbaum, Lynch, Green \& Wheeler, 2006, Bull. Am. Mus. Nat. Hist., 297: 366.

MNCN 3057.- HOLOTIPO.- H.- Ad.- ECF.- Andes de Chanchamayo, al Noroeste de, Tarma, Junín, PERÚ.[09/11-1863].- Colectó: J. Isern.

OBSERVACIONES: Recogido en Jiménez de la Espada (1875a: 185-188) como «Oxyrhynchus iserni».

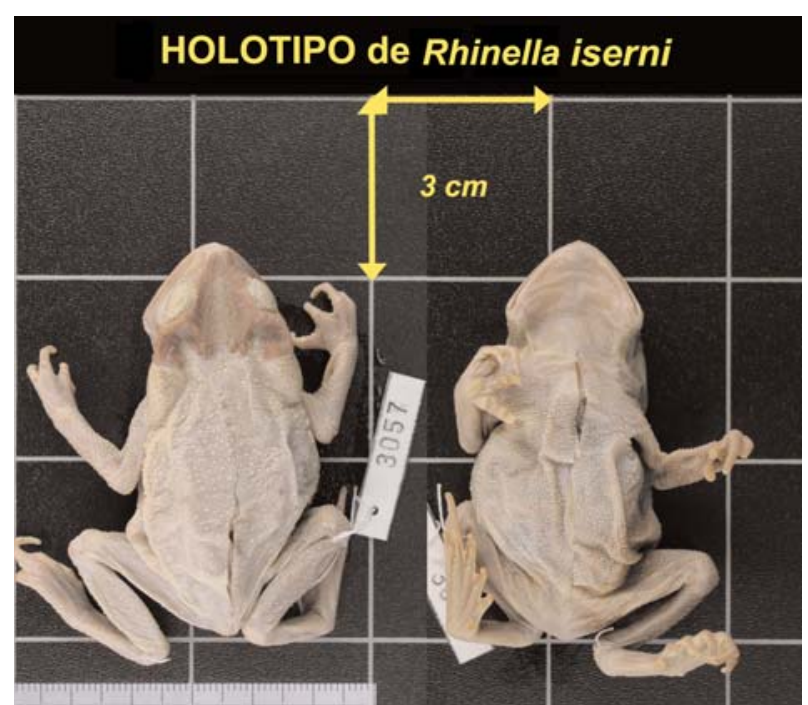

Rhinella margaritifer (Laurenti, 1768)

Rana typhonia Linnaeus, 1758, Syst. Nat., Ed. 10, 1: 211.

Bufo typhonius, Schneider, 1799, Hist. Amph., 1: 207.

Rana margaritifera Laurenti, 1768, Synops. Rept.: 30.

Bufo margaritifer, Latreille, 1801, In Sonnini \& Latreille, Hist. Nat. Rept., 2: 118. Daudin, 1802, Hist. Nat. Rain. Gren. Crap.: 89.

Bufo perlatus Cuvier, 1817, Regne Animal, ed. 1, 2: 97.

Bufo (Oxyrhynchus) naricus Spix, 1824, Spec. Nov. Testud. Ran. Brasil:: 49.

Otilophus typhonius, Tschudi, 1838, Classif. Batr.: 52, 89.

Otilophus margaritifer, Günther, 1859 «1858», Cat. Batr. Sal. Coll. Brit. Mus.: 317.

Oxyrhynchus typhonius, Jiménez de la Espada, 1875, Vert. Viaj. Pacif., Batr: 171.

Sinonimizada con Bufo margaritifer por Duméril \& Bibron, 1841, Erp. Gén., 8: 719.

Rhinella margaritifer, Frost, Grant, Faivovich, Bain, Haas, Haddad, De Sá, Channing, Wilkinson, Donnellan, Raxworthy, Campbell, Blotto, Moler, Drewes, Nussbaum, Lynch, Green \& Wheeler, 2006, Bull. Am. Mus. Nat. Hist., 297: 366 .

Aunque la denominación de Oxyrhynchus typhonius Jiménez de la Espada, 1875a, está recogida por Frost 2002-2004 bajo el taxon Hoplobatrachus tigerinus (Daudin, 1802) esto se debe al histórico error de Peters (1873, Monatsber. Preuss. Akad. Wiss. Berlin, 1873: 623), O’Shaughnessy (1875, Zool. Rec., 10: 97) y Boulenger (1882, Cat. Batr. Sal. Brit. Mus.: 317) que consideran Bufo margaritifer como un sinónimo posterior de Rana typhonia Linnaeus, 1758 [= Rana tigerina, actualmente Hoplobatrachus tigerinus (Daudin, 1802)]. La distribución de esta especie (Nepal, India y Sri Lanka) dista mucho de alcanzar el continente americano. Hasta 1989, se ha empleado por diferentes autores el nombre de Bufo typhonius para referirse a Bufo margaritifer (Hoogmoed, 1989), siendo ese también el criterio adoptado por 
Jiménez de la Espada en Vertebrados del Viaje al Pacífico I. Batracios: 177, pues si bien cita Rana typhonia, también lo hace con Rana margaritifer, Bufo margaritifer y Otilophus margaritifer.

MNCN 3023.- H.- Ad.- ECF.- BRASIL.- [08/11-1862].Donó: ¿Comisión Científica del Pacífico?.

OBSERVACIONES: Martínez Rica (1980) anotó en la ficha antigua: «Las crestas cefálicas están muy desarrolladas, en grado comparable al del ejemplar citado como ejemplo por Cochran (USNM 108987)». Por las elevadas crestas cefálicas, deducimos que se trata de una hembra y no de un macho como indica MartínezRica en su ficha. Por otra parte, no figura citado como «Oxyrhynchus typhonius» por Jiménez de la Espada (1875a: 177). Todos los ejemplares citados por Jiménez de la Espada, son de San José de Moti ${ }^{*}$ (Ver comentario al final de este catálogo) y «del Oriente de Ecuador», provincia que en 1865, además de las actuales provincias de Ecuador de Napo, Sucumbíos, Orellana y Pastaza, incluía una parte importante de la actual provincia peruana de Loreto, hasta su frontera con Brasil, de donde quizás podría proceder el ejemplar. Por el color, textura y aspecto general, debe tratarse de un ejemplar de la época, pero no podemos tampoco asegurar que no pueda ser un ejemplar procedente del Museo de París, pues Jiménez de la Espada no hace ningún comentario sobre él en su libro. En última instancia, podría tratarse de un error de datación o de una traslocación de etiquetas o de frasco.

MNCN 3024-3046.- (MM+HH).- 23Ad.- ECF.- Provincia de Oriente del Ecuador y San José de Moti ${ }^{*}$ Napo, ECUADOR.- 1865.- Colectó: M. Jiménez de la Espada. OBSERVACIONES: ${ }^{*}$ (Ver comentario al final de este catálogo) Recogidos en Jiménez de la Espada (1875a: 171-178) como «Oxyrhynchus typhonius».

\section{Rhinella proboscidea (Spix, 1824)}

Bufo (Oxyrhynchus) proboscideus Spix, 1824, Spec. Nov. Testud. Ran. Brasil.: 52.

Otilophus typhonius Peters, 1871, Monatsber. Preuss. Akad. Wiss. Berlin, 1871: 403.

Oxyrhynchus proboscideus, Jiménez de la Espada, 1875, Vert. Viaj. Pacif., Batr.: 178.

Bufo proboscideus, Hoogmoed, 1986, Stud. Herpetol., Prague: 147-150.

Rhinella proboscidea, Frost, Grant, Faivovich, Bain, Haas, Haddad, De Sá, Channing, Wilkinson, Donnellan, Raxworthy, Campbell, Blotto, Moler, Drewes, Nussbaum, Lynch, Green \& Wheeler, 2006, Bull. Am. Mus. Nat. Hist., 297: 366

MNCN 3047-3056.- MM+HH.- $10(\mathrm{Ad}+\mathrm{Jv})$.- ECF.Archidona de Quijos (=Archidona) Napo, ECUADOR.[04/05-1865].- Colectó: M. Jiménez de la Espada. OBSERVACIONES: Recogidos en Jiménez de la Espada (1875a: 178-185) como «Oxyrhynchus proboscideus».

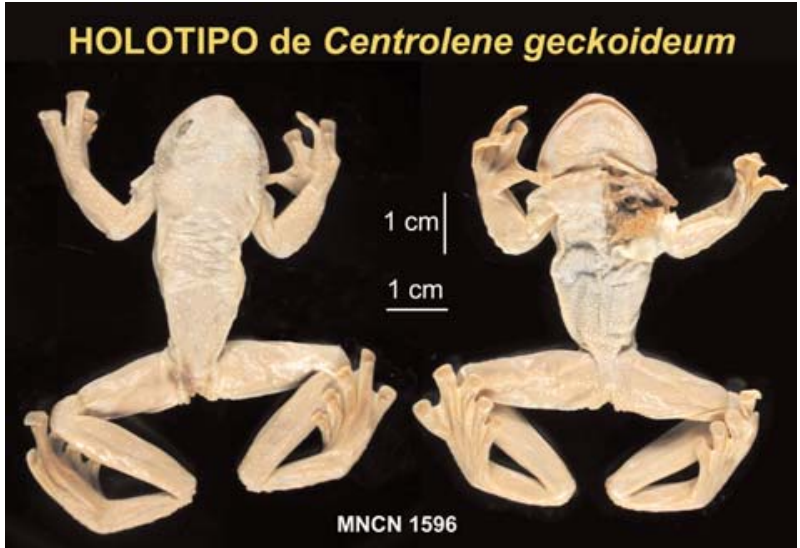

\section{Familia Centrolenidae}

Centrolene geckoideum Jiménez de la Espada, 1872 Centrolene geckoideum Jiménez de la Espada, 1872, An. Soc. Esp. Hist. Nat., 1: 88.

MNCN 1596.- HOLOTIPO.- Ad.- ECF.- Orillas del río Napo $^{(*)}$ ECUADOR.- [1865].- Colectó: M. Jiménez de la Espada.

OBSERVACIONES: ${ }^{*}$ Aparentemente existe un error en la cita de Jiménez de la Espada, ya que la especie no se distribuye al este de los Andes. Nosotros compartimos las tesis de Frost (1985, 2006), Ruiz-Carranza et al. (1986: 435-436) y recogidas en De la Riva (2000: 79): “...habita en los bosques nublados de las laderas andinas occidentales de Colombia y Ecuador". Recogido en Jiménez de la Espada (1872a: 88) y figurado en Jiménez de la Espada (1875a: Lam. 2, fig. 5).

\section{Familia Ceratophryidae}

\section{Batrachyla taeniata (Girard, 1855)}

Cystignathus taeniatus Girard, 1855 "1854", Proc. Acad. Nat. Sci. Philadelphia, 7: 226.

Cystignathus hidalgoi Jiménez de la Espada, 1875, Vert. Biaj. Pacif. Verif., Batr.: 76.

Borborocoetes hidalgi, Boulenger, 1882. Cat. Batr. Sal. Coll. Brit. Mus., Ed. 2: 253.

Sinonimizado con Paludicola nodosa por Werner, 1898 «1897», Zool. Jahrb., Jena, Suppl., 4: 266.

Sinonimizado con Eupsophus taeniatus por Gorham, 1966, Das Tierreich, 85: 119.

Batrachyla taeniata, Lynch, 1971, Misc. Publ. Mus. Nat. His. Univ. Kansas, 53: 129

MNCN 3528.- SINTIPO de Cystignathus hidalgoi (Jiménez de la Espada, 1875).- H.- Ad.- ECF.- Valdivia, CHILE.- Colectó: M. Jiménez de la Espada \& R.A. Phillippi. 


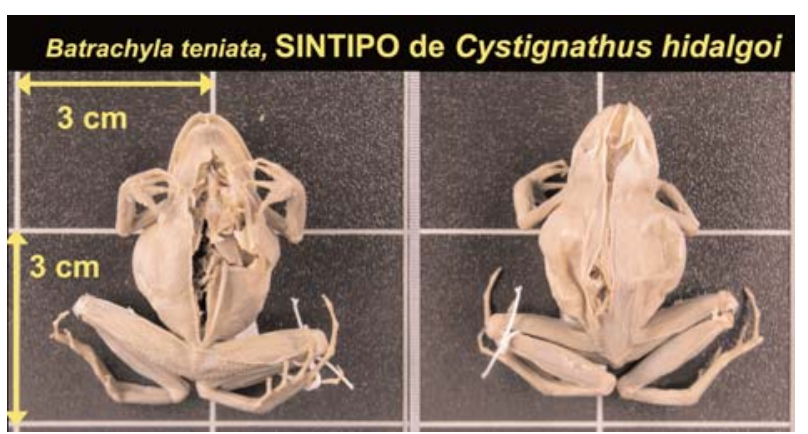

OBSERVACIONES: Fue clasificado como «Leptodactilidae» por Martínez-Rica en 1980. Revisado por J. M. Cei en 1985, lo determinó como «Bathrachyla taeniata». Esta especie descrita por Jiménez de la Espada como Cystignathus hidalgoi, tras diversas sinonimias fue transferida a $« B$. taeniata $»$ De la Riva (2000: 81). De alguna forma es lógico que ante la falta de indicaciones, respecto a su condición de ejemplar tipo, Cei la determinara como B. taeniata, separándola del ejemplar del MNCN 3527 (Hylorhina sylvatica) con quien compartía frasco y del cual, evidentemente, difería. Nosotros pensamos que se trata de uno de los sintipos de «Cystignathus hidalgoi» recogidos en Jiménez de la Espada (1875a: 81-82).

MNCN 3531-3532.- SINTIPOS de Cystignathus hidalgoi (Jiménez de la Espada, 1875).- M y H.- 2Ad.ECF.- [Valdivia] CHILE.- Colectó: M. Jiménez de la Espada y R.A. Phillippi.

OBSERVACIONES: Fueron clasificados como «Leptodactilidae» por Martínez-Rica (1980) con la siguiente nota: «Se parece bastante a Cyclorhamphus eleuterodactylus, del Brasil, pero a diferencia de éste posee membrana en las patas posteriores. Posiblemente sea especie nueva». Revisados por J. M. Cei en 1985, lo determinó como «Bathrachyla taeniata». Esta especie descrita por Jiménez de la Espada como Cystignathus hidalgoi, tras diversas sinonimias fue transferida a $\ll B$. taeniata» De la Riva (2000: 81). De alguna forma es lógico que ante la falta de indicaciones, respecto a su condición de ejemplar tipo, Cei la determinara como B. taeniata, separándola del ejemplar del MNCN 3527 (Hylorhina sylvatica) con quien compartía frasco y del cual, evidentemente, diferían. Nosotros pensamos que se trata de dos de los sintipos de «Cystignathus hidalgoi» recogidos en Jiménez de la Espada (1875a: 8182).

Ceratophrys cornuta (Linnaeus, 1758)

Rana cornuta Linnaeus, 1758, Syst. Nat., Ed. 10, 1: 212.

Bufo cornutus, Laurenti, 1768, Synops. Rept.: 25

Ceratophris daudini Cuvier, 1829, Règne Animal, ed. 2, 2: 106.
Ceratophris spixii Cuvier, 1829, Règne Animal, ed. 2, 2: 106. Phrynoceros vaillanti Tschudi, 1838, Classif. Batr.: 44, 82.

Ceratophrys megastoma Wagler, 1830, Nat. Syst. Amph.: 204; Günther, 1859 «1858», Cat. Batr. Sal. Brit. Mus.: 25.

Ceratophrys megastoma, Jiménez de la Espada, 1875, Vert. Viaje Pacifico, Batr.: 26-34

Ceratophrys (Stombus) cornuta, Lynch, 1982, Syst. Zool., 31: 166-179.

MNCN 1730.- [M].- [Ad].- ECF.- Orillas del río Napo, Tarapoto, Loreto, PERU.- [07-1865].- Colectó: M. Jiménez de la Espada.

OBSERVACIONES: Por alguna razón desconocida para nosotros, se confeccionó una ficha (¿hacia 1930?) con el número 174, que contiene los siguientes datos: "Ceratophrys cornuta, Archidona, Ecuador, Viaje al Pacífico" y que sustituyó a la $\mathrm{n}^{\circ} 172$ (de la época de Jiménez de la Espada) que contiene estos datos: "Tarapoto, orillas del Napo, Ecuador". Esta última ficha fue revisada y validada por Zulueta en 1911. Nosotros pensamos que ésta es la datación correcta del ejemplar. Hoy en día, el antiguo territorio de Oriente de Ecuador en el que se encuentra Tarapoto, pertenece al departamento de Loreto, Perú. Así pues creemos que salvo por el cambio de adscripción política, la información contenida en la ficha 172, es coincidente con los datos consignados en Jiménez de la Espada (1875: 26-34), bajo la denominación de «Ceratophrys megastoma».

\section{Familia CyCloRAMPHIDAE}

Alsodes nodosus (Duméril \& Bibron, 1841)

Cystignathus nodosus Duméril \& Bibron, 1841, Erp. Gén., 8: 413 No empleado por Jiménez de la Espada es sus publicaciones. Alsodes nodosus, Gallardo, 1970, Neotropica, 16(50): 83;

Determinados como Alsodes nodosus por J.M. Cei en 1985.

MNCN 4057-4062.- 2H/M/2H /M.- Jv/5Ad.- ECF.Valdivia, Los Lagos, CHILE.- [1863-1864].-Colectó: M. Jiménez de la Espada.

OBSERVACIONES: Etiqueta antigua con datos de colecta pero sin determinación. Martínez-Rica los determino como Leptodactylidae.

\section{Eupsophus roseus (Duméril \& Bibron, 1841)}

Cystignathus roseus Duméril \& Bibron, 1841, Erp. Gén., 8: 414. Cystignathus roseus, Jiménez de la Espada, 1875, Vert. Viaje Pacifico, Batr.: 73-76.

Eupsophus roseus, Schmidt, 1954, Lunds Univ. Arsskrift. N. F., (2) 49(19): 5.

No empleado por Jiménez de la Espada es sus publicaciones.

Figuraba en la ficha antigua como Borborocoetes roseus (D \& B).

MNCN 1722-1727.- ECF.- Valdivia, Los Lagos, CHILE.[1863/1864].- Colectó: M. Jiménez de la Espada. OBSERVACIONES: Recogidos en Jiménez de la Espada (1875: 73-76) como «Cystignathus roseus». 
Hylorina sylvatica Bell, 1843

Hylorina sylvatica Bell, 1843, Zool. Voy. Beagle, 5: 44.

Hylorhinus silvatica, Günther, 1859 «1858», Cat. Batr. Sal. Coll. Brit. Mus.: 23.

Cystignathus aeneus Guichenot in Gay, 1848, Hist. Nat. Chile, 2: 102 .

Hylorhina ${ }^{(*)}$ sylvatica, Jiménez de la Espada, 1875, Vert. Viaj. Pacif., Batr.: $10^{(*)}$ Error de escritura del nombre genérico ("rh" por "r")

MNCN 3527.- H.- Ad.- ECF.- [Valdivia] CHILE.Colectó: M. Jiménez de la Espada \& R.A. Phillippi. OBSERVACIONES: Fue clasificada como «Leptodactilidae» por Martínez-Rica en 1980. Revisado por J. M. Cei en 1985, lo separó del ejemplar MNCN 3528 (Bathrachyla taeniata) determinándolo como Hylorina sylvatica. Recogido en Jiménez de la Espada (1875a: 10-14) como "Hylorhina sylvatica".

Odontophrynus americanus (Duméril \& Bibron, 1841)

Pyxicephalus americanus Duméril \& Bibron, 1841, Erp. Gén., 8: 446.

Pyxicephalus americanus, Jiménez de la Espada, 1875, Vert. Viaje Pacifico, Batr: 20.

Odontophrynus americanus, Miranda-Ribeiro, 1920, Rev. Mus. Paulista, São Paulo, 12: 290.

MNCN 1728.- M.- Ad.- ECF.- Pampas del Uruguay ${ }^{(*)}$, URUGUAY.- [12/01-1863].- Colectó: M. Jiménez de la Espada.

(*) Aunque la etiqueta antigua que le acompaña, al igual que la ficha revisada por Zulueta en 1911 y la ficha confeccionada por Martínez-Rica a principios de los ochenta, indican Montevideo (como lugar de colecta), al tratarse inequívocamente de un macho, seguramente se trata del ejemplar que, como procedente de las Pampas del Uruguay, describe Jiménez de la Espada (1875a: 25), ya que las medidas que posee el ejemplar coinciden plenamente con las indicadas por este autor. OBSERVACIONES: Zulueta hace referencia a dos ejemplares, mientras que Martínez-Rica sólo a uno (el que actualmente se conserva); suponemos que, al no hacer ningún tipo de referencia al segundo ejemplar, éste debió extraviarse entre ambas fechas. Recogido en Jiménez de la Espada (1875a: 20-25) como "Pyxicephalus americanus".

Rhinodema darwinii Duméril \& Bibron, 1841

Rhinoderma darwinii Duméril \& Bibron, 1841, Erp. Gén., 8: 659.

Rhinoderma darwinii, Jiménez de la Espada, 1875, Vert. Viaje Pacifico, Batr.: 129.

MNCN 1587-1595.- 9(M+H) ${ }^{(*)}$.- 9Ad+2Lv.- ECF.Valdivia, Los Lagos, CHILE.- [<1863].- Colectó: R. A. Philippi.

(*) En su trabajo sobre la reproducción de Rhinoderma darwinii (Jiménez de la Espada, 1872b), además de descubrir que eran los machos y no las hembras los que incubaban y cuidaban de los renacuajos hasta su desarrollo y que este proceso se realizaba en los extensísimos sacos vocales de los machos, hizo un pormenorizado recuento de las larvas existentes en cada uno de los cinco machos por él diseccionados y mención expresa al considerable tamaño de los huevos de la hembra estudiada. Por desgracia, el paso de los años, el descuido y, por qué no decirlo, la desidia en la conservación, inexistente en alguna triste etapa de nuestra más reciente historia, ha hecho que uno de los machos estudiados por Jiménez de la Espada haya desaparecido, y que tan sólo se conserven unas pocas larvas de las que él estudió.

OBSERVACIONES: Recogidos todos ellos también en Jiménez de la Espada (1875a: 129-138).

MNCN 17194.- Lv.- ECF.- Valdivia, Los Lagos, CHILE.- [<1863].- Colectó: R. A. Phillippi.

OBSERVACIONES: Es una de las pocas larvas de cierto tamaño, de las cerca de cincuenta estudiadas por Jiménez de la Espada, que aún se conservan. Recogido en Jiménez de la Espada (1872b: 139-151; 1875a: 129-138).

\section{Familia Dendrobatidae}

Hyloxalus bocagei Jiménez de la Espada, 1871

Hyloxalus bocagei Jiménez de la Espada, 1871 «1870», J. Math. Phys. Nat. Acad. Real Sci. Lisboa, 3: 59

Colostethus bocagei, Edwards, 1971, Proc. Biol. Soc. Washington, 84: 148.

Colostethus bocagei, Coloma, 1995, Misc. Publ. Mus. Nat. Hist. Univ. Kansas, 87: 21. Designa lectotipo y paralectotipo.

Hyloxalus bocagei, rehabilitado por Grant, Frost, Caldwell, Gagliardo, Haddad, Kok, Means, Noonan, Schargel \& Wheeler, 2006, Bull. Am. Mus. Nat. Hist., 299: 168.

NOTA: El aspecto muy deteriorado de todos los ejemplares que se conservan, delata una deshidratación en alguna época anterior a 1990.

MNCN 1583.- LECTOTIPO designado por Coloma (1995).- ECF.- San José de Moti, ${ }^{*}$ N) Napo, ECUADOR.- 06-1865.- Colectó: M. Jiménez de la Espada. OBSERVACIONES: ${ }^{*}$ Ver comentario al final de este catálogo. Recogido en Jiménez de la Espada (1871: 59) y figurado en Jiménez de la Espada (1875a: Lam. 3, fig. 2, 2a, 2b), como «Hyloxalus bocagei». También recogido en Coloma (1995: 21-23) como Colostethus bocagei.

MNCN 1584.- PARALECTOTIPO designado por Coloma (1995).- ECF.- San José de Moti ${ }^{(*)}$ Napo, ECUADOR.- 06-1865.- Colectó: M. Jiménez de la Espada.

OBSERVACIONES: $\left.{ }^{*}\right)$ Ver comentario al final de este catálogo. Recogido en Jiménez de la Espada (1871: 59) y figurado en Jiménez de la Espada (1875a: Lam. 


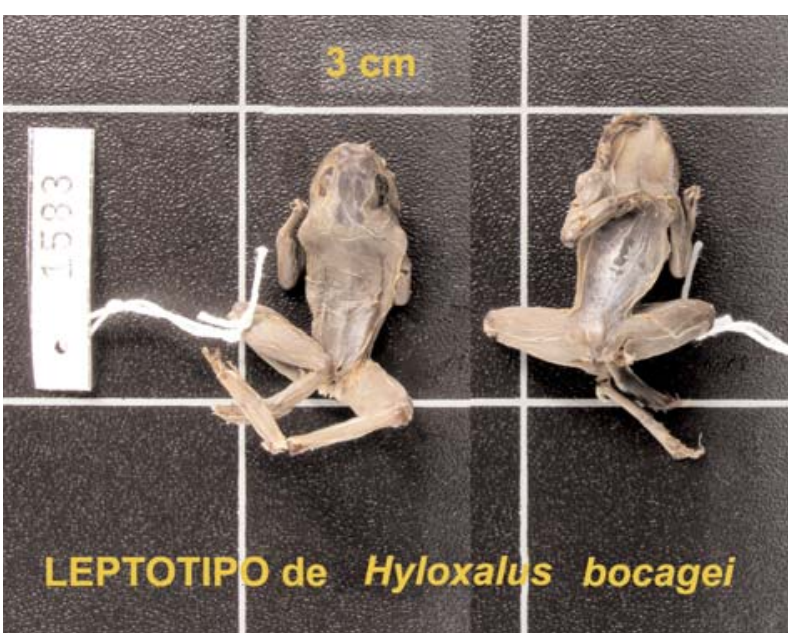

3, fig. 2, 2a, 2b), como «Hyloxalus bocagei». También recogido en Coloma (1995: 21-23) como Colostethus bocagei.

Hyloxalus fuliginosus Jiménez de la Espada, 1871

Hyloxalus fuliginosus Jiménez de la Espada, 1871 «1870», J. Sci. Math. Phys. Nat., Lisboa, 3: 59.

Hylixalus fuliginosus, Boulenger, 1882, Cat. Batr. Sal. Brit. Mus.: 138.

Hylixalus fuliginosus, Savage 1968. Copeia, 4 : 753

Colostethus fuliginosus, Edwards, 1971, Proc. Biol. Soc. Washington, 84: 148.

Hyloxalus fuliginosus rehabilitado por Grant, Frost, Caldwell, Gagliardo, Haddad, Kok, Means, Noonan, Schargel \& Wheeler, 2006, Bull. Am. Mus. Nat. Hist., 299: 168.

MNCN 1585.- PARALECTOTIPO como consecuencia de la designación del otro sintipo (MNCN 1586) como lectotipo por Savage (1968: 753).- H.- Ad.ECF.- San José de Moti(*), Napo, ECUADOR.- 061865.- Colectó: M. Jiménez de la Espada.

MNCN 1586.- LECTOTIPO designado por Savage (1968: 753).-H.- Ad.- ECF.- San José de Moti(*), Napo, ECUADOR.- 06-1865.- Colectó: M. Jiménez de la Espada.

(*) Ver comentario al final de este catálogo.

OBSERVACIONES: Uno de ellos, podría ser el ejemplar figurado en Jiménez de la Espada (1875a: Lam. 3, fig. 1, 1a, 1b), recogidos en Savage (1968: 753), en ambos casos como "Hyloxalus fuliginosus", y en Coloma (1995: 31-33) como Colostethus fuliginosus.

\section{Familia Hemiphractidae}

Hemiphractus bubalus (Jiménez de la Espada, 1871) Cerathyla bubalus Jiménez de la Espada, 1871 "1870", $J$. Sci. Math. Phys. Nat., Lisboa, 3: 64.

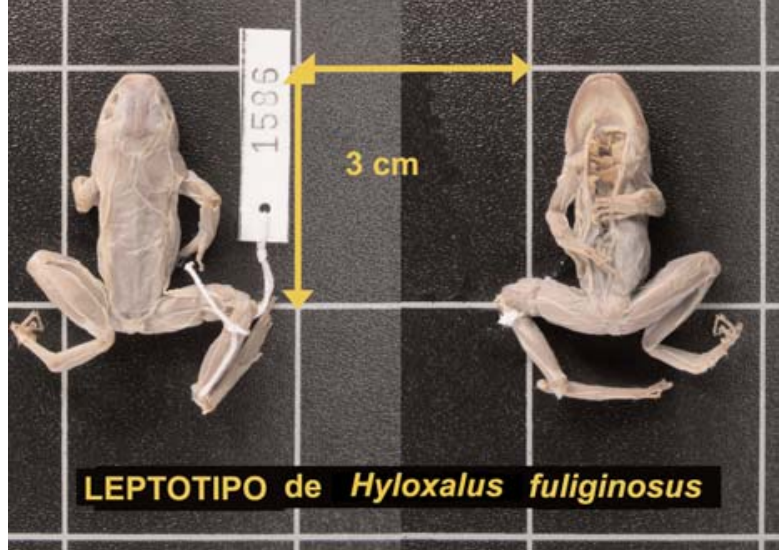

Cerathyla braconnieri Jiménez de la Espada, 1871 «1870», J. Sci. Math. Phys. Nat., Lisboa, 3: 64.

Sinonimizado con Hemiphractus bubalus por Trueb, 1974, Occas. Pap. Mus. Nat. Hist. Univ. Kansas, 29: 23.

Cerathyla palmarum Jiménez de la Espada, 1871 «1870», J. Sci. Math. Phys. Nat., Lisboa, 3: 64

Sinonimizado con Hemiphractus bubalus por Trueb, 1974, Occas. Pap. Mus. Nat. Hist. Univ. Kansas, 29: 23.

Cerathyla bubalus Jiménez de la Espada, 1871 «1870», $J$, Sci. Math. Phys. Nat., Lisboa, 3: 64.

Hemiphractus bubalus, Trueb, 1974, Occas. Pap. Mus. Nat. Hist. Univ. Kansas, 29: 23.

MNCN 1735.- HOLOTIPO de Cerathyla braconnieri, Jiménez de la Espada, 1871.- Ad.- ECF.- Archidona de Quijos (=Archidona) Napo, ECUADOR.- [04-1865].Colectó: [M. Jiménez de la Espada].

OBSERVACIONES: Recogido en Jiménez de la Espada (1871: 64; 1898: 407-410) y figurado en Jiménez de la Espada (1875a: Lam. 6, fig. 2, 2a), en todos los casos como «Cerathyla braconnieri». Recogido en Trueb (1974: 1-60).

MNCN 1736.- HOLOTIPO.- ECF.- Archidona de Quijos (=Archidona) Napo, ECUADOR.- [05-1865].Colectó: M. Jiménez de la Espada.

OBSERVACIONES: Recogido en Jiménez de la Espada (1871: 64; 1898: 402-404) y figurado en Jiménez de la Espada (1875a: Lam. 5, fig. 3, $3^{\mathrm{a}}$ ), en todos los casos como «Cerathyla bubalus». Recogido en Trueb (1974: $1-60)$.

MNCN 1738.- HOLOTIPO de Cerathyla palmarum (Jiménez de la Espada, 1871).- ECF.- San José de Moti (*) Napo, ECUADOR.- 06-1865.- Colectó: M. Jiménez de la Espada.- Donó: CCP.

(*) Ver comentario al final de este catálogo

OBSERVACIONES: Recogido en Jiménez de la Espada (1871: 64), figurado en Jiménez de la Espada (1875a: Lam. 6, fig. 2, $2^{\mathrm{a}}$ ) y recogido también en Jiménez de la Espada (1898: 404-407), en todos los casos como «Cerathyla palmarum». Recogido en Trueb (1974: 1$60)$. 


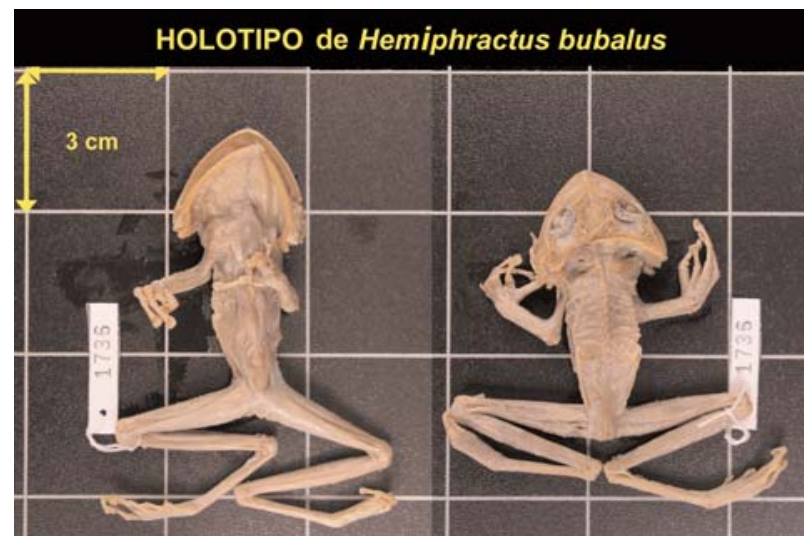

Hemiphractus proboscideus (Jiménez de la Espada, 1871) Cerathyla proboscidea Jiménez de la Espada, 1871 «1870», J. Sci. Math. Phys. Nat., Lisboa, 3: 64

Ceratohyla proboscidea, Boulenger, 1882, Cat. Batr. Sal. Brit. Mus.: 453.

Hemiphractus proboscideus, Noble, 1926, Am. Mus. Novit., 212: 19.

MNCN 1737.- HOLOTIPO.- [Jv].- ECF.- Selvas cercanas al volcan Sumaco, Sumaco, Napo, ECUADOR.[16/17]-06-1865.- Colectó: M. Jiménez de la Espada.Donó: CCP.

OBSERVACIONES: Recogido en Jiménez de la Espada (1871: 64; 1898: 399-401) y figurado en Jiménez de la
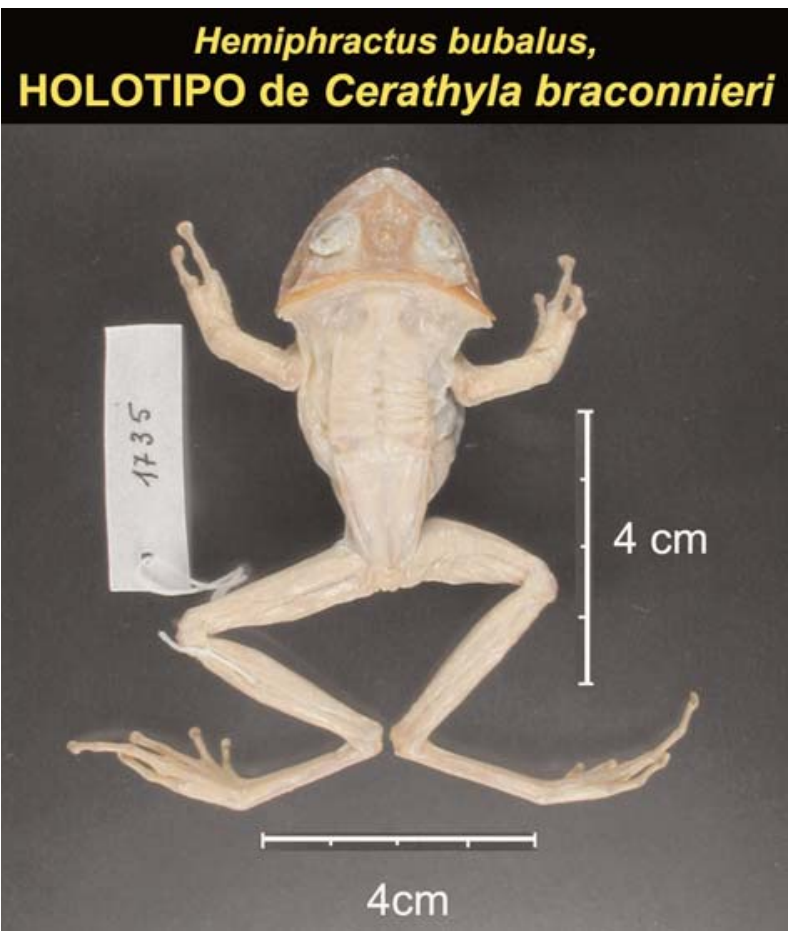
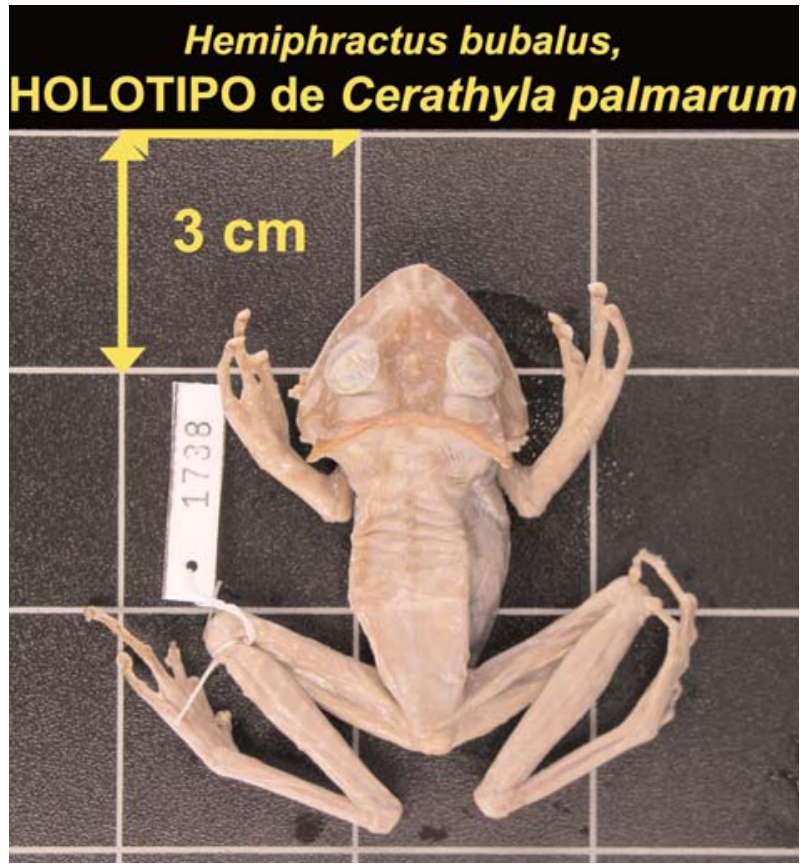

Espada (1875a: Lam.: 5, fig. 2, 2a, 2b), en todos los casos como «Cerathyla proboscidea». Recogido en Trueb (1974: 38).

Hemiphractus scutatus (Spix, 1824)

Rana scutata Spix, 1824, Spec. Nov. Testud. Ran. Brasil.: 28.

Hemiphractus spixii Wagler, 1828, Isis von Oken, 21: 743.

Hemiphractus scutatus, Peters, 1862, Monatsber. Preuss. Akad. Wiss. Berlin, 1862: 146.

Hemiphractus scutatus, Jiménez de la Espada, 1871 «1870», J. Sci. Math. Phys. Nat. Lisboa, 3: 64.

Hemiphractus scutatus, Jiménez de la Espada, 1875, Vert. Biaj. Pacif., Batr., Lam. 5 fig. 2, 2a, 2 b.

Hemiphractus scutatus, Jiménez de la Espada, 1898, An. Soc. Esp. Hist. Nat., 27: 379.

MNCN 3511- 3513.- Ad y 2Jv.- ECF.- San José de Moti (*) Napo, ECUADOR.- [06/07-1865].- Colectó: M. Jiménez de la Espada.

${ }^{*}$ Ver comentario al final de este catálogo.

OBSERVACIONES: Recogidos en Jiménez de la Espada (1871: 63); alguno de ellos (probablemente el adulto) puede ser el figurado en Jiménez de la Espada (1875a: Lam. 5, fig. 2, 2a, 2b); recogidos también en Jiménez de la Espada (1898: 395-399).

MNCN 24609.- Ad.- EDP.- Archidona de Quijos (=Archidona), Napo, Ecuador.- [ 04/05-1865].Colectó: M. Jiménez de la Espada.

ObSERVACIONES: Recogido en Jiménez de la Espada (1871: 63), puede ser el figurado en Jiménez de la Espada (1875a: Lam. 5, fig. 2, 2a, 2b); recogido también en Jiménez de la Espada (1898: 395-399). En este 
último trabajo Jiménez de la Espada indica: “...la descripción ha sido hecha en base a los cuatro ejemplares, dos adultos y dos jóvenes, que se conservan en la colección, procedentes de Moti y de Archidona...". Los ejemplares que actualmente se conservan completos, son los procedentes de San José de Moti, un adulto y dos juveniles cuyas medidas se corresponden con las mencionadas por Jiménez de la Espada (1898: 398): 62,37 y $23 \mathrm{~mm}$, respectivamente. Con respecto al adulto procedente de Archidona, Jiménez de la Espada (op. cit.) comenta que se encuentra en peor estado. Mucho nos extraña que si Jiménez de la Espada hubiera encontrado restos animales en el estomago de alguno de los adultos estudiados y mucho más ¡del tamaño de éstos!, no hubiera hecho ninguna mención a ellos en sus publicaciones. Zulueta en 1911, añade un comentario en la ficha antigua $n^{\circ} 192$, correpondiente a los actuales MNCN 3511-3513, diciendo: "en un tubito hay restos animales y vegetales procedentes del ejemplar adulto" (el MNCN 3511). Por otra parte, en la ficha antigua $\left(\mathrm{n}^{\circ} 191\right)$, cuyos datos son: "nombre científico, Hemiphractus scutatus (Spix); localidad, Archidona (Ecuador); colector, Espada; Clasificador, Espada; 1 ejemplar." Vuelta de la ficha: "Vease 1870* (*2a edición de 1883). Espada Jor. Sci. Lisboa p. 59. 1875.- Espada, Vert. Viaj. Pl. Vf. 1. 1898.- Espada. An. Soc. Esp. Hist. Nat. P 377. Boulenger 1882 (Cat. Brit. Mus) dice que las figuras y descrip. de Espada no corresponden al H. scutatus (spix) sino quizás H. divaricatus Cope Zulueta 1911". Zulueta no pone el sello de "Zulueta reviso 1911" en la casilla de clasificador al lado del nombre Espada, como en la mayoría de las fichas por el confeccionadas. Por otra parte, al analizar estos “... restos animales y vegetales...”, se observan los restos óseos momificados de una extremidad posterior derecha completa de anuro, de un tamaño similar, a la del ejemplar adulto de cuyo estómago se supone que proceden (MNCN 3511). Todo esto nos hace pensar que dichos restos pertenecen al cuarto ejemplar estudiado por Jiménez de la Espada procedente de Archidona [de Quijos], que tanto Zulueta en 1911 como MartínezRica (1980) no localizaron e interpretaron como restos de otro animal engullido por el MNCN 3511.

\section{Familia HyLIDAE}

Dendropsophus leucophyllatus (Beireis, 1783)

Rana leucophyllata Beireis, 1783, Schr. Ges. Naturforsch. Freunde Berlin, 4: 182.

Hyla leucophylla Gmelin, 1789, Linn. Syst. Nat., 3: 1055. Error por Hyla leucophyllata.

Hyla (Hyla) leucophyllata, Burmeister, 1856, Erläut. Fauna Brasil.: 104.

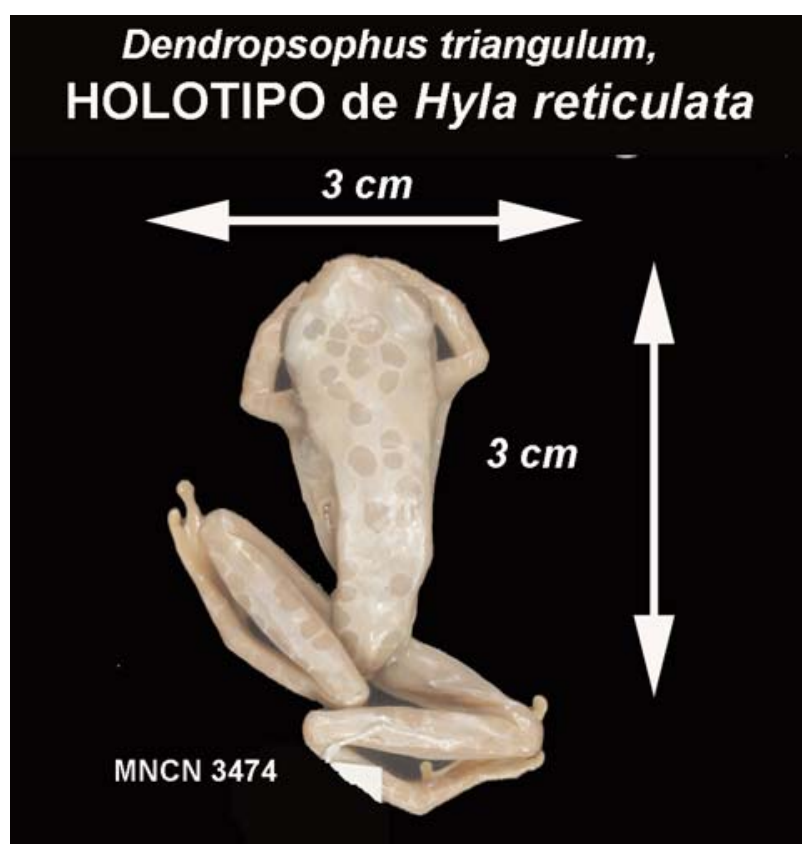

No empleado por Jiménez de la Espada es sus publicaciones.

Determinado como Hyla leucophylla por A. Zulueta en 1911 y revisado por J. M. CEI en 1985.

Dendropsophus leucophyllatus, Faivovich, Haddad, García, Frost, Cambell \& Wheeler, 2005. Bull. Am. Mus. Nat. Hist., 294: 91.

MNCN 3473.- Ad.- ECF.- [Orillas del río Napo, en las proximidades de] Mazán ${ }^{(*)}$ [Loreto] Perú.- 07-1865.Colectó: M. Jiménez de la Espada.

OBSERVACIONES: ${ }^{*}$ Aunque actualmente Mazán pertenece a Perú, en el momento de colecta pertenecía a la provincia de Oriente en Ecuador.

Dendropsophus triangulum (Günther, 1869 «1868»)

Hyla triangulum Günther, 1869 «1868», Proc. Zool. Soc. London, 1868: 489.

Hyla reticulata Jiménez de la Espada, 1871 «1870», J. Sci. Math. Phys. Nat., Lisboa, 3: 61-62.

Sinonimizado con Hyla triangulum por Duellman (1974) Occas. Pap.Mus. Nat. Hist. Univ. Kansas, 27: 19

Dendropsophus triangulum, Faivovich, Haddad, García, Frost, Cambell \& Wheeler, 2005. Bull. Am. Mus. Nat. Hist., 294: 91

MNCN 3474.- HOLOTIPO de Hyla reticulata (Jiménez de la Espada, 1871).- [H] ${ }^{(*)}$ - Ad.- ECF.- Orillas del río Napo [en las proximidades de Mazán], Loreto, Perú.[08-1865].- Colectó: M. Jiménez de la Espada.

${ }^{(*)}$ Aunque Jiménez de la Espada (1871: 61) no lo indica, Duellman (1974: tabla 6) habla de una hembra cuando hace referencia al holotipo de $H$. reticulata, y así lo recogemos aquí. 
OBSERVACIONES: Recogido en Jiménez de la Espada (1871: 61-62) como «Hyla reticulata», donde aparece como de Ecuador; aunque Mazán actualmente pertenece a Perú, entonces era parte integrante de la provincia ecuatoriana de Oriente. Figurada en Jiménez de la Espada (1875a: Lam. 7, fig. 7, 7 a); también recogida en Duellman (1974: 19 y tabla 6).

Hypsiboas sin determinar especie.

MNCN 4031-4036.- 5 H+M.- 6 Ad.- ECF.- 1862/1865.

Hypsiboas albomarginatus Spix, 1824

Hyla albomarginata Spix, 1824, Spec. Nov. Testud. Ran. Brasil.: 33.

No empleado por Jiménez de la Espada es sus publicaciones. Boana albomarginatus, Wiens, Fetzner, Parkinson \& Reeder, 2005, Syst. Biol, 54: 743.

Hypsiboas albomarginatus, Faivovich, Haddad, García, Frost, Cambell \& Wheeler, 2005. Bull. Am. Mus. Nat. Hist., 294: 87.

MNCN 3465-3470.- 6Ad.- ECF.- Tijuca, Río de Janeiro, BRASIL.- 11-1862.- Colectó: M. Jiménez de la Espada.

MNCN 3472.- Ad.- ECF.- Bahía de Todos los Santos (=Salvador de Bahía) Bahía, BRASIL.- 09-1862.Colectó: M. Jiménez de la Espada.

\section{Hypsiboas fasciatus Günther, 1858}

Hyla fasciata Günther 1858, Arch. Naturgesch., 24: 327 No empleado por Jiménez de la Espada es sus publicaciones. Determinada por J. M. CEI en 1985.

Boana albomarginatus, Wiens, Fetzner, Parkinson \& Reeder, 2005, Syst. Biol, 54: 743.

Hypsiboas albomarginatus, Faivovich, Haddad, García, Frost, Cambell \& Wheeler, 2005. Bull. Am. Mus. Nat. Hist., 294: 86.

MNCN 3475.- H.- Ad.- ECF.- [Frontera entre Perú y Brasil] Tabatinga, Amazonas, BRASIL.- 08-09-1865.Colectó: M. Jiménez de la Espada.

OBSERVACIONES: Martínez-Rica en 1980 la determinó como Hyla geographica. J.M. Cei en 1985, utilizó los criterios de Duellman (1973) sobre el grupo Hyla geographica, para la determinación específica como Hyla fasciata, como por otra parte aparecía determinada por Jiménez de la Espada y Zulueta en la etiqueta antigua.

Hypsiboas pulchellus Duméril \& Bibron, 1841

Hyla pulchella Duméril \& Bibron, 1841, Erp. Gén., 8: 588.

No empleado por Jiménez de la Espada es sus publicaciones.

Determinados como Hyla pulchella pulchella por J.M. Cei en 1885.

Boana pulchella, Wiens, Fetzner, Parkinson \& Reeder, 2005, Syst. Biol., 54: 743.

Hypsiboas pulchellus, Faivovich, Haddad, García, Frost, Cambell \& Wheeler, 2005. Bull. Am. Mus. Nat. Hist., 294: 88.

MNCN 3246-3250.- ECF.- La Plata ${ }^{*}$ Buenos Aires, ARGENTINA.- 1862/1863.- Colectó: M. Jiménez de la Espada.
(*) Podría suceder que se tratara de un error por traslocación de etiquetas, circunstancia que estaría justificada por alguno de los siguientes motivos: 1) No existe ninguna ficha antigua anterior a la realizada por MartínezRica en 1980 donde se indique algún dato taxonómico o geográfico. 2) Los datos anotados por Martínez-Rica en la ficha que confeccionó son: número de bote (1084), Atelopus sp. (tachado) nigricans (tachado también) stelzneri; colector (Espada); Localidad (La Plata); $\mathrm{n}^{\circ} \mathrm{de}$ ejemplares (5). 3) Las etiquetas antiguas que acompañan a los ejemplares en cuestión, indican: "Phryniscus, La Plata, Col. Espada" y "Atelopus, La Plata, Espada"; es evidente que no son bufónidos, por lo que estas etiquetas no deben corresponder a estos ejemplares. 4) J.M. Cei en 1985 las determinó como "Hyla pulchella pulchella". Así pues, hemos de creer que las etiquetas ya estaban cambiadas erróneamente cuando MartínezRica revisó los ejemplares en 1980; o bien se había realizado una determinación errónea de los ejemplares y por tanto los datos geográficos (aunque geográficamente extensos) serían los correctos. Nosotros nos inclinamos por la validez de los datos geográficos; de todos modos y aunque hemos considerado La Plata como la zona argentina del mismo nombre, bien pudiera referirse a la cuenca del río de La Plata, que comprendería tanto a Argentina como a Uruguay.

Scinax ruber (Laurenti, 1768)

Hyla rubra Laurenti, 1768, Synops. Rept.: 5.

Scinax rubra, Duellman \& Wiens, 1992, Occas. Pap. Mus. Nat. Hist. Univ. Kansas, 151: 23.

Scinax ruber, Köhler \& Böhme, 1996, Rev. Fr. Aquariol., 23: 139.

No empleado por Jiménez de la Espada es sus publicaciones. Figuraba en la ficha antigua como Hyla rubra, Daudin ${ }^{(*)}$

Determinados como Ololygon rubra por J.M. Cei en 1985.

MNCN 3477-3480.- ECF.- Orillas del río Napo, Napo (ECUADOR) - Loreto (PERU).- [03/08-1865].Colectó: M. Jiménez de la Espada.

(*) Error, ya que Daudin no describió ninguna Hyla rubra, ni ningún sinónimo de ésta (Frost, 2006).

Sphaenorhynchus lacteus (Daudin, 1801)

Hyla lactea Daudin, 1801, In Sonnini \& Latreille, Hist. Nat. Rept., 2: 178.

Hyla aurantiaca Daudin, 1802, Hist. Nat. Rain. Gren. Crap.: 28.

Sphaenorhynchus lacteus, Tschudi, 1838, Class. Batr.: 71.

No empleado por Jiménez de la Espada es sus publicaciones.

Figuraba en la ficha antigua como Hyla auranciata Daudin (Probable error de escritura en lugar de Hyla aurantiaca Daudin, 1802, Hist. Nat. Rain. Gren. Crap.: 28, pl. 9, fig. 39).

MNCN 3471.- H.- Ad.- ECF.- San José de Moti ${ }^{*}$ Napo, ECUADOR.- 06-1865.- Colectó: M. Jiménez de la Espada.

${ }^{*}$ Ver comentario al final de este catálogo. 


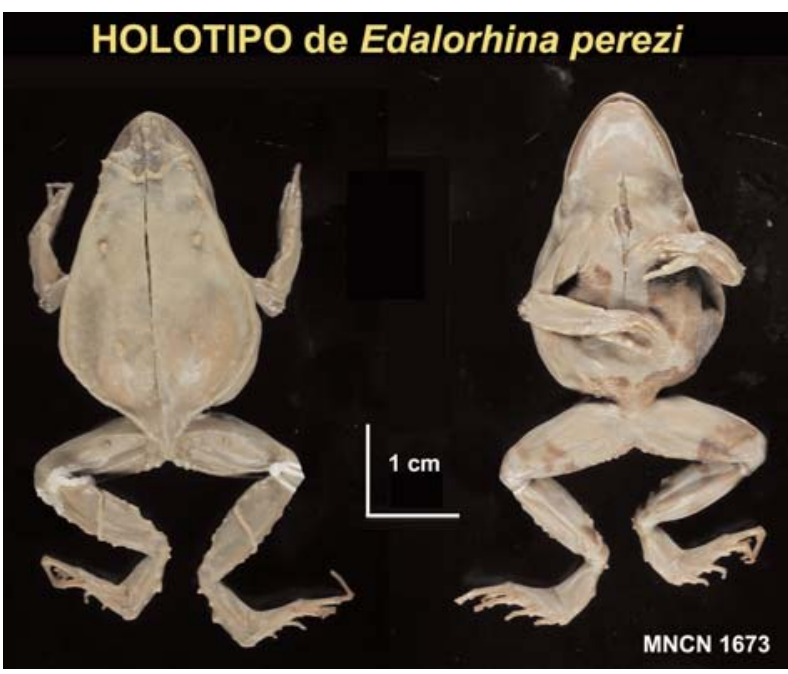

Familia HyLOdIDAe

Hylodes nasus (Lichtenstein, 1823)

Hyla nasus Lichtenstein, 1823, Verz. Doubl. Zool. Mus. K. Univ. Berlin: 106.

Enydrobius nasus, Cope, 1866, J. Acad. Nat. Sci. Philadelphia, Ser. 2, 6: 96

Hylodes nasus, Myers, 1946, Bol. Mus. Nac. Rio de Janeiro, 55: 10,28

MNCN 1597-1598.- ECF.- Monte Corcovado, Río de Janeiro, Río de Janeiro, BRASIL.- [10/11-1862].Colectó: M. Jiménez de la Espada.

ObSERVACIONES: Determinado por Jiménez de la Espada y revisado por Zulueta en 1911 como "Elosia nasus". Martínez-Rica aumentó de uno a dos los ejemplares, sin indicar la razón de ello; desconocemos por tanto si encontró otro material de otra procedencia y lo añadió al existente, o si históricamente era un error.

\section{Familia LeIUPERIDAE}

Edalorhina perezi Jiménez de la Espada, 1871 «1870» Edalorhina Perezi Jiménez de la Espada, 1871 «1870», J. Sci. Math. Phys. Nat., Lisboa, 3: 58.

Pleurodema perezi, Nieden, 1923, Das Tierreich, 46: 498. Edalorhina Perezi, Dunn, 1949, Am. Mus. Novit, 1416: 2.

MNCN 1673.- HOLOTIPO.- H?.- Ad.- ECF.- Orillas del río Napo, Napo (=Puerto Napo) Napo, ECUADOR.[13/19-05-1885] ${ }^{(*)}$.- Colectó: M. Jiménez de la Espada. OBSERVACIONES: ${ }^{*}$ Existe una cierta información contradictoria con respecto a la fecha de colecta; mientras en la publicación de descripción (Jiménez de la Espada, 1871: 58) afirma “...mens. Apr. Nobis invento...", es decir, encontrada por nosotros en el mes de abril, en la publicación de 1875 (Jiménez de la Espada,
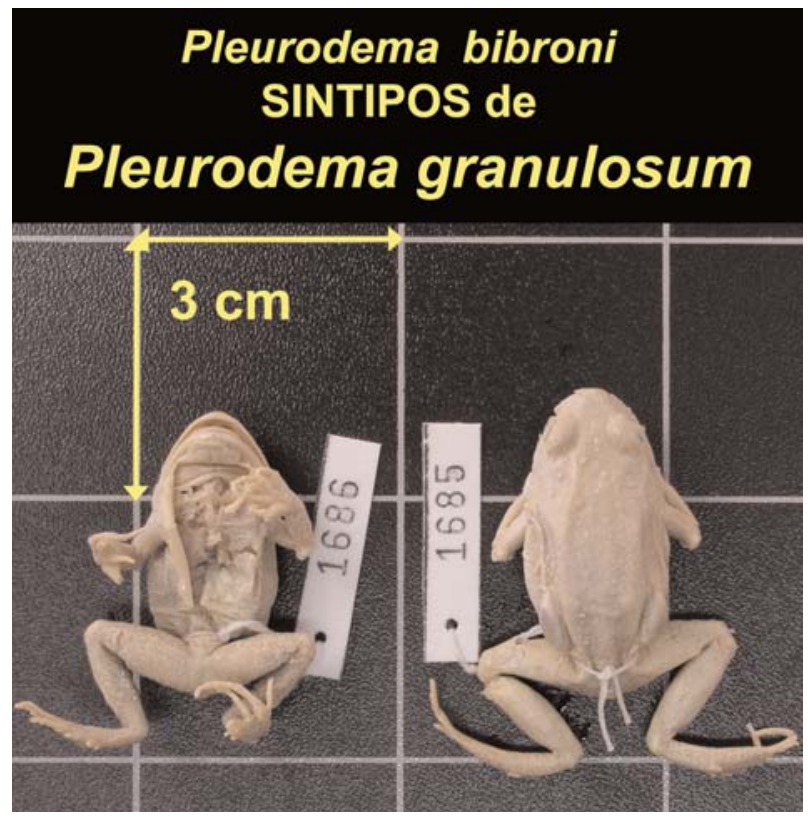

1875a: 114) afirma “...obtúvele en el mes de mayo de unos indios....". Habida cuenta que la llegada al río Napo (según los diarios de los diferentes expedicionarios) fue a mediados de mayo de 1865 y que en la población de Napo (actualmente Puerto Napo) estuvieron entre el 13 y el 19 de dicho mes, entre estas fechas debe estar la más probable de captura. Recogido en Jiménez de la Espada (1871: 58) y en Jiménez de la Espada, (1875a: 105-114).

\section{Pleurodema bibroni Tschudi, 1838}

Pleurodema bibroni Tschudi, 1838, Classif. Batr.: 85.

Pleurodema granulosum Jiménez de la Espada, 1875, Vert. Viaje Pacifico, Batr: 95

Sinonimizado con Pleurodema bibroni por Cei, 1980, Monit. Zool. Ital., N. S., Monogr. 2: 217.

Determinados como Pleurodema bibroni por J.M. Cei en 1985.

MNCN 1685-1686.- SINTIPOS de Pleurodema granulosum Jiménez de la Espada, 1875.- 2H.- 2 Ad.- ECF.Montevideo, Canelones, URUGUAY.- [12/01-1863].Colectó: Sr. Gibert.

OBSERVACIONES: Recogidos en Jiménez de la Espada (1875a: 95-99). Uno de ellos podría ser el figurado en Jiménez de la Espada (1875a: Lam. I, fig. 6) como «Pleurodema granulosum».

\section{Pleurodema thaul (Lesson, 1826)}

Bufo thaul Lesson, 1826, In DuPerry (ed.), Voy. Coquille, Zool:: 64 .

Pleurodema bibroni Tschudi, 1838, Classif. Batr.: 85.

Pleurodema darwinii Bell, 1843, Zool. Voy. Beagle, Pt. 5 (Rept.): 36. 
Pleurodema elegans Bell, 1843, Zool. Voy. Beagle: 37.

Cystignathus bibroni, Duméril \& Bibron, 1841, Erp. Gén., 8: 410.

Cystignathus elegans, Guichenot, 1848, in Gay, Hist. Chile, Zool.: 101 .

Pleurodema bibroni, Jiménez de la Espada, 1875, Vert. Viaje Pacifico, Batr: 87.

Determinados como Pleurodema thaul por J.M. Cei en 1985.

MNCN 1674-1681.- 5H.- 4Jv/Pm/3Ad.- ECF.- Valdivia, Los Lagos, CHILE.- [1863/1864].- Colectó: M. Jiménez de la Espada.

OBSERVACIONES: Recogidos en Jiménez de la Espada (1875a: 87-95). como «Pleurodema bibroni».

MNCN 1684.- ECF.- CHILE.- [1863/1864].- Colectó: M. Jiménez de la Espada.

OBSERVACIONES: Recogido en Jiménez de la Espada (1875a: 87-95) como «Pleurodema bibroni».

\section{Familia LEPTODACTYLIDAE}

Leptodactylus gracilis (Duméril \& Bibron, 1841)

Cystignathus gracilis Duméril \& Bibron, 1841, Erp. Gén., 8: 406.

Leptodactylus gracilis, Jiménez de la Espada, 1875, Vert. Viaje Pacifico, Batr.: 44-48.

MNCN 1689.- H.- Ad.- ECF.- [Cerros de Betete y de las Ánimas] (*), Canelones, URUGUAY.- [12-1862].Colectó: M. Jiménez de la Espada.

ObSERVACIONES: Recogido en Jiménez de la Espada (1875a: 40-44). ${ }^{(*)}$ Jiménez de la Espada (1875a: 48) menciona haberlo capturado en "... Montevideo. Yo lo hallé entre ese último punto y Maldonado, ... en la serie de collados que tiene por nombre Betete y Las Ánimas; ... costóme mucho trabajo cazar el único individuo de nuestra colección".

Leptodactylus labrosus Jiménez de la Espada, 1875 Leptodactylus labrosus Jiménez de la Espada, 1875, Vert. Viaj. Pacif., Batr.: 36.

Leptodactylus labrosus, Heyer \& Peters, 1971. Proc. Biol. Soc. Washington, 84: 167 designan lectotipo.

MNCN 3524.- LECTOTIPO designado por Heyer \& Peters (1971).- H.- Ad.- ECF.- Orillas del río Daule, Pimocha, Guayas, ECUADOR.- $[<06-1863]$.- Colectó: A. Desturge (quien lo regaló a Martínez y Sáez). OBSERVACIONES: Recogido en Jiménez de la Espada (1875a: 36-40) y Heyer \& Peters (1971: 164-165).

Leptodactylus labyrinthicus $^{(1)}$ (Spix, 1824)

Rana labyrinthica Spix, 1824, Spec. Nov. Testud. Ran. Brasil.: 31.

Leptodactylus labyrinthicus, Girard, 1853, Proc. Acad. Nat. Sci. Philadelphia, 6: 420.

Leptodactylus wuchereri Jiménez de la Espada, 1875, Vert. Viaj. Pacif. Verif., Batr.: 68.

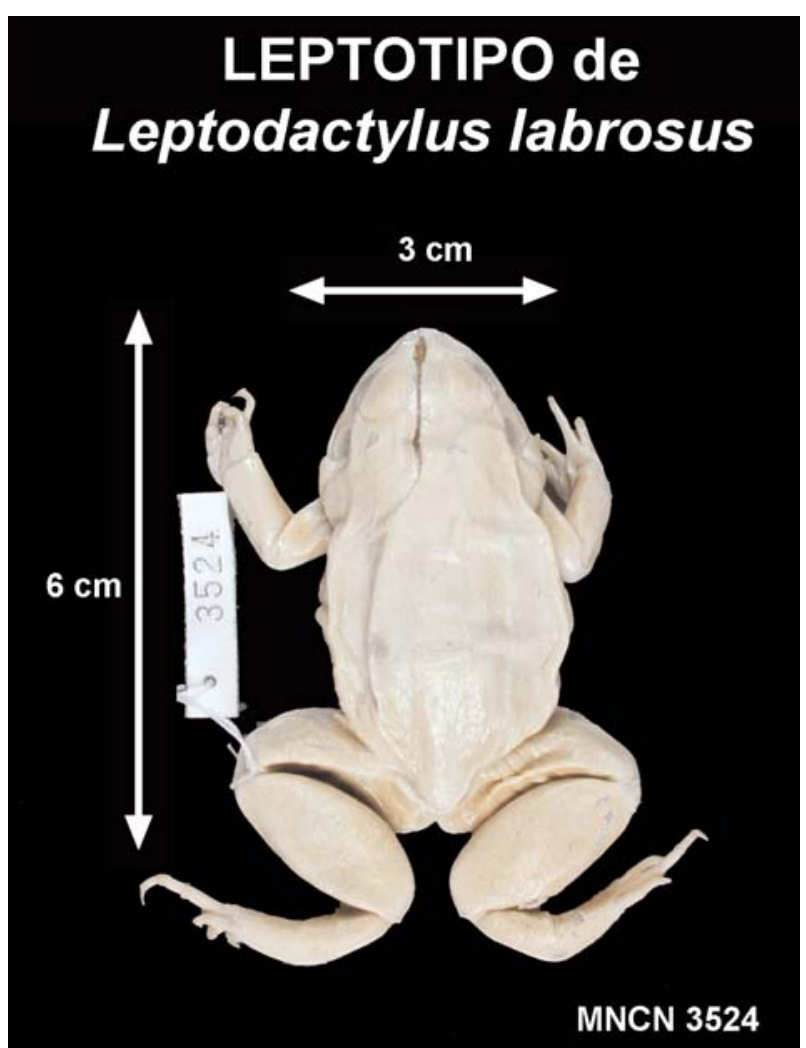

Sinonimizado con Leptodactylus mystacinus Gorhan, 1966. Das Tierreich, 85: 1-222.

Leptodactylus pentadactylus Heyer, 1969, Herpetologica, 2: 1-8. Sinonimizado con Leptodactylus labyrinthicus por Heyer, 1979, Smithson. Contrib. Zool., 301: 15.

(1) Aunque después de los trabajos de Heyer (1979) y Cei (1980) parecía que la posición taxonómica de $L$. wuchereri quedaba clara, De la Riva (2000: 81) pone en cuestión la seguridad de esta asignación específica, al recoger que el propio Jiménez de la Espada al final de la descripción original (Jiménez de la Espada, 1875a: 72) indica: "Habita en la República Argentina; lo recogió mi difunto compañero el Sr. Amor en la travesía de Montevideo a Santiago de Chile por la cordillera; ignoro dónde y en qué parajes vivía, y nada sé de sus costumbres". Como indica De la Riva (op.cit.): "La travesía terrestre de Amor y otros miembros de la expedición discurrió siempre aproximadamente al sur del paralelo $31^{\circ} \mathrm{S}$, y en todo momento bastante alejada del área de distribución de L. labyrinthicus en Argentina (Misiones y norte de Corrientes; Cei, 1980). En cambio esta trayectoria cae de lleno en el área de distribución de L. mystacinus. Considero por tanto que el debate sobre la posición taxonómica de L. wuchereri no debe darse por concluido". Recientemente, y haciéndose eco de lo manifestado por De la Riva (2000), aunque a nuestro entender no interpretándolo correctamente, Heyer (2005) se ratifica en su opinión de que el ejemplar en cuestión no es L. mystacinus. Probablemente todo el malentendido pueda derivarse de la incompleta interpretación de las palabras de Jiménez de la Espada, ya que si bien es cierto que sus compañeros de viaje atravesaron la República argentina al sur del paralelo $34^{\circ} \mathrm{S}$, no es menos cierto que 


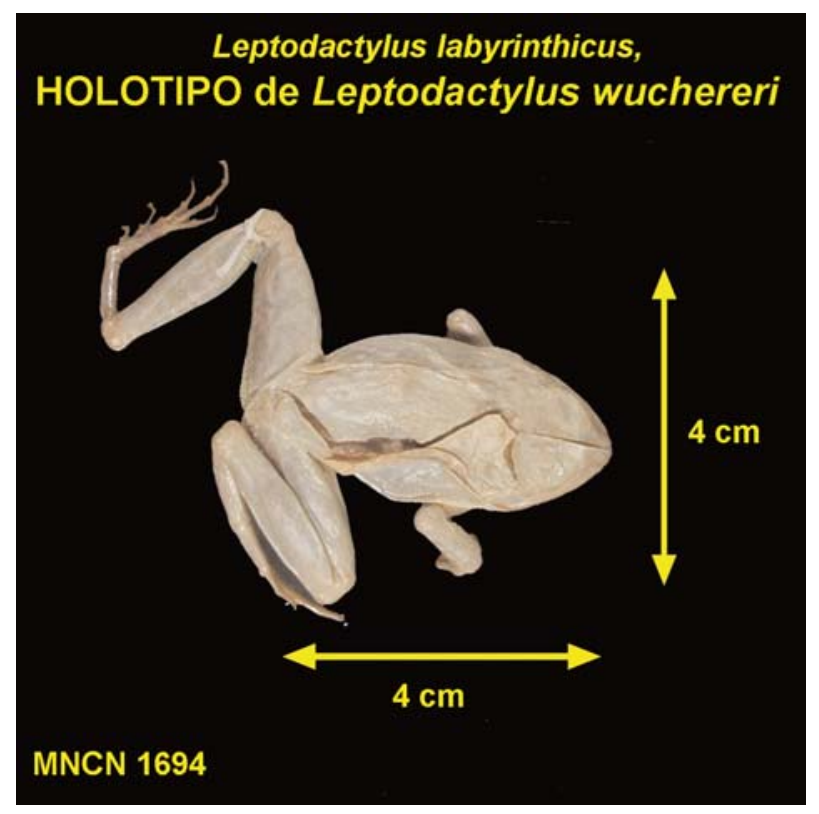

antes de emprender el viaje desde La Plata a Santiago de Chile, y atravesar la cordillera andina, ascendieron por el río Uruguay hasta Concordia (Argentina), situada frente a la localidad uruguaya de Salto, aproximadamente a 3130'S Por tanto el ejemplar pudo colectarse al oeste del Uruguay. Debido a esta controversia y, a falta de estudios definitivos, nosotros lo incluimos provisionalmente, en la sinonimia de L. labyrinthicus.

MNCN 1694.- HOLOTIPO de Leptodactylus wuchereri Jiménez de la Espada, 1875.- H.- Jv ${ }^{(*)}$.- ECF.- ARGENTINA.- [10/04-1863].- Colectó: F. Amor.

${ }^{(*)}$ Aunque Jiménez de la Espada indica que se trata de un ejemplar adulto, Heyer (1969: 6) considera que se trata de un juvenil de L. pentadactylus.

OBSERVACIONES: Recogido en Jiménez de la Espada (1875a: 68-72) y Heyer (1969: 6-8; 1979: 14-15) como «eptodactylus wuchereri».

Leptodactylus latinasus Jiménez de la Espada, 1875 Leptodactylus latinasus Jiménez de la Espada, 1875, Vert. Viaj. Pacif., Batr: 40.

MNCN 1695.- HOLOTIPO.- H.- Ad ${ }^{(*)}$-- ECF.Montevideo, Canelones, URUGUAY.- [12/01-1863].Colectó: M. Jiménez de la Espada.

${ }^{(*)}$ Aunque Jiménez de la Espada (1875a ) indica en la descripción de la especie que se trata de una hembra joven, Heyer (1969) afirma que la coloración amarillenta de los huevos indica que se trata de un individuo adulto.

OBSERVACIONES: Se encuentra en un deplorable estado de conservación; esta circunstancia ya fue indicada por Heyer (op. cit.) cuando estudió el ejemplar.

\section{HOLOTIPO de Leptodactylus latinasus}

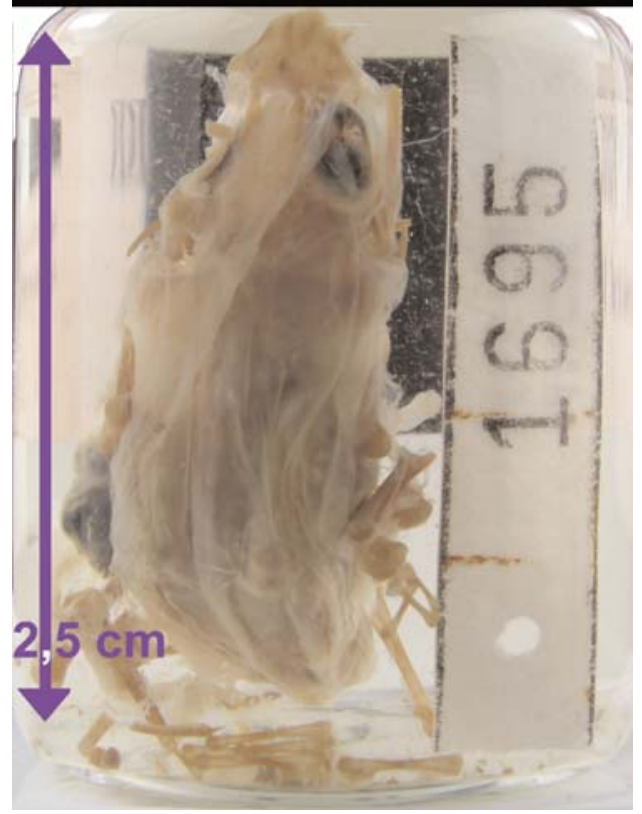

Recogido en Jiménez de la Espada (1875a: 40-43) y en Heyer (op. cit.).

Leptodactylus lineatus (Schneider, 1799)

Rana lineata Schneider, 1799, Hist. Amph., 1: 138.

Hylodes lineatus, Duméril \& Bibron, 1841, Erp. Gén., 8: 625.

Hylodes (Lithodytes) lineatus, Cope, 1862, Proc. Acad. Nat. Sci. Philadelphia, 14: 153.

Leptodactylus (Lithodytes) lineatus, Parker, 1935, Proc. Zool. Soc. London, 1935: 507.

No empleado por Jiménez de la Espada es sus publicaciones.

Figuraba en la ficha antigua como Hylodes lineatus (Schneider)

MNCN 1637-1640.- 3Ad / Jv.- ECF.- Archidona de Quijos, (=Archidona), Napo, ECUADOR.- [04/051865].- Colectó: M. Jiménez de la Espada.

\section{Leptodactylus ocellatus (Linnaeus, 1758)}

Rana ocellata Linnaeus, 1758, Syst. Nat., Ed. 10, 1: 211.

Cystignathus ocellatus, Wagler, 1830, Nat. Syst. Amph.: 203.

Leptodactylus serialis Girard, 1853, Proc. Acad. Nat. Sci. Philadelphia, 6: 421.

Leptodactylus ocellatus, Girard, 1853, Proc. Acad. Nat. Sci. Philadelphia, 6: 420.

Cystignathus pachypus Günther, 1859 «1858», Cat. Batr. Sal. Coll. Brit. Mus.: 27.

Leptodactylus pachypus, Jiménez de la Espada, 1875, Vert. Viaj. Pacif. Verif., Batr.: 48.

Leptodactylus (Pachypus) ocellatus, Lutz, 1930, Mem. Inst. Oswaldo Cruz., 23: 1, 21. 
MNCN 1692.- M.- Ad.- ECF.- Cercanías de Río de Janeiro, Río de Janeiro, BRASIL.- [10-1862].- Colectó: M. Jiménez de la Espada.

ObSERVACIONES: Recogido en Jiménez de la Espada (1875a: 48-57) como «Leptodactylus pachypus».

MNCN 1696.- H.- Ad.- ECF.- Bahía de Todos los Santos (=Salvador de Bahía) BRASIL.- [10-1862].- Colectó: O. Wucherer.

OBSERVACIONES: Recogido en Jiménez de la Espada (1875a: 48-57) como «Leptodactylus pachypus».

MNCN 1699-1700.- H / M.- 2Ad.- ECF.- Río Grande, Río Grande do Sul, BRASIL.- [11-1862].- Colectó: M. Jiménez de la Espada.

OBSERVACIONES: Recogidos en Jiménez de la Espada (1875a: 48-57) como «Leptodactylus pachypus».

MNCN 1701.- H.- Ad.- ECF.- La Tijuca, Río de Janeiro, BRASIL.- [11-1862].- Colectó: M. Jiménez de la Espada. OBSERVACIONES: Recogido en Jiménez de la Espada (1875a: 48-57) como «Leptodactylus pachypus».

MNCN 1702.- M.- Ad.- ECF.- Montevideo, Canelones, URUGUAY.- [12/01-1863].- Colectó: M. Jiménez de la Espada.

OBSERVACIONES: Aunque Jiménez de la Espada (1875:

57) habla de dos machos de Montevideo, actualmente sólo hay uno. Existe una etiqueta confeccionada por Zulueta en 1913, pero no indica el número de ejemplares; la ficha antigua de esta época no existe; la más antigua debe datar de los años 1930-1940 y en ésta se recoge la presencia de un único ejemplar, el que actualmente se conserva.

MNCN 4063-4068.- 3H.- 3Ad+3jv.- ECF.- Facenda [Imperial] de Santa Cruz ${ }^{(*)}$, Río de Janeiro, BRASIL.[10/12-1862].- Colectó: Jiménez de la Espada.

OBSERVACIONES: ${ }^{*}$ Hacienda que el emperador Pedro II de Brasil poseía en la localidad de Santa Cruz, a 14 leguas -unos 67,5 km- de Río de Janeiro y en la cual colectaron los expedicionarios, con autorización y por expreso deseo del emperador. Recogido en Jiménez de la Espada (1875a: 48-57) como «Leptodactylus pachypus».

MNCN 15614-15618.- 5Jv.- ECF.- BRASIL-URUGUAY.[10-1862/01-1863].- Colectó: M. Jiménez de la Espada \& O. Wucherer.

OBSERVACIONES: Recogido en Jiménez de la Espada (1875a: 48-57) como «Leptodactylus pachypus». Se distinguen dos grupos de tres ejemplares cada uno; el primero tiene aspecto de haberse deshidratado, mientras que el segundo no y estos ejemplares además estan diseccionados; para mayor confusión, hay una antigua etiqueta externa de bote con la indicación: "Chile".

Leptodactylus pentadactylus (Laurenti, 1768)

Rana pentadactyla Laurenti, 1768, Synops. Rept.: 32.

Cystignathus pentadactylus, Peters, 1872, Monatsber. Akad. Wiss. Berlin, 1872: 198.

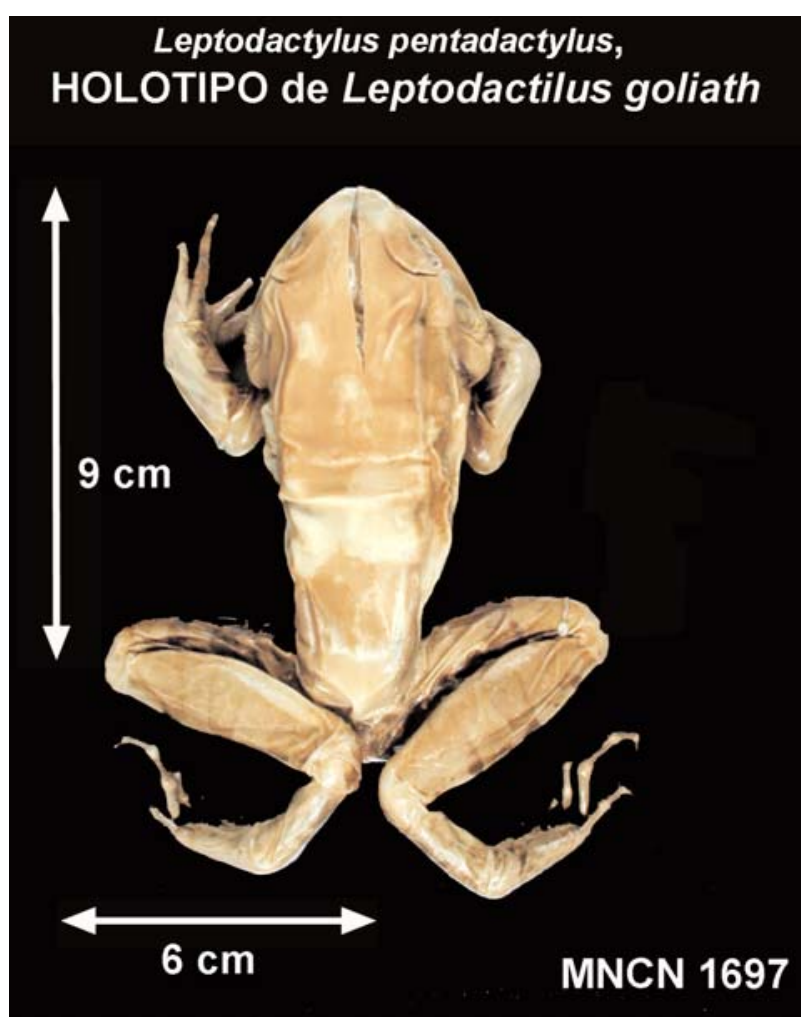

Leptodactylus goliath Jiménez de la Espada, 1875, Vert. Viaj. Pacif. Verif., Batr.: 57.

Sinonimizado con Leptodactylus pentadactylus por Boulenger, 1882, Cat. Batr. Sal. Brit. Mus.: 241.

Leptodactylus pentadactylus, Heyer \& Peters, 1971, Proc. Biol. Soc. Washington, 84: 167. designan un lectotipo.

MNCN 1690.- PARALECTOTIPO ${ }^{(*)}$ de Leptodactylus goliath Jiménez de la Espada, 1875.- M.- Ad.- ECF.Archidona de Quijos, (=Archidona), Napo, ECUADOR.[04/05-1865].- Colectó: M. Jiménez de la Espada.

(*) Este ejemplar no fue localizado en 1971 por Heyer \& Peters: al haberse hallado durante el presente estudio, lo manifestamos aquí expresamente así como su determinación como paralectotipo, como consecuencia de la designación del MNCN 1691 como lectotipo (Heyer \& Peters, 1971: 167).

ObSeRvaCiones: Recogido en Jiménez de la Espada (1875a: 57-64) como «Leptodactylus goliath».

MNCN 1691.- LECTOTIPO de Leptodactylus goliath Jiménez de la Espada, 1875, designado por Heyer \& Peters, 1971.- H.- Ad.- ECF.- Archidona de Quijos, (=Archidona), Napo, ECUADOR.- [04/05-1865].Colectó: M. Jiménez de la Espada.

OBSERVACIONES: Recogido en Jiménez de la Espada (1875a: 57-64) como «Leptodactylus goliath» y en Heyer \& Peters (1971: 167) y Heyer (1979: 15, 26). 
MNCN 1697.- PARALECTOTIPO(*) de Leptodactylus goliath Jiménez de la Espada, 1875.-H.- Jv.- ECF.[Chinitambo ${ }^{\left({ }^{2} ?\right)}$ Sierra de Guacamayos, Napo, ECUADOR.- [04-1865].- Colectó: M. Jiménez de la Espada. (*) Este ejemplar no fue localizado en 1971 por Heyer \& Peters; al haber sido localizado durante el presente estudio, lo manifestamos aquí expresamente, así como su determinación como paralectotipo, como consecuencia de la designación del MNCN 1691 como lectotipo (Heyer \& Peters, 1971: 167).

OBSERVACIONES: Recogido en Jiménez de la Espada (1875a: 57-64) como «Leptodactylus goliath». Faltan la ficha y las etiquetas antiguas. La ficha confeccionada por Martínez-Rica indica Quijos como localidad de colecta, pero por el material descrito por Espada (1875a) debe de tratarse de la hembra joven (LT=110 mm) de Chinitambo (probablemente palabra compuesta de Chini y de tambo, procedente de la palabra quechua "tampu" que recibían en la época las construcciones indígenas destinadas a albergue o posada, de pocas o nulas condiciones). Esta población, situada en la Sierra de Guacamayos, no ha podido ser localizada geográficamente durante este trabajo, pero se encontraría situada entre las poblaciones de Cosanga y Sarayacu, en la Provincia de Napo. Esto estaría de acuerdo también con el comentario de Frost (2004) sobre el error de datación geográfica cometido por Heyer \& Peters (1971: 167) en el trabajo de designación de lectotipo.

NOTA: Aunque Heyer \& Peters (1971: 167) indican que [Jiménez de la] Espada menciona cuatro jemplares en la descripción de la especie (Jiménez de la Espada, 1875: 63), creemos que se trató sólo de tres y que estos autores malinterperetaron la indicación de Jiménez de la Espada “... $\sigma^{\top}, \quad$,,$y \sigma^{\top}$ joven... ” ya que a nuestro modo de ver, Jiménez de la Espada quiso hacer referencia a una hembra joven y no a una hembra más un joven. Por ello consideramos que los tres ejemplares localizados constituyen el total de la serie típica original.

Leptodactylus stenodema Jiménez de la Espada, 1875

Leptodactylus stenodema Jiménez de la Espada, 1875, Vert. Viaj. Pacif., Batr.: 64.

Leptodactylus stenodema, Heyer \& Peters, 1971, Proc. Biol. Soc. Washington, 84: 168, designan un lectotipo.

MNCN 1687.- LECTOTIPO designado por Heyer \& Peters 1971.- H.- Ad.- ECF.- San José de Moti ${ }^{*}$ Napo, ECUADOR.- [06-1865].- Colectó: M. Jiménez de la Espada.

(*) Ver comentario al final de este catálogo.

OBSERVACIONES: Recogido en Jiménez de la Espada (1875a: 64-68), en Heyer y Peters (1971: 168) y Heyer (1979: 15, 34-36).

MNCN 1688.- PARALECTOTIPO consecuentemente a la designación del ejemplar anterior como lectotipo

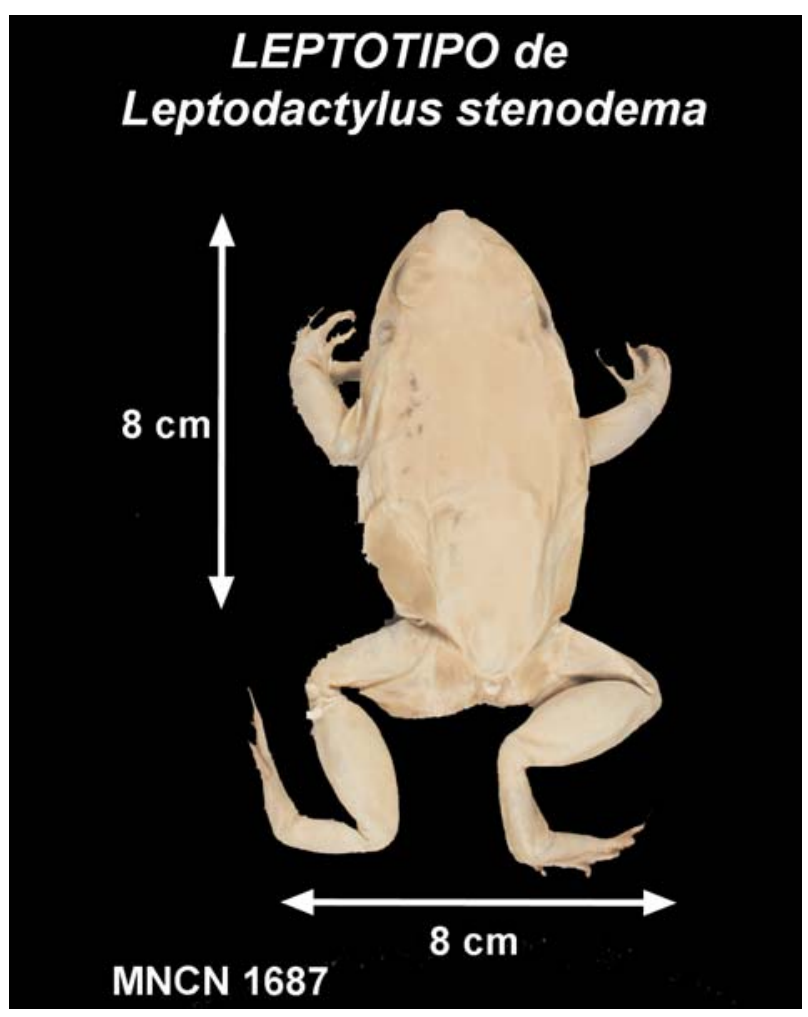

por Heyer \& Peters, 1971.-H.- Ad.- ECF.- San José de Moti ${ }^{(*)}$ Napo, ECUADOR.- [06-1865].- Colectó: M. Jiménez de la Espada.

(*) Ver comentario al final de este catálogo.

OBSERVACIONES: Recogido en Jiménez de la Espada (1875a: 64-68), en Heyer y Peters (1971: 168) y Heyer (1979: 15, 34-36).

\section{Leptodactylus wagneri (Peters, 1862)}

Plectromantis wagneri Peters, 1862. Monatsber. Preuss. Akad. Wiss. Berlin: 232

Leptodactylus wagneri, Nieden, 1923. Das Tierreich, 46: 479

No empleado por Jiménez de la Espada es sus publicaciones.

Determinados como Leptodactylus wagneri por I. De la Riva en 2006.

NOTA: Se encontraban bajo la denominación de Litopleura maritimum Jiménez de la Espada, 1875 pero ninguno de los dos ejemplares que se incluyen en la ficha confeccionada, con el $n^{\circ} 1157$ por Martínez-Rica hacia 1980, bajo la denominación de Limnomedusa macroglosa, se corresponde con el ejemplar tipo descrito por Jiménez de la Espada. Ignoramos la procedencia de estos dos ejemplares y cualquier dato sobre ellas, así como dónde puede encontrase el verdadero ejemplar tipo de Litopleura maritimum.

MNCN 3529-3530.- 2 Ad.- ECF.- 1862/1865. 


\section{Orden CAUDATA \\ Familia Plethodontidae}

\section{Ensatina eschscholtzii Gray, 1850}

Urotropis platensis Jiménez de la Espada, 1875. An. Soc. Esp. Hist. Nat., 4: 71

Plethodon platensis, Boulenger, 1882, Cat. Batr. Grad. Coll. Brit. Mus.: 55.

Ensatina platensis, Dunn, 1923, Proc. New England Zool. Club, 7: 39.

Sinonimizado con Ensatina sierrae por Myers \& Carvalho, 1945. Bol. Mus. Nac., Rio de Janeiro, Zool., 35: 1-24.

Sinonimizado con Ensatina eschscholtzii platensis por Stebbins, 1949, Univ. California Publ. Zool., 48: 434.

MNCN 1256.- HOLOTIPO de Urotropis platensis (Jiménez de la Espada, 1875).- Ad.- ECF.- Parque estatal de "Big trees" $\left.{ }^{*}\right)$ Condado de Calaveras, California, EEUU.- [22/23-10-1863].- Colectó: F. Martínez y Sáez. (*) Sin duda el ejemplar fue colectado por F. Martínez y Sáez durante su estancia en California, en octubre de 1863 (Wake \& Marks, 1993) pero éste olvidó el dato y lo mezcló por error con otro material colectado por Amor y Paz durante la estancia en Montevideo, de ahí la "terra tipica" proporcionada por Jiménez de la Espada: Cuencas del Río de la Plata, Montevideo? Uruguay (Jiménez de la Espada, 1875b: 69-73).

OBSERVACIONES: Recogido como «Urotropis platensis» y figurado en la Lámina 1 (op. cit.). Aunque inicialmente no llamara la atención la descripción de la primera salamandra en el cono sur, sí fue durante décadas motivo de dudas y controversias (ver De la Riva, 2000: 83-84).

\section{Orden GYMNOPHIONA \\ Familia CAECILIIDAE}

\section{Caecilia gracilis Shaw, 1802}

Caecilia gracilis Shaw, 1802, Gen. Zool., 3: 597.

No empleado por Jiménez de la Espada es sus publicaciones. Revisado por Mark Wilkinson \& David Gower (02-2004).

MNCN 1231.- H.- Ad.- ECF.- Concepción [en la margen izquierda] del río Napo ${ }^{(*)}$, Napo, ECUADOR.- 01-061865.- Colectó: M. Jiménez de la Espada.

(*) La revisión del material por parte de Wilkinson \& Gower en 2004 en la Colección de Anfibios y Reptiles del MNCN y su adscripción a $C$. gracilis, permite ampliar el rango de distribución de la especie a Ecuador, donde no se había citado con anterioridad (De la Riva, comunicación personal).

\section{Caecilia tentaculata Linnaeus, 1758}

Caecilia tentaculata Linnaeus, 1758, Syst. Nat., Ed. 10, 1: 229. No empleado por Jiménez de la Espada es sus publicaciones. Determinado como Caecilia tentaculata por Mark Wilkinson \& David Gower (02-2004).

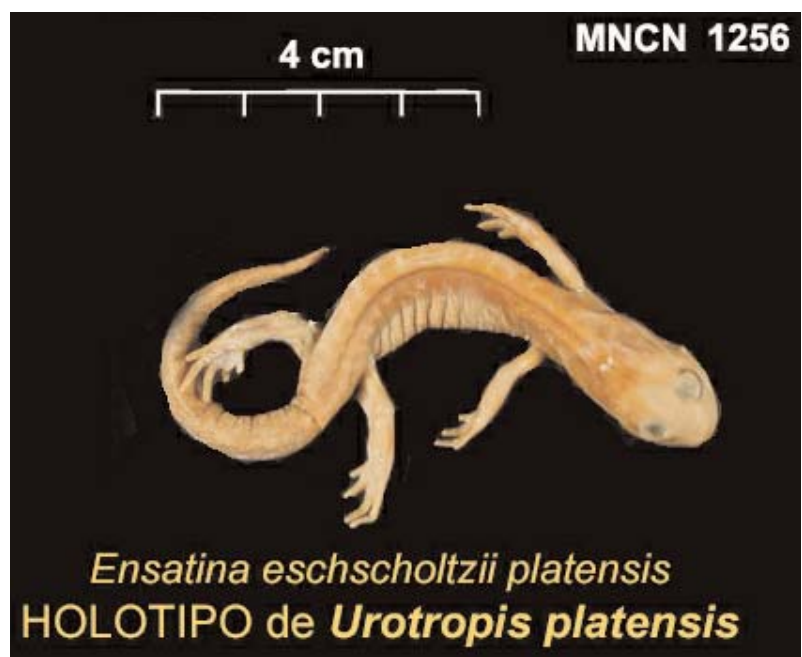

MNCN 1236-1237.- M / ¿?.- Ad+Jv.- ECF.- Quito ${ }^{(*)}$, Pichincha, ECUADOR.- [<24-10-1864].- Colectó: M. Villavicencio $^{(* *)}$.

(*) Aunque la localidad de colecta indicada sea Quito, sin duda en este caso es incorrecta, y consecuencia del modo en que fue conseguido este material. Los ejemplares no pudieron ser colectados en dicha localidad o en sus alrededores ya que $C$. tentaculata es propia de tierras bajas situadas al este de los Andes (De la Riva, comunicación personal).

${ }^{(*)}$ El material es integrante de la donación que D. Manuel Villavicencio hizo a la CCP el 24-10-1865; éste procedía de la compra a cazadores y preparadores, siguiendo el encargo (realizado un año antes) de D. Patricio Paz, según consta en la página 198 del diario de Martínez y Sáez (Calatayud-Arinero, 1994).

Siphonops annulatus (Mikan, 1820)

Caecilia annulata Mikan, 1820, Delect. Flor. Faun. Brasil.: pl. 11.

Siphonops annulata, Duméril \& Bibron, 1841, Erp. Gén., 8: 282. No empleado por Jiménez de la Espada es sus publicaciones. Revisado por Mark Wilkinson \& David Gower (02-2004).

MNCN 1235.- Ad.- ECF.- [Isla de] Itaparica, Bahía (=Salvador de Bahía) Bahía, BRASIL.- [11/15-091862].- Colectó: M. Jiménez de la Espada.

\section{(*) Comentario sobre la población de San José de Moti.}

En la actual provincia de Orellana, antiguamente Oriente del Ecuador y posteriormente Napo, al norte de la ciudad de Loreto, existen tres poblaciones con el nombre de San José: San José Viejo o San José de Suno $\left(0^{\circ} 32^{\prime} \mathrm{S} / / 77^{\circ} 25^{\prime} \mathrm{O}\right)$, San José 
Nuevo o San José de Mote $\left(0^{\circ} 26^{\prime} \mathrm{S} / / 77^{\circ} 19^{\prime} 600\right)$ y San José de Payamino ( $\left.0^{\circ} 30^{\prime} \mathrm{S} / / 77^{\circ} 16^{\prime} \mathrm{O}\right)$, distantes unas de otras unos $10 \mathrm{~km}$. Eliminado San José de Payamino, nos quedan los otros dos San José, el Nuevo y el Viejo. Según el relato de Jiménez de la Espada, San José debía estar en las proximidades del río Suno, por tanto su San José se debería corresponder con San José de Suno, es decir, San José Viejo; pero por otra parte las etiquetas y las publicaciones de Jiménez de la Espada, hablan de San José de Moti. ¿Se está refiriendo al actual San José de Mote y por tanto a San José Nuevo? La polémica se acrecienta al consultar la bibliografía de los investigadores de los trabajos y especies descritas por Jiménez de la Espada; así, mientras Peters (1955) habla del río Suno (= San José de Suno o Viejo) y de San José de Moti (es decir, San José de Mote o Nuevo), Savage (1968: 753) sugiere que San José de Moti se corresponde con San José Viejo $\left(\ll 0^{\circ} 32^{\prime} \mathrm{S}\right.$ and $\left.77^{\circ} 25^{\prime} \mathrm{W} »\right)$, justo al norte del valle del río Suno, a unos $1200 \mathrm{~m}$ de altitud. Pero Peters (1973: 40) corrige San José de Moti por San José Nuevo $\left(0^{\circ} 26^{\prime} \mathrm{S} / / 77^{\circ} 19^{\prime} 60 \mathrm{O}\right)$. Por otra parte, Jiménez de la Espada (1898: 398) indica San José de Mote o Moti, lo que parece una contradicción, pues de alguna manera está asimilando ambas poblaciones. ¿Consultó Jiménez de la Espada, para documentar su trabajo, algún atlas donde aparecía San José de Mote y lo confundió con su San José de Moti? ¿Realmente fue San José de Moti el que visitó Jiménez de la Espada? De no ser así, la posibilidad más verosímil a nuestro juicio es que el camino de vuelta hacia [San Antonio del] Coca (actual Puerto Francisco de Orellana) fuera a través de San José Nuevo o de Mote, lo que supondría que Jiménez de la Espada colectó en ambos lugares. Pero eso de momento no podremos discernirlo, al carecer de las páginas finales del diario.

\section{AGRADECIMIENTOS}

A Ignacio de la Riva su impagable ayuda y sus siempre acertados comentarios e indicaciones. Al servicio de documentación (Archivo y Biblioteca) del MNCN su desinteresada colaboración. A José Manuel Padial la revisión de algunos ejemplares. Al Servicio de Fotografía del MNCN, a Óscar Soriano y a Marisol Ayuso, su ayuda en la realización de algunas fotografías. Al Proyecto REN-20010466/GLO del MICYT su apoyo logístico.

\section{Referencias}

Almagro, M., 1866. Breve descripción de los viajes hechos en América por la Comisión Científica enviada por el Gobierno de S.M.C. durante los años de 1862 a 1866. M. Rivadeneyra. Madrid. 174 pp. y 2 mapas.

Álvarez, T., 2004. La expedición al Pacífico en www.giarte.com. (Marzo-2004).

BArreiro, A. J., 1925. Homenaje a la memoria de D. Juan Isern. Boletín de la Sociedad Española de Historia Natural. Actas, 25: 417-419.

BArreiro, A. J., 1926. Historia de la Comisión Científica del Pacífico (1862-1865). Museo Nacional de Ciencias Naturales. Madrid. 525 pp. y un mapa.

BArreiro, A. J., 1927. Biografía de D. Marcos Jiménez de la Espada (1831-1898). Madrid. 43 pp.

Barreiro, A. J., 1928. Diario de la Expedición al Pacífico llevado a cabo por una comisión de naturalistas españoles durante los años 1862-1865, escrito por D. Marcos Jiménez de la Espada, miembro que fue de la misma. Publicaciones de la Real Sociedad Geográfica. Madrid. 257 pp.

Barreiro, A. J., 1992. El Museo Nacional de Ciencias Naturales (1771-1935). Museo Nacional de Ciencias Naturales \& Doce Calles. Madrid. 509 pp.

Boulenger, G. A., 1882. Catalogue of the batrachia gradientia Salientia Caudata and batrachia apoda in the collection of the British Museum. The Trustees of the British Museum. London. Xvi +503 pp.

Cabodevilla, M. A., 1998. El Gran Viaje. Abay-Yala. Quito. $250 \mathrm{pp}$.

Calatayud Arinero, M. A., 1994. Diario de don Francisco de Paula Martínez y Sáez, Miembro de la Comisión Científica del Pacífico, 1862.1865. CSIC. Madrid. 334 pp.

CALLE.COM/WORLD, 1996-2004. Global Gazetteer (Version 2.1). Página web de Falling Rain Genomics, Inc (http:// www.calle.com/world/) (Marzo-2004).

Cannatella, D. C. \& Duellman, W. R., 1984. Leptodactilid frogs of the Physalaemus postulosus group. Copeia, 1984(4): 902-921.

Caramashi, U. \& Canedo, C., 2006. Reassessment of the taxonomic status of the genera Ichnocnema Reinhardt and Lütken, 1862 and Oreobates Jimenezde-la-Espada, 1872, with notes on the synonymy of Leiuperus verrucosus Reinhardt and Lütken, 1862 (Anura: Leptodactylidae). Zootaxa, 1116: 43-54.

CAStro y OrdóÑEZ, R., 1863 La Expedición científica del Pacífico. San Francisco de California, 27 de octubre de 1863. El Museo Universal, Madrid, 1864: 36-37.

CEI, J. M., 1980. Amphibians of Argentina. Monitore zoologico Italiano (Nova Serie) Monographies, 2: 1-609.

Coloma, L. A., 1995. Ecuadorian frogs of the Genus Colostethus (Anura: Dendrobatidae). Miscellaneous Publications of the Museum of Natural History, the University of Kansas, 87: 1-72 + 3 Lam.

Coloma, L. A., 2002. Two new species of Atelopus (Anura: Bufonidae) from Ecuador. Herpetologica, 58(2): 229-252. 
Coloma, L. A., Lötters, S. \& Salas, A. W., 2000. Taxonomy of the Atelopus ignescens complex (Anura: Bufonidae): designation of a neotype of Atelopus ignescens and recognition of Atelopus exiguus. Herpetologica, 56(3): 303-324.

Cuatrecasas, J., 1935. Plantae iserninianae, I. Anales de la Universidad de Madrid (Ciencias), IV(2, junio): 206-265.

DE LA RivA, I. 2000. La obra Herpetológica de Jiménez de la Espada: su relevancia y validez después de un siglo. In: López-Ocón, L. \& Pérez-Montes, C. M. (eds.). Marcos Jiménez de la Espada (1831-1898). Tras la senda de un explorador. Consejo Superior de Investigaciones Científicas, Instituto de Historia. Madrid: 76-90.

Duellman, W. E., 1973. Frogs of the Hyla geographica Group. Copeia, 1973(3): 515-533.

Duellman, W. E., 1974. A Reassessment of the taxonomic status of some neotropical Hylyd frogs. Occasional Pappers of the Museum of Natural History the University of Kansas, 27: 1-27.

Duellman, W. E., 1977. Liste der rezernten Amphibien und reptilien: Hylidae, Centrolenidae, Pseudidae. Das Tierreich, 95: 1-225.

Duellman, W. E., 1978. The Biology of an Equatorial Herpetofauna in Amazonian Ecuador. Miscelaneus Publications of the Museum of Natural History the University of Kansas 65: 1-352

EDWARDS, S. R., 1971. Taxonomic noters on South American Colostethus with description of two new species (Amphibia, Dendrobatidae). Proceedings of the Biological Society of Washington, 84(18): 147-162.

Faivovich, J., Haddad, C. F. B., García, P. C. A., Frost, D. R., Campbell, J. A. \& Wheeler, W. C., 2005. Systematic review of the fro family Hylidae, whit special reference to Hylinae: Phylogenetic analysis and taxonimic revision. Bulletin of the American Museum of Natural History, 294: 1-240.

Frost, D. R. (Ed.). 1985. Amphibian species of the world. A taxonomic and geographic reference. Allen Press \& The Association of Systematics Collections Lawrence. $732 \mathrm{pp}$.

Frost, D. R., 2004. World Wide Web page of the American Museum of Natural History, Department of Herpetology: "Amphibian species of the world V2.21 Database" (1998-2004). Department of Herpetology, American Museum of Natural History. New York.

Frost, D. R., 2006. Amphibian Species of the World: an Online Reference. Version 4 (17 August 2006). Electronic Database accessible en: http: //research.amnh.org/herpetology/amphibia/index.php. American Museum of Natural History, New York, USA.

Frost, D. R., Grant, T., Faivovich, J., Bain, R. H., HaAs, A., Haddad, C. F. B., De Sá, F. O., Channing, A., Wilkinson, M., Donnellan, S. C., RaXworthy, C. J.,
Campbell, J. A., Blotto, B. L., Moler, P., Drewes, R. C., Nussbaum, R. A., Lynch, J. D., Green, D. M. \& WheEler, W. C., 2006. The amphibian tree of life. Bulletin of the American Museum of Natural History, 297: 1-370.

Gallardo, J. M., 1957. Las subespecies argentinas de Bufo granulosus Spix. Revista del Museo Argentino de Ciencias Naturales Bernardino Rivadavia (Zool.) 3(6): 337-374.

Gallardo, J. M., 1964. Los anfibios de la Provincia de Entre Ríos, Argentina y algunas notas sobre su distribución geográfica y ecológica. Neotropica, 10(31): $23-28$.

Gallardo, J. M., 1965. Especiación en tres Bufo neotropicales. Papeis avulsos do Departamento de Zoología (São Paulo), 17: 57-75.

GogorzA, J., 1908. Datos biográficos del profesor D. Francisco de Paula Martínez y Sáez (con un retrato). Boletín de la Sociedad Española de Historia Natural, 8: 208-215.

GonZÁLEZ-FernÁndEZ, J. E., 2000. Marcos Jiménez de la Espada, el coleccionista. In: López-Ocón, L. \& PérezMontes, C. M. (eds.). Marcos Jiménez de la Espada (1831-1898). Tras la senda de un explorador. Consejo Superior de Investigaciones Científicas e Instituto de Historia. Madrid: 72-75.

GonZÁLEZ-FernÁndeZ, J. E., 2002. Colección de Anfibios y Reptiles. In: Catálogo de las Colecciones Zoológicas de Asia del Museo Nacional de Ciencias Naturales, III: Vertebrados. Manuales técnicos de Museología. Vol. 13. Museo Nacional de Ciencias Naturales (CSIC), Madrid: 61-180.

GonzÁlez-Fernández, J. E., 2004. Catálogo de los anfibios colectados por la Comisión Científica del Pacífico (1862-1865): Memoria presentada para la obtención del Diploma de Estudios Avanzados. Edición del autor. Fuenlabrada. xviii + 114 pp.

GorHAM, S. W., 1966. Liste der rezenten Amphibien und Reptilien, Ascaphidae, Leiopelmatidae, Pipidae, Discoglossidae, Pelobatidae, Leptodactylidae, Rhinophrynidae. Das Tierreich, 85: XVI + 222 pp.

Grant, T., Frost, D. R., Caldwell, J. P., Gagliardo, R., Haddad, C. F. B., KoK, P. J. R., Means, B. D., Noonan, B. P., Schargel, W. \& Wheeler, W. C., 2006. Phylogenetic systematics of dart-poison frogs and their relatives (Anura: Athesphatanura: Dendrobatidae). Bulletin of the American Museum of Natural History, 299: 1-262.

Heyer, W. R., 1969. Studies on frogs of the genus Leptodactylus (Amphibia, Leptodactilidae). V. Taxonomic notes on L. latinasus, rhodonotus, roma$n i$, and wucherreri. Herpetologica, 25: 1-8.

HeYER, W. R., 1979. Systematics of the pentadactylus species group of the frog genus Leptodactylus (Amphibia: Leptodactylidae). Smithsonian Contributions to Zoology, 301: 1-43. 
Heyer, W. R., 2005. Variation and taxonomic clarification of the large species of the Leptodactylus pentadactylus species group (Amphibia: Leptodactylidae) from middle America, Northerm South America and Amazonia. Museu de Zoología da Universidade de São Paulo, 37(3): 269-348.

Heyer, W. R. \& Hardy, L. M., 1991. A new species of frog of the Eleutherodactylus lacrimosus assembly from Amazonia, South America (Amphibia: Anura: Leptodactylidae). Proocedings of the Biological Society of Washington, 104(3): 436-447.

Heyer, W. R. \& Peters, J. A., 1971. The frogs Genus Leptodactylus in Ecuador. Proceedings of the Biological Society of Washington 84: 163-170.

Hoogmoed, M. S., 1986. Biosystematic Studies of the Bufo "typhonius" Group. A preliminary Progress Report. In: Z. Rocek (ed.). Studies in Herpetology. Charles University. Praga: 147-150.

Hoogmoed, M. S., 1989. South American Bufonids (Amphibia: Anura: Bufonidae), an enigma for taxonomists.Treballs de la Societat Catalana d'Ictiologia i Herpetologia, 2(1989): 167-180.

JIMÉNEZ DE LA ESPADA, M., 1871. 1. Faunae neotropicalis species quaedam nondum cognitae. Jornal de Sciencias Mathematicas Physicas e Naturaes, III: 57-65.

JiMÉNEZ DE LA EsPADA, M., 1872a. Nuevos Batracios Americanos. Anales de la Sociedad Española de Historia Natural, 1: 85-88.

JiMÉNEZ DE LA ESPADA, M., 1872b. Sobre la reproducción de Rhinoderma darwinii. Anales de la Sociedad Española de Historia Natural, I: 140-151.

JIMÉNEZ DE LA ESPADA, M., 1875a. Vertebrados del Viaje al Pacífico. Tomo I: Batracios. Imprenta de Miguel Ginesta. Madrid. 208 pp. y 7 Lam.

JIMÉNEZ DE LA ESPADA, M., 1875b. Urotropis platensis. Anales de la Sociedad Española de Historia Natural, 4: 69-73.

JIMÉNEZ DE LA ESPADA, M., 1875c. Nota biográfica acerca de D. Patricio $\mathrm{M}^{\mathrm{a}}$ Paz y Membiela. Anales de la Sociedad Española de Historia Natural. Actas, IV: 22-29.

JiMÉNEZ DE LA EsPaDA, M., 1898. Análisis descriptivo del grupo de los Hemiphractus. Anales de la Sociedad Española de Historia Natural, 7: 377-410.

López-Ocón, L. \& Pérez-Montes, C. M. (eds.). 2000. Marcos Jiménez de al Espada (1831-1898) Tras la senda de un Explorador. CSIC. Madrid. 384 pp.

LuTz, A., 1934.Notas sobre especies brasileiras do genero Bufo. Memórias do Instituto Oswaldo Cruz, 28(1): 111-113.

LYNCH, J. D., 1970. Systematic Status of the American Leptodactylid Frog Genera Engystomops, Eupemphis, and Physalaemus. Copeia, 1970: 488-496

LYNCH, J. D., 1971. Evolutionary relationships, Osteology, and Zoogeography of Leptodactiloid Frogs.
Miscellaneus Publication of the Museum of Natural History, The University of Kansas, 53: 1-237.

LYNCH, J. D., 1975. A review of the broad-headed Eleutherodactyline frogs of South America (Leptodactylidae). Occasional Pappers of the Museum of Natural History, The University of Kansas, 38: 1-46.

Lynch, J. D. \& Duellman, W. E., 1980. The Eleutherodactylus of the Amazonian slopes of the ecuadorian Andes (Anura: Leptodactílidae). Miscellaneous Publications of the Museum of Natural History, The University of Kansas, 69: 1-86.

Lynch, J. D. \& SchwarTz, A., 1971. Taxonomic Disposition of some $19^{\text {th }}$ Century leptodactylid frog names. Journal of Herpetology, 5(3-4): 103-114.

MartíneZ, F. DE P., 1898. Nota Bibliográfica de D. Marcos Jiménez de la Espada (con un retrato). Anales de la Sociedad Española de Historia Natural. Actas, 27: 207-228.

Microsoft, 2001. Atlas Mundial Encarta 2001. 2 discos compactos (CD-rom). Microsoft, USA.

Miller, R. R., 1983. Por la ciencia y la gloria nacional la expedición científica española a América (18621866). Serbal. Barcelona. 256 pp.

MUlTimap.COM, 2004. Página web de Multimap.com, 150 Holborn. Londres (http://multimap.com/) (Marzo2004).

Myers, G. S. \& Carvalho, L., 1945. Notes on some new or little know brazilian Amphibians, with an examination of the Plata Salamander Ensatina platensis. Boletim do Museu Nacional. Nova serie. Zoologia, 35: 1-24.

Nascimento, L. B., Caramaschi, U. \& Gonçalvez CruZ, C. A., 2005. Taxonomic review of the species groups of the genus Physalaemus Fitzinger, 1826 with revalidation of the genera Engystomops Jiménez de la Espada, 1872 and Eupemphix Steindachner, 1863 (Amphibia, Anura, Leptodactylidae). Arquivos do Museu Nacional, Rio de Janeiro, 63(2): 297-320.

Olmedilla y Puig, J., 1872. Elogio Histórico de D. Fernando Amor y Mayor. G. Juste. Madrid. 3 pp.

Ortiz, J. C. \& Lescure, J., 1989. Les types d'amphibiens anoures du Chili dans les collections du Museum national d'Histoire naturelle. Catalogue critique. Bulletin du Museum National d'Histoire Naturelle, Section A, Zoologie, Biologie et Écologie Animales, 1990; 11(3): 113-122 (Suppl.).

OSORIO Y BERNARD, M., 1875. Galería biográfica de artistas españoles del siglo XIX. Madrid. Imprenta Giner. viii +749 pp.

PACIFICO.ES, 2004. Página web del Consejo Superior de Investigaciones Científicas sobre la Comisión Científica al Pacífico. (Marzo-2004). (http://www.pacifico.csic.es/uym3/default.htm).

Peters, J. A., 1955. Herpetological type localities in Ecuador. Revista Ecuatoriana Entomología - Parasitología 2: 335-352. 
Peters, J. A., 1973. The frog genus Atelopus in Ecuador. Smithsonian Contributions to Zoology, 145: 1-49.

Puig-SAmper, M. A., 1988. Crónica de una Expedición Romántica al Nuevo Mundo. La Comisión Científica del Pacífico (1862-1866). CSIC, Centro de Estudios Históricos. Madrid. XVIII + 459 pp.

Ron, S. R., Duellman, W. E., Coloma, L. A. \& BustaMAnTE, M. R., 2002. Population Decline of the Jambato Toad Atelopus ignescens (Anura: Bufonidae) in the Andes of Ecuador. Journal of Herpeto$\log y, 37(1)$ : 116-126.

Ruiz-Carranza, P. M., Hernández-Camacho, J. \& Ardila-Robayo, M. C., 1986. Una nueva especie colombiana del género Centrolene Jiménez de la Espada 1872 (Amphibia: Anura) y redefinición del género. Caldasia, XV(71-75): 431-444.

Savage, J. M., 1968. The Dendrobatid Frogs of Central America. Copeia, 1968(4): 745-776.

SAVAGE, J. M., 1978. Marcos Jiménez de la Espada, naturalist explorer of the Andes and upper Amazon Basin. En: Vertebrados del Viaje al Pacífico verificado de 1862 a 1865 por una comisión de naturalistas enviada por el Gobierno Español: Batracios. Reproducción facsímil de la edición original. Society for the Study of Amphibians and Reptiles. Lawrence: vii-xvi.

Times-Rialp, 1993. The Times-Rialp Atlas of the Word. Comprehensive edition. Times-Rialp. Madrid. 222 pp. y 123 mapas.
TRUeB, L., 1974. Systematic relationships of Neotropical horned frogs, genus Hemipractus (Anura: Hylidae). Occasional Pappers of the Museum of Natural History the University of Kansas, 29: 1-60.

WAKE, D. B. \& MARKS, S. B., 1993. Development and Evolution of Plethodontid Salamanders: a review of prior studies and a prospectus for future researchs. Herpetologica, 49(2): 194-203.

Wiens, J. J., Fetzner, J. W., PARkinson, C. L. \& Reeder, T. W. 2005. Hylyd frog Phylogeny and sampling strategies for speciose clades. Systematic Biology, 54: 743.
Recibido, 3-III-2005 Aceptado, 20-XI-2006 Publicado, 29-XII-2006 
Apéndice 1.- Táxones descritos por Jiménez de la Espada y su denominación actual. La siguiente relación recoge los táxones descritos por Jiménez de la Espada de entre todos los anfibios que la CCP trajo a España. Los táxones están agrupados por categorías taxonómicas, indicándose en la primera columna el año de descripción del taxon (sólo cuando ésta fue realizada por Jiménez de la Espada). Cuando Jiménez de la Espada cambió de género alguna de las especies descritas previamente por él, se indican los dos binomios que empleó. En la segunda columna, se indica además de la denominación actual -según los criterios recogidos en Frost et al. (2006)- el autor y el año de la descripción del taxon. CLAVES: (A) Táxones descritos por Jiménez de la Espada Admitidos como válidos. (s) Táxones descritos por Jiménez de la Espada sinonimizados. $(\boldsymbol{N})$ : Táxones cuyos ejemplares No han sido localizados durante este trabajo.

Appendix 1.- Taxa described by Jiménez de la Espada and their current names. This relation includes all taxa described by Jiménez de la Espada from amphibians collected by the CCP. Taxa are grouped by taxonomic category ; the first column includes the year of description of the taxon (when the description was made by Jiménez de la Espada); when a species previously described by Jiménez de la Espada was placed by him in another genus, both binomial forms are indicated. The second column shows the current name -following Frost et al. (2006)- author, and year of description. KEYS: (A) Taxa described by Jiménez de la Espada currently accepted. (s) taxa described by Jiménez de la Espada currently synonymyzed. (N) taxa for which specimens were not located during this work.

\begin{tabular}{|c|c|c|}
\hline $\begin{array}{l}\text { Nombre otorgado por Jiménez de la Espada } \\
\text { y año de descripción }\end{array}$ & Clave & Nombre actual, autor y año de descripción \\
\hline \multicolumn{3}{|l|}{ Familia Bufonidae } \\
\hline Atelopus planispina 1875. & $\mathbf{A}$ & Atelopus planispina Jiménez de la Espada, 1875. \\
\hline Bufo marinus fluminensis 1875. & $\mathbf{s}$ & Chaunus marinus (Linnaeus, 1758). \\
\hline Bufo marinus napensis 1875. & $\mathbf{s}$ & Chaunus marinus (Linnaeus, 1758). \\
\hline Bufo marinus platensis 1875. & $\mathbf{s}$ & Chaunus arenarum (Hensel, 1875). \\
\hline Oxyrhynchus iserni 1875. & $\mathbf{A}$ & Rhinella iserni (Jiménez de la Espada, 1875). \\
\hline Pyxicephalus leiboldi 1875. & $\mathrm{~s}-\mathrm{N}$ & Chaunus spinulosus (Wiegmann, 1834). \\
\hline Familia Dendrophryniscidae 1871. & $\mathbf{s}$ & Familia Bufonidae \\
\hline Género Dendrophryniscus 1871 & $\mathbf{A}$ & $\begin{array}{l}\text { Dendrophryniscus Jiménez de la Espada, } 1871 . \\
\text { Género tipo de la familia Dendrophryniscidae. }\end{array}$ \\
\hline Dendrophryniscus brevipollicatus 1871 & $\mathrm{~A}-\boldsymbol{N}$ & $\begin{array}{l}\text { Dendrophryniscus brevipollicatus Jiménez de la Espada, } 1871 . \\
\text { Especie tipo del género. }\end{array}$ \\
\hline \multicolumn{3}{|l|}{ Familia Centrolenidae } \\
\hline Género Centrolene 1872. & $\mathbf{A}$ & Centrolene Jiménez de la Espada, 1872. \\
\hline Centrolene geckoideum 1872. & $\mathbf{A}$ & Centrolene geckoideum Jiménez de la Espada, 1872. \\
\hline \multicolumn{3}{|l|}{ Familia Dendrobatidae } \\
\hline Género Hyloxalus 1871. & $\mathbf{A}$ & Hyloxalus Jiménez de la Espada, 1871. \\
\hline Hyloxalus bocagei 1871. & $\mathbf{A}$ & Hyloxalus bocagei Jiménez de la Espada, 1871. \\
\hline Hyloxalus fuliginosus 1871. & $\mathbf{A}$ & $\begin{array}{l}\text { Hyloxalus fuliginosus Jiménez de la Espada, } 1871 . \\
\text { Especie tipo del género Hyloxalus . }\end{array}$ \\
\hline Género Phyllodromus, 1875. & $\mathbf{s}$ & Hyloxalus Jiménez de la Espada, 1875. \\
\hline Phyllodromus pulchellum 1875. & $\mathrm{~A}-\mathrm{N}$ & $\begin{array}{l}\text { Hyloxalus pulchellus (Jiménez de la Espada, 1875). } \\
\text { Especie tipo del género Phyllodromus. }\end{array}$ \\
\hline \multicolumn{3}{|l|}{ Familia Hylidae } \\
\hline Hyla reticulata 1871. & $\mathbf{s}$ & Dendropsophus triangulum (Günther, 1869). \\
\hline \multicolumn{3}{|l|}{ Familia Amphignathodontidae } \\
\hline Nototrema testudineum 1871. & $\mathbf{A}$ & Gastrotheca testudinea (Jiménez de la Espada, 1871). \\
\hline \multicolumn{3}{|l|}{ Familia Hemiphractidae } \\
\hline Género Cerathyla 1871. & $\mathbf{s}$ & Hemiphractus Wagler, 1828. \\
\hline Cerathyla braconnieri 1871. & $\mathbf{s}$ & Hemiphractus bubalus (Jiménez de la Espada, 1871). \\
\hline Cerathyla bubalus 1871. & $\mathbf{A}$ & $\begin{array}{l}\text { Hemiphractus bubalus (Jiménez de la Espada, 1871). } \\
\text { Especie tipo del género Cerathyla. }\end{array}$ \\
\hline Cerathyla palmarum 1871. & $\mathbf{s}$ & Hemiphractus bubalus (Jiménez de la Espada, 1871). \\
\hline Cerathyla proboscidea 1871. & $\mathbf{A}$ & Hemiphractus proboscideus (Jiménez de la Espada, 1871). \\
\hline
\end{tabular}




\begin{tabular}{|c|c|c|}
\hline $\begin{array}{l}\text { Nombre otorgado por Jiménez de la Espada } \\
\text { y año de descripción }\end{array}$ & Clave & Nombre actual, autor y año de descripción \\
\hline \multicolumn{3}{|l|}{ Familia Brachycephalidae } \\
\hline Género Cyclocephalus. & $\mathbf{s}$ & Eleutherodactylus Duméril y Bibron, 1841. \\
\hline Cyclocephalus lacrimosus 1875. & A- $N$ & $\begin{array}{l}\text { Eleutherodactylus lacrimosus (Jiménez de la Espada, 1875). } \\
\text { Especie tipo del género Cyclocephalus. }\end{array}$ \\
\hline \multicolumn{3}{|l|}{ Familia Ceratophryidae } \\
\hline Cystignathus hidalgoi 1875. & $\mathbf{s}$ & Batrachyla taeniata (Girad, 1855). \\
\hline \multicolumn{3}{|l|}{ "Incertae Sedis" } \\
\hline Cystignathus humilis 1875. & A- $N$ & “Cystignathus” humilis Jiménez de la Espada, 1875. \\
\hline \multicolumn{3}{|l|}{ Familia Leiuperidae } \\
\hline Género Edalorhina 1871. & A & Edalorhina Jiménez de la Espada, 1871. \\
\hline Edalorhina perezi 1871 & $\mathbf{A}$ & $\begin{array}{l}\text { Edalorhina perezi Jiménez de la Espada, } 1871 . \\
\text { Especie tipo del género. }\end{array}$ \\
\hline Género Engystomops 1872. & A & Engystomops Jiménez de la Espada, 1872. \\
\hline Engystomops petersi 1872. & A- $N$ & $\begin{array}{l}\text { Engystomops petersi Jiménez de la Espada, } 1872 . \\
\text { Especie tipo del género Engystomops. }\end{array}$ \\
\hline \multicolumn{3}{|l|}{ Familia Brachycephalidae } \\
\hline Hylodes diadematus 1875. & $\mathrm{~A}-\mathrm{N}$ & Eleutherodactylus diadematus (Jiménez de la Espada, 1875). \\
\hline Hylodes rubicundus 1875. & $\mathrm{~A}-\boldsymbol{N}$ & Eleutherodactylus rubicundus (Jiménez de la Espada, 1875). \\
\hline Hylodes philippi 1875. & $\mathbf{s}$ & Oreobates quixensis Jiménez de la Espada, 1872. \\
\hline Hylodes verrucosus 1875. & $\mathbf{s}$ & Oreobates quixensis Jiménez de la Espada, 1872. \\
\hline Género Limnophys 1871. & $\mathbf{s}$ & Eleutherodactylus Duméril y Bibron, 1841. \\
\hline \multicolumn{3}{|l|}{ Limnophys cornutus 1871.} \\
\hline (= Strabomantis cornutus 1872$)$ & A- $N$ & $\begin{array}{l}\text { Eleutherodactylus cornutus (Jiménez de la Espada, 1871). } \\
\text { Especie tipo del género Limnophys. }\end{array}$ \\
\hline Limnophys napaeus 1871. & $\mathbf{s}$ & Eleutherodactylus cornutus (Jiménez de la Espada, 1871). \\
\hline Género Oreobates 1872. & $\mathbf{A}$ & Oreobates Jiménez de la Espada, 1872. \\
\hline Oreobates quixensis 1872. & $\mathbf{A}$ & $\begin{array}{l}\text { Oreobates quixensis Jiménez de la Espada, } 1872 . \\
\text { Especie tipo del género. }\end{array}$ \\
\hline Género Pristimantis 1871. & $\mathbf{s}$ & Eleutherodactylus Duméril y Bibron, 1841. \\
\hline Pristimantis galdi 1871. & A & $\begin{array}{l}\text { Eleutherodactylus galdi (Jiménez de la Espada, 1871). } \\
\text { Especie tipo del género Pristimantis. }\end{array}$ \\
\hline \multicolumn{3}{|l|}{ Familia Leptodactylidae } \\
\hline Leptodactylus goliath 1875. & $\mathbf{s}$ & Leptodactylus pentadactylus (Laurenti, 1768). \\
\hline Leptodactylus labrosus 1875. & $\mathbf{A}$ & Leptodactylus labrosus Jiménez de la Espada, 1875. \\
\hline Leptodactylus latinasus 1875. & $\mathbf{A}$ & Leptodactylus latinasus Jiménez de la Espada, 1875. \\
\hline Leptodactylus stenodema 1875. & $\mathbf{A}$ & Leptodactylus stenodema Jiménez de la Espada, 1875. \\
\hline Leptodactylus wuchereri 1875. & $\mathbf{s}$ & Leptodactylus labyrinthicus (Spix, 1824). \\
\hline \multicolumn{3}{|l|}{ Familia Cycloramphidae } \\
\hline Género Litopleura 1875. & $\mathbf{s}$ & Limnomedusa Fitzinger, 1843. \\
\hline Litopleura maritimum 1875. & $\mathrm{~s}-\mathrm{N}$ & $\begin{array}{l}\text { Limnomedusa macroglossa (Dumeril y Bibron, 1841). } \\
\text { Especie tipo del género Litopleura. }\end{array}$ \\
\hline \multicolumn{3}{|l|}{ Familia Leiuperidae } \\
\hline Género Peralaimos 1875. & $\mathbf{s}$ & Eupemphyx Steindachner, 1863. \\
\hline \multicolumn{3}{|l|}{ Bufo stentor 1872.} \\
\hline$(=$ Peralaimos stentor 1875$)$ & $\mathrm{s}-\mathrm{N}$ & Engystomops pustulosus (Cope, 1864). \\
\hline & & Especie tipo del género Peralaimos. \\
\hline Pleurodema granulosum 1875. & $\mathbf{s}$ & Pleurodema bibroni Tschudi, 1838. \\
\hline \multicolumn{3}{|l|}{ Orden CAUDATA } \\
\hline \multicolumn{3}{|l|}{ Familia Plethodontidae } \\
\hline Género Urotropis 1875. & $\mathbf{s}$ & Ensatina Gray, 1850. \\
\hline Urotropis platensis 1875 & $\mathbf{s}$ & $\begin{array}{l}\text { Ensatina eschscholzii Gray, } 1850 . \\
\text { Especie tipo del género Urotropis. }\end{array}$ \\
\hline
\end{tabular}


Apéndice 2.- Especies descritas por Jiménez de la Espada cuyos ejemplares tipo no han sido localizados en el presente trabajo, pero sí sus fichas antiguas (confeccionadas hacia 1911-1913).

Appendix 2.- Species described by Jiménez de la Espada, whose type specimens have not been found during this research, but whose old cards (made around 1911-1913) have been found by us.

\section{Familia BRACHYCEPHALIDAE}

Eleutherodactylus cornutus (Jiménez de la Espada, 1871)

Limnophys cornutus, Jiménez de la Espada, 1871 «1870», J. Sci. Math. Phys. Nat., Lisboa, 3: 60

Sinonimizado con Strabomantis biporcatus por Jiménez de la Espada, 1872, An. Soc. Esp. Hist. Nat., 1: 85.

Eleutherodactylus cornutus cornutus, Rivero, 1961, Bull. Mus. Comp. Zool., 126: 55

Eleutherodactylus cornutus, Gorham, 1966: 66. Das Tierreich, 85 222

Eleutherodactylus (Eleutherodactylus) cornutus Lynch, 1966, In

Powell \& Henderson (eds.), Cont. W. Indian Herpetol: 154

Jiménez de la Espada (1871: 60) no habla del número de ejemplares estudiados al describir esta especie (aunque sí indica las medidas de uno de ellos). En cualquier caso y desgracidamente, durante el presente estudio, no ha podido ser localizado ninguno perteneciente a esta especie, y sólo hemos localizado una ficha antigua ( $\mathrm{la}^{\circ} 193$ ) con los siguientes datos: nombre científico, Hylodes brevipollicatus (Espada); localidad, Suno cerca de S. José de Moti (Ecuador); Colector, Espada; clasificador, Espada; Modo de adquisición, Viaje al Pacífico, 2 ejemplares; fecha de colecta, junio. Vuelta: "Ejemplar tipo de la especie y también del gen. Limnophis Espada sinÓnimo de Strabomantis y de Hylodes según Boulenger 1882 (Cat. Mus. Bs). Vease: 1872.- Espada. An. Soc. Esp. Hist. Nat. P 85. 1870$71^{*}$.- Espada Jor. Sci. Lisboa p. 60. (*2a edic. en 1883)”. Como en los los casos anteriores, no está anotado en la ficha que ésta fuera revisada por Zulueta; no obstante creemos que sí realizó el resto de las anotaciones que figuran en la misma. Por lo que sabemos, Martínez-Rica ya no los encontró en 1980.

Eleutherodactylus diadematus (Jiménez de la Espada, 1875)

Hylodes diadematus Jiménez de la Espada, 1875. Vert. Viaje Pacifico, Batr: Lam. 3 bis, fig. 3, 3a 3 b, 3c.

Eleutherodactylus diadematus, Gorham, 1966, Das Tierreich, 85: 99. Eleutherodactylus (Eleutherodactylus) rubicundus, Lynch, 1966, In Powell \& Henderson (eds.), Cont. W. Indian Herpetol.: 154.

Jiménez de la Espada (1875a) ilustró esta especie, actualmente admitida como válida, pero no la describió, y tampoco indicó ninguna otra información sobre ella, por lo que ignoramos el $n^{\circ}$ de ejemplares colectados por la CCP así como cualquier otro dato sobre la colecta, colector, etc. Durante el curso de este trabajo, nos ha sido imposible encontrar ningún ejemplar que pudiera pertenecer a esta especie. Al no haber encontrado la ficha antigua, creemos que ésta tampoco debió de ser confeccionada por Zulueta en 1911.

Eleutherodactylus galdi (Jiménez de la Espada, 1871)

Pristimantis galdi Jiménez de la Espada, 1871 «1870», J. Sci. Math. Phys. Nat., Lisboa, 3: 61.

Eleutherodactylus galdi, Peters, 1955, Rev. Ecuat. Entomol. Parasitol., 3-4: 350.

Eleutherodactylus (Eleutherodactylus) galdi, Lynch, 1966, In Powell \& Henderson (eds.), Cont. W. Indian Herpetol: 154.

Como en todas las especies descritas en este trabajo, Jiménez de la Espada (1871: 61) no habla de ningún número concreto de sintipos (aunque describe uno de ellos). Algunos de éstos han sido localizados durante este trabajo y se indican en el lugar correspondiente del catálogo confeccionado; desgraciadamente, los correspondientes a esta ficha antigua (la $\mathrm{n}^{\circ}$ 200) no han podido ser localizados, en ella se indican: "nombre científico, Hylodes galdoi (Espada); localidad, San José de Moti (Ecuador)?; clasificador, Zulueta 1911; Modo de adquisición, Viaje al Pacífico, 1 ejemplar". Vuelta de la ficha: "Hallado con la denominación errónea Brachyla leptopus Bell. Que no pudo darle Espada que conoció bien esta especie. Probablemenete es un cotipo de la especie galdoi y del género Pristimantis Espada y sirvió para dibujar un detalle anatómico, Vease: 1870-71*.- Espada Jor. Sci. Lisboa p. 60. 1875.Espada. Viaj. Pacif. Lam. 3. fig.6. Lam. 3bis. fig.6. (*2 ${ }^{a}$ edic. en 1883)". La ficha también carece del sello (Zulueta revisó. 1911); Martínez-Rica no lo encontró en 1980.

Eleutherodactylus lacrimosus (Jiménez de la Espada, 1875)

Cyclocephalus lacrimosus Jiménez de la Espada, 1875, Vert. Viaje Pacifico, Batr: Lam. 3bis, fig. 5, $5^{\mathrm{a}}$, 5 b.

Hylodes lacrimosus, Nieden, 1923, Das Tierreich, 46: 467.

Eleutherodactylus lacrimosus, Gorham, 1966. Das Tierreich, 85: 80.

Eleutherodactylus (Eleutherodactylus) rubicundus, Lynch, 1966, In Powell \& Henderson (eds.), Cont. W. Indian Herpetol.: 154.

Como en algún caso anterior, actualmente se considera una especie válida, y fue otra de las especies descritas por Jiménez de la Espada (1875a), sólo en base a ilustraciones. Al no indicar ninguna otra información sobre ella, desconocemos el número real de ejemplares colectados por la CCP, así como cualquier otro dato sobre su colecta, colector, etc. De la Riva (2000: 82) comenta: “...Heyer \& Hardy (1991), señalaron que en realidad dicha entidad correspondia a un complejo de once especies y dado que el ejemplar tipo original de E. lacrimosus se ha perdido, designaron un neotipo...". Dudamos que Zulueta en 1911 lo encontrara y confeccionase una ficha. Después de nuestro trabajo nos ha sido imposible encontrar ningún ejemplar que pudiera pertenecer a esta especie, por lo que debemos corroborar su pérdida.

Eleutherodactylus rubicundus (Jiménez de la Espada, 1875)

Hylodes rubicundus Jiménez de la Espada, 1875, Vert. Viaje Pacifico, Batr: Lam. 3bis, fig. 4, $4^{\mathrm{a}}$, 4b.

Eleutherodactylus rubicundus, Gorham, 1966: 66. Das Tierreich, 85: 99. Eleutherodactylus (Eleutherodactylus) rubicundus, Lynch, 1966, In Powell \& Henderson (eds.), Cont. W. Indian Herpetol: 154.

Como en otros casos, Jiménez de la Espada (1875a) no indica el número de ejemplares por él estudiados, ya que la descripción de la especie consiste sólo en una ilustración (Jiménez de la Espada, 1875a: Lam. 3bis, fig. 4, 4a, 4b). Durante nuestro trabajo; hemos encontrado una ficha antigua con el $\mathrm{n}^{\mathrm{o}} 139$ que contiene los siguientes datos: nombre científico, Hylodes rubicundus Espada; localidad, San José de Moti (Ecuador); colector, Espada; clasificador, Espada; Modo de adquisición, Viaje al Pacífico, 3 ejemplares. Vuelta: "Tipos de la especie, Vease: 1875.- Espada (M. Jimenez de la) Vertebrados del Viaje al Pacífico (Madrid, 1 vol., $4^{\circ}$ ).- 
Lam. 3bis fig.4.”. En la ficha llaman la atención dos cosas: la primera de ellas es que falta el sello de "Zulueta revisó 1911", como en los recientes casos anteriores y a diferencia de la mayoría de la demás fichas localizadas; la segunda es que el inicial $\mathrm{n}^{\mathrm{o}} 2$ con el que indicó el número de ejemplares al que hacía referencia la ficha, fue cuidadosamente retocado por él mismo a un 3. Esto nos hace sospechar que quizás Zulueta no localizó los ejemplares en 1911 o tuvo sus dudas al respecto. Quien desde luego no los localizó fue MartínezRica en 1980 y desgraciadamente tampoco nosotros ahora. Por todo ello, debemos ratificar la afirmación de Lynch \& Duellman (1980: 54) en el sentido de la pérdida de los sintipos de la especie.

\section{Familia BUFONIDAE}

\section{Chaunus spinulosus (Wiegmann, 1834)}

Pyxicephalus leyboldi Jiménez de la Espada, 1875, Vert. Viaje Pacifico, Batr.: 15.

Sinonimizado con Ceratophrys leyboldi por Boulenger, 1882, Cat. Batr. Grad. Coll. Brit. Mus.

Sinonimizado con Bufo spinulosus por Gorham, 1974, Checklist World Amph.

Incertae sedis Pyxicephalus leyboldi Jiménez de la Espada, 1875 , según Frost (2004)

Jiménez de la Espada (1875a: 15-20) habla de dos hembras, una de ellas joven, de Coquimbo (Chile), ninguna de las cuales ha podido ser localizada durante este estudio; tan sólo se ha localizado una ficha antigua con el $\mathrm{n}^{\circ} 171$ y los siguientes datos: nombre científico, Ceratophrys leyboldi Espada; Sexo, 우 ; localidad, Coquimbo (Chile); Colector, Espada; clasificador, Espada; Modo de adquisición, Viaje al Pacífico, 1 ejemplar. Vuelta: "Tipo de la especie. Vease: 1875.- Espada. Viaje. Pacif. p. 15”. Sin duda Zulueta se refería a la especie Pyxicephalus leyboldi Jiménez de la Espada, 1875. Aunque no está anotado en la ficha que ésta fuera revisada por Zulueta, creemos que sí realizó el resto de las anotaciones que figuran en la ficha. Al parecer MartínezRica ya no encontró el ejemplar en 1980. Nosotros tampoco en esta ocasión.

Dendrophryniscus brevipollicatus Jiménez de la Espada, 1871 Dendrophryniscus brevipollicatus Jiménez de la Espada, 1871. J. Sci. Math. Phys. Nat., Lisboa, 3: 65.

Jiménez de la Espada (1871: 65) no dice el número de ejemplares colectados, aunque indica las medidas de un ejemplar. Su terra tipica es el monte Corcovado, en las cercanías de Rio de Janeiro. Aunque no hemos localizado ningún ejemplar que pudiera pertenecer a esta especie, hemos localizado la ficha antigua (la $\left.{ }^{\circ} 164\right)$ con los siguientes datos: nombre científico, Dendrophryniscus brevipollicatus Espada; localidad, Rio de Janeiro (monte Corcovado); Colector, Espada; clasificador, Espada; Modo de adquisición, Viaje al Pacífico, 1 ejemplar. Vuelta: "Tipo del género y de la especie. Vease: 1875.Espada. Viaj. Pacif. pl.VI. fig.3. 1883.- Espada Jor. Sci. Lisboa p. 60". Tampoco en esta ficha está anotado que ésta fuera revisada por Zulueta, pero también creemos que sí realizó el resto de las anotaciones que figuran en ella. Desgraciadamente Martínez-Rica ya no lo encontró en 1980.

\section{Familia CyCloRAMPHIDAE}

Limnomedusa macroglossa (Duméril \& Bibron, 1841)

Cystignathus macroglossus Duméril \& Bibron, 1841, Erp. Gén., 8: 405. Litopleura maritimum Jiménez de la Espada, 1875, Vert. Viaj. Pacif. Verif., Batr.: 82.

Limnomedusa macroglossa, Cope, 1866, J. Acad. Nat. Sci. Philadelphia, 6: 94

Sinonimizado con Limnomedusa macroglossa, por Boulenger, 1882, Cat. Batr. Sal. Brit. Mus.: 250.

Jiménez de la Espada (1875: 82), nos indica que fue en la playa de Ramírez, cercana a Montevideo (Uruguay), donde colectó el único ejemplar que le sirvió para describir Litopleura maritimum. Existe una ficha con el número 1157, confeccionada por Martínez Rica hacia 1980 que recoge los datos de dicho ejemplar, pero dudamos mucho que no se tratara de uno de los dos ejemplares MNCN 3529-3529 que se encontraban erróneamente catálogados con esta denominación (ver Leptodactylus wagneri). Basamos nuestro criterio en que Zulueta en 1911 no encontró y confeccionó ninguna ficha para este taxon y hasta la fecha (y por desgracia), no hemos encontrado ningún ejemplar tipo que ya no existiera en tiempos de Zulueta. Ignoramos dónde puede encontrase el verdadero ejemplar tipo de Litopleura maritimum.

\section{Familia LEIUPERIDAE}

Engystomops pustulosus (Cope, 1864)

Bufo stentor Jiménez de la Espada, 1872, An. Soc. Esp. Hist. Nat., 1: 85

Peralaimos stentor, Jiménez de la Espada, 1875. Vert. Viaje Pacifico, Batr: 163.

Sinonimizado con Physalaemus pustulosus Lynch, 1970, Copeia, 1970: 493. Cannatella \& Duellman, 1984, Copeia, 1984: 912.

Engystomops pustulosus, rehabilitado por Grant, Frost, Caldwell, Gagliardo, Haddad, Kok, Means, Noonan, Schargel \& Wheeler, 2006, Bull. Am. Mus. Nat. Hist., 299: 168.

Tampoco en este caso Jiménez de la Espada (1872a: 85) habla de un número determinado de ejemplares, durante la descripción de la especie; pero en Jiménez de la Espada (1875: 166) indica específicamente que fueron dos machos de la isla de Taboga (Panamá) los colectados y estudiados por él. Lamentablemente, no nos ha sido posible encontrar ninguno de ellos durante nuestra investigación; hemos debido conformarnos con una ficha antigua (la $\left.\mathrm{n}^{\circ} 119\right)$ que confirmaba la existencia en tiempos pasados de este material en el MNCN y cuyos datos son: nombre científico, Engystomops stentor (Espada); sexo, O'; localidad, Isla de Taboga (Golfo de Panamá); colector, Espada; clasificador, Espada; Modo de adquisición, Viaje al Pacífico, 2 ejemplares. Vuelta: "Tipos de la especie y del género Peralaimos Espada, sinónimo de Engystomops, según Boulenger, 1882 Cat. Brit. Mus. Vease: 1872.- Espada (M. J. de la) Nuevos Batracios americanos (Madrid, Ana. Soc. Esp. Hist. Nat. I, 85-88.) 1875.- Espada (M. J. de la ) Vertebrados del Viaje al Pacífico Batracios (Madrid, Ginesta, 1 vol., )". Como en los casos anteriores, Martínez-Rica no los encontró en 1980, al igual que nos ha ocurrido a nosotros ahora y probablemente a Zulueta en 1911. 
Apéndice 3.- Especies descritas por Jiménez de la Espada cuyos ejemplares tipo, no han sido localizados en el presente trabajo y de los cuales tampoco se ha encontrado ninguna ficha o etiqueta antigua.

Appendix 3.- Species described by Jiménez de la Espada, for which no type specimens or old cards have been found during this research.

\section{Familia Dendrobatidae}

Hyloxalus pulchellus (Jiménez de la Espada, 1875)

Phyllodromus pulchellum Jiménez de la Espada, 1875. Vert. Viaje Pacifico, Batr: Lam. 3, fig. 3, 3a , 3b, 3c.

Colostethus pulchellus, Edwards, 1971. Proc. Biol. Soc. Washington, 84: 148

Colostethus pulchellus, Coloma, 1995, Misc. Publ. Mus. Nat. Hist. Univ. Kansas, 87: 46. Designa neotipo.

Hyloxalus pulchellus, Grant, Frost, Caldwell, Gagliardo, Haddad, Kok, Means, Noonan, Schargel \& Wheeler, 2006, Bull. Am. Mus. Nat. Hist., 299: 168.

Ignoramos el $\mathrm{n}^{\circ}$ de ejemplares colectados por la CCP así como cualquier otra información sobre la colecta, al no haber sido especificada por Jiménez de la Espada (1975a), ya que en este trabajo se limita a ilustrar la especie. Lamentablemente, no nos ha sido posible localizar ningún ejemplar perteneciente a esta especie en la colección del MNCN; ni cualquier otro documento, ficha o etiqueta antigua que nos pudiera dar, como en otros casos, idea aproximada de cuándo pudo producirse la pérdida o destrucción del/los ejemplares en cuestión. Ignoramos si ello es debido a que en tiempos de Zulueta (1911) ya había desaparecido y por ello no confeccionó una ficha -que lógicamente ni Martínez-Rica (1980) ni nosotros ahora, hemos podido encontrar- o a que ésta, al igual que el ejemplar, se ha perdido.

\section{Familia LEIUPERIDAE}

Engystomops petersi Jiménez de la Espada, 1872

Engystomops Petersi Jiménez de la Espada, 1872. An. Soc. Esp. Hist. Nat., 1: 86.

Physalaemus petersi, Lynch, 1970, Copeia, 1970: 488-496; Cannatella \& Duellman, 1984, Copeia, 1984: 908.

Engystomops petersi, rehabilitado por Nascimento, Caramaschi \& Gonçalvez Cruz, 2005, Arq. Mus. Nac. Rio de Janeiro, 63: 312.

NOTA: Un reciente trabajo (Nascimento et al., 2005), aparecido durante la redacción de éste catálogo, rehabilita la validez del género Engystomops Jiménez de la Espada, 1872 y por tanto la denominación original Engystomops petersi Jiménez de la Espada, 1872 para la especie.
Aunque Jiménez de la Espada no aporta ningún dato concreto sobre el número de ejemplares colectados en la descripción de la especie (Jiménez de la Espada, 1872), en Jiménez de la Espada (1875a: 160-163) hace una detallada redescripción de la especie, e indica que contó para su estudio con dos hembras procedentes de Archidona, cerca de las orillas del río Napo, suponemos que colectadas entre abril y mayo de 1865 . Por desgracia, no nos ha sido posible localizar, durante nuestro trabajo, ninguno de los dos ejemplares que menciona Jiménez de la Espada, por lo que debemos corroborar su pérdida. Pensamos que ya en tiempos de Zulueta (1911) debían de haber desaparecido, pues tampoco hemos podido localizar ninguna ficha suya de esta especie. Tampoco Martínez-Rica lo encontró

\section{INCERTAE SEDIS}

“Cystignathus” humilis Jiménez de la Espada, 1875

Cystignathus humilis Jiménez de la Espada, 1875. Vert. Viaje Pacifico, Batr.: Lam. 1, fig. 2, $2^{\mathrm{a}}$

Incertae sedis "Cystignathus" humilis. Frost, 2004

Jiménez de la Espada ilustró esta enigmática especie como recoge De la Riva (2000: 83): "Hasta la fecha no se sabe a qué puede corresponder este nombre, que ni siquiera fue recogido en catálogos posteriores (Boulenguer, 1882; Nieden, 1923; Gorham, 1966)." Como en el caso anterior, no sabemos si la inexistencia de ninguna ficha antigua se debe a la no confección de la misma por Zulueta en 1911 o a su pérdida posterior. 
Apéndice 4.- Ejemplares citados o no por Jiménez de la Espada en sus publicaciones que no han sido localizados, pero de los que sí se ha localizado una ficha antigua.

Appendix 4. - Specimens cited or not by Jiménez de la Espada not found in this research, for which old cards (made about 1911) have been found by us.

\section{Familia AMPHignathodontidae}

Gastrotheca riobambae (Fowler, 1913) ${ }^{(*)}$

Nototrema marsupiatum, Günther, 1859 «1858», Cat. Batr. Sal. Coll. Brit. Mus.: 116

Nototrema marsupiatum, Jiménez de la Espada, 1875, Vert. Viaj. Pacif., Batr.: Lam. 4, fig. 1.

Hyla riobambae Fowler, 1913. Proc. Acad. Nat. Sci. Philadelphia, 65: 157

Gastrotheca riobambae, Duellman \& Fritts, 1972. Occas. Pap. Mus. Nat. Hist. Univ. Kansas, 9: 11

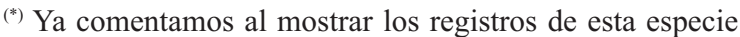
en el catálogo que, aunque Jiménez de la Espada determinó los ejemplares como $N$. marsupiatum, actualmente se conoce que estos no pueden pertenecer a dicha especie, ya que G. marsupiata se distribuye exclusivamente en el sur de Perú y Bolivia y por tanto de las posibles 16 especies que habitan Ecuador, lo más probable es que se trate de ejemplares de $G$. riobambae (De la Riva, comunicación personal).

Como al margen de la ilustración (Jiménez de la Espada, 1875a: Lam. 4, fig. 1) nominada como $N$. marsupiatum no tenemos más datos de los ejemplares colectados por la CCP, debemos considerar la información contenida en la ficha antigua $n^{\circ}$ 157 como correspondiente a material adicional al que se conserva (MNCN 3490 al 3509) y que se recoge en el catálogo. Los datos contenidos en la ficha revisada por Zulueta en 1911 son: Nombre científico, Nototrema marsupiatum Dum. et Bibr.; localidad, Guaranda (Ecuador); colector, Espada. Clasificador, Espada; 1 ejemplar. Vuelta "Vease: 1875.- Espada Vert. Viaj. Pacif. Lam. IV.f.1”. Aparentemente Martínez-Rica no lo localizó y nosotros lamentablemente tampoco hemos podido hacerlo.

\section{Familia BRACHYCEPHALIDAE}

\section{Brachycephalus ephippium (Spix, 1824)}

Bufo ephippium Spix, 1824, Animal. Nova Spec. Nov. Test. Ran Brasil.: 48

Brachycephalus ephippium, Fitzinger, 1826, Neue Class. Rept.: 65. Ephippipher aurantiacus Cocteau, 1835, Mag. Zool., Guérin, 5: 12. Ephippipher spixii Cocteau, 1835, Mag. Zool., Guérin, 5: 12.

Brachycephalus aurantiacus, Girard, 1858, U.S. Explor. Exped. 18381842, 20: 99.

Brachycephalus ephippium, Jiménez de la Espada, 1875. Vert. Viaje Pacifico, Batr.: 120-128.

Jiménez de la Espada (1875a: 15-20) habla de un ejemplar colectado en el monte Corcovado, cercano a Río de Janeiro, "...á grande altura, en el mes de octubre, muy de mañana, en unos matorrales y al mismo tiempo que el Dendrophryniscus brevipollicatus." Durante este trabajo hemos localizado una ficha antigua (la $n^{\circ} 220$ ) confeccionada por Zulueta en 1911 , con los siguientes datos: Nombre científico: Brachycephalus ephippium (Spix). Localidad, Corcovado, Río Janeiro. Colector Espada. Clasificador Espada, Zulueta revisó 1911. Martínez-Rica ya no localiza el ejemplar a 1980. Lo mismo nos ha sucedido a nosotros ahora.

\section{Eleutherodactylus Duméril \& Bibron, 1841}

Hylodes conspicillatus Günther, 1858, Arch. Naturgesch., 24: 326. Lithodytes conspicillatus, Cope, 1868. Proc. Acad. Nat. Sci. Philadelphia, 14: 153 .

No empleado por Jiménez de la Espada es sus publicaciones.

(*) Eleutherodactylus Duméril \& Bibron, 1841. Erp. Gen. 8: 620.

(*) No hemos encontrado ningún ejemplar asociado a la ficha antigua número 207, cuyos datos son: "nombre científico, Hylodes conspicillatus (Cope); localidad, El Jorgei?, Guayaquil; colector, Espada; Clasificador, Espada, Zulueta revisó 1911; modo de adquisición, Viaje al Pacífico".

Por otra parte Jiménez de la Espada nunca publicó ninguna información con respecto a Eleutherodactylus conspicillatus, y es imposible conocer con seguridad de qué especie se trataba. Si los datos de colecta fueran correctos (y no hemos podido localizar ninguna población denominada El Jorge), este ejemplar nunca sería E. conspicillatus que no habita en el oeste de Ecuador (De la Riva, comunicación personal), sino que debería tratarse de alguna de las especies del género Eleutherodactylus que habitan en la zona oeste de Ecuador. Aparentemente localizado por Zulueta en 1911. No fue encontrado por MartínezRica (1980). Nosotros tampoco lo hemos encontrado ahora.

\section{Familia BUfONIDAE}

Atelopus ignescens (Cornalia, 1849)

Phryniscus ignescens Cornalia, 1849, Vert. Syn. Mus. Mediolanense Extant: 14.

Phryniscus laevis Günther, 1858, Arch. Naturgesch., 24: 321.

Phrynidium laeve, Cope, 1867, J. Acad. Nat. Sci. Philadelphia, (2)6: 196. Atelopus laevis, Cope, 1868, Proc. Acad. Nat. Sci. Philadelphia, 20: 117. Atelopus ignescens, Jiménez de la Espada, 1875, Vert. Viaj. Pacif., Batr: 139.

Atelopus ignescens, Coloma, Lötters, \& Salas, 2000, Herpetologica, 56: 304 Designan neotipo.

Aunque Jiménez de la Espada (1875a: 148) en la relación de ejemplares colectados de $A$. ignescens indica “...50" 5 오 : Páramo de Mojanda (Ecuador)..." no hemos encontrado ningún ejemplar de dicha procedencia, pero sí una ficha antigua (con el número 182). Revisada por Zulueta en 1911, en ella se indica: "Nombre científico: Phryniscus laevis Günther. Localidad Páramo de Mojanda. Colector Martínez [y Sáez]. Clasificador Espada. 13 ejemplares”. Así pues, Zulueta localizó los ejemplares y revisó la ficha en 1911, pero Martínez-Rica en 1980 y nosotros ahora, no los hemos localizado en la colección. También llama la atención que sea mayor el número de ejemplares que el indicado por Espada en su trabajo. Mucho nos tememos que todo ello sea consecuecia de las inapropiadas manipulaciones y mezclas de frascos que históricamente se han debido de realizar (ver comentario en el registro correspondiente a los ejemplares de Atelopus ignescens MNCN 1418-1469).

Atelopus longirostris Cope, 1868

Atelopus longirostris Cope, 1868, Proc. Acad. Nat. Sci. Philadelphia, 20: 116. 
Atelopus longirostris, Jiménez de la Espada, 1875, Vert. Viaj. Pacif., Batr: 155.

Jiménez de la Espada (1875a: 159) en la relación de ejemplares colectados de $A$. longirostris indica " $6 \sigma^{\top} 8$ 우 : Nanegal. Recogidos por el Sr. Martínez y Sáez”. Estos ejemplares no han podido ser encontrados a lo largo del presente estudio, aunque sí hemos encontrado una ficha antigua (la $n^{\circ} 222$ ) revisada por Zulueta en 1911, que corrobora la pasada presencia en la colección de estos ejemplares. Sus datos son: nombre científico Phryniscus longirostris, Cope. Localidad Nanegal (Ecuador). Colector Martínez Sáez. Clasificador Espada. Modo de adquisición Viaje al Pacífico. Número de ejemplares 14. Vuelta: "Vease 1875 Espada. Vert. Viaje Pacif. P 155, lam 2, f 1-2”. Ni Martínez-Rica en 1980 ni nosotros durante este estudio hemos podido localizarlos, aunque mucho nos tememos que se encuentran mezclados con otros ejemplares de Atelopus ignescens, pues el número de ejemplares localizados es superior -en 13 ejemplares-al indicado por Jiménez de la Espada (1975: 148).

Chaunus spinulosus Wiegmann, 1834.

Phryniscus nigricans Wiegmann, 1834, Nov. Act. Leop.: 264.

Chaunus formosus Tschudi, 1838. Classif. Der Batr.: 87.

Phryniscus nigricans, Jiménez de la Espada, 1875, Vert. Viaj. Pacif., Batr: 115.

Sinonimizado con Bufo spinulosus por Duméril \& Bibron, 1841, Erp. Gen., 8, : 722

Rhaebo spinulosus, Frost, Grant, Faivovich, Bain, Haas, Haddad, De Sá, Channing, Wilkinson, Donnellan, Raxworthy, Campbell, Blotto, Moler, Drewes, Nussbaum, Lynch, Green \& Wheeler, 2006, Bull. Am. Mus. Nat. Hist., 297: 364.

Jiménez de la Espada (1875a: 120) en la relación de ejemplares colectados de Phryniscus nigricans indica: "Vive en las orillas del río de la Plata y su habitat se extiende por las orillas del Uruguay;... $\sigma^{\top}$ y 2 o: República Oriental o del Uruguay; (sin indicación más determinada, pues fueron recogidos por nuestro compañero el difunto Sr. Amor, en su viaje de Montevideo a Santiago de Chile, a través de las Pampas y de la Cordillera); - O : Montevideo." Resulta curioso encontrar la ficha antigua $\mathrm{n}^{\circ} 221$ con las siguientes indicaciones: Nombre científico, Phryniscus nigricans Wiegm..; localidad, Nanegal (Ecuador); colector, Espada; clasificador, Zulueta revisó 1911; modo de adquisición, Viaje al Pacífico; 4 ejemplares." por cuanto Jiménez de la Espada (1875: 120) no cita Phryniscus nigricans como del Ecuador. Martínez-Rica posteriormente anotó en esta ficha: "Material estropeado y perdido, 1980". Ignoramos si el grado de deterioro de los ejemplares era tal que no podrían haberse conservado los restos óseos que muy difícilmente desaparecen por completo. Nosotros no hemos encontrado ningún resto adjudicable a esta ficha. En cualquier caso, Chaunus spinulosus no habita ni en Ecuador ni en Uruguay. Nosotros pensamos que quizás pudiera tratarse de cuatro de los 14 ejemplares de Atelopus longirostris Cope, 1868; colectados por Jiménez de la Espada en Nanegal, pero como no se conserva ningún tipo de resto, no deja de ser una elucubración.

Rhaebo guttatus Schneider, 1799

Bufo guttatus Schneider, 1799, Hist. Amph. Nat:: 218.

Bufo leschenaultii Duméril \& Bibron, 1841, Erp. Gén., 8: 662.

Rhaebo leschenaultii, Cope, 1862, Proc. Acad. Nat. Sci. Philadelphia, 14: 357 .

Rhaebo leschenaultii, Jiménez de la Espada, 1875, Vert. Viaj. Pacif., Batr: 167.
Bufo guttatus, Rivero, 1961, Bull. Mus. Comp. Zool., 126: 21.

Rhaebo guttatus, Frost, Grant, Faivovich, Bain, Haas, Haddad, De Sá, Channing, Wilkinson, Donnellan, Raxworthy, Campbell, Blotto, Moler, Drewes, Nussbaum, Lynch, Green \& Wheeler, 2006, Bull. Am. Mus. Nat. Hist., 297: 365.

Jiménez de la Espada (1875a: 170) en la relación de ejemplares colectados de Rhaebo leschenaultii indica: " $\sigma$ " : Ávila de Quíjos;- — O : Quíjos;_— ㅇ joven: id”. Durante el presente estudio, se localizaron dos $R$. leschenaultii recogidos en el catálogo bajo la denominación de Rhaebo guttatus (MNCN 3095-3096) procedentes de la provincia de Quijos, por lo que suponemos que el ejemplar al que se refiere la ficha antigua localizada con el $\mathrm{n}^{\mathrm{o}} 122$, es el indicado por Jiménez de la Espada (1875a: 170), como procedente de Ávila de Quijos. Los datos que recoge esta ficha son: Nombre científico, Bufo guttatus Schneid.; sexo, O' edad, etc. adulto; localidad, Provincia de Quijos (Ecuador); colector, Espada; clasificador, Zulueta revisó 1911. 1 ejemplar; fecha de colecta, abril a junio. No encontrado por Martínez-Rica (1980). Nosotros tampoco lo hemos localizado.

\section{Familia DendrobatidaE}

Hyloxalus bocagei (Jiménez de la Espada, 1871).

Hyloxalus bocagei Jiménez de la Espada, 1871 «1870», J. Math. Phys. Nat. Acad. Real Sci. Lisboa, 3: 59

Colostethus bocagei, Edwards, 1971, Proc. Biol. Soc. Washington, 84: 148.

Colostethus bocagei, Coloma, 1995, Misc. Publ. Mus. Nat. Hist. Univ. Kansas, 87: 21. Designa lectotipo y paralectotipo.

Hyloxalus bocagei, rehabilitado por Grant, Frost, Caldwell, Gagliardo, Haddad, Kok, Means, Noonan, Schargel \& Wheeler, 2006, Bull. Am. Mus. Nat. Hist., 299: 168.

El trabajo de Jiménez de la Espada (1871: 59), no hace mención al número de sintipos empleados por él para la descripción del taxon. La información recogida en la ficha antigua $\mathrm{n}^{\mathrm{o}} 278$ hace referencia, además de al lectotipo y al paralectotipo conservados (MNCN 1583-1584), a cinco ejemplares más que pudieron ser utilizados por Jiménez de la Espada. La información contenida en esta ficha es: Nombre científico, Hylixalus bocagei Espada; localidad Tena (Ecuador); Colector, Espada; Clasificador, Espada; 5 ejemplares. Vuelta, "Vease 1870* (*2a edición de 1882). Espada Jor. Sci. Lisboa p. 59. 1875, Espada, Vert. Viaj. Pacif. Lam. IIIf. 2." . Suponemos que fue localizado por Zulueta en 1911, aunque en la ficha no se indica como en las demás "Zulueta revisó 1911", lo que nos plantea la duda de si realmente Zulueta tuvo en sus manos estos ejemplares. No encontrado por Martínez-Rica en 1980. Tampoco nosotros los hemos localizado ahora

\section{Familia HyLIDAE}

Scinax quinquefasciata ${ }^{(*)}$ (Fowler, 1913)

Hyla quinquefasciata Fowler, 1913. Proc. Acad. Nat. Sci. Philadelphia, 65: 160.

Ololygon quinquefasciata, Fouquette \& Delahoussaye, 1977, J. Herpetol., 11: 392.

Scinax quinquefasciata, Duellman \& Wiens, 1992. Occas. Pap. Mus. Nat. Hist. Univ. Kansas, 151: 23.

No empleado por Jiménez de la Espada es sus publicaciones. 
(*) Dado que Jiménez de la Espada nunca publicó ninguna información con respecto a Scinax ruber, que no hemos encontrado ningún ejemplar asociado a la ficha antigua número 142 para poder determinar su verdadera denominación, y que no conocemos ningún dato de ningún tipo diferente a los incluidos en la ficha $\mathrm{n}^{\circ} 142$, si los datos de colecta fueran correctos este ejemplar no debería pertenecer a S. ruber (que no habita en el oeste de Ecuador), sino que probablemente debió tratarse de un ejemplar de $S$. quinquefasciata (De la Riva, comunicación personal).

Los datos contenidos en la ficha $\mathrm{n}^{\circ} 141$ son los siguientes: nombre científico, Hyla rubra Daud.; localidad, Pimocha (Ecuador); colector, Espada; Clasificador, Zulueta reviso 1911; 1 ejemplar. No fue encontrado por Martínez-Rica (1980). Nosotros tampoco hemos podido encontra el ejemplar durante nuestra investigación.

\section{Familia LEIUOPERIDAE}

Pleurodema bibroni Tschudi, 1838

Pleurodema bibroni Tschudi, 1838, Classif. Batr: 85.

Pleurodema bibroni, Jiménez de la Espada, 1875, Vert. Viaje Pacifico, Batr:: 87

Jiménez de la Espada (1875a: 92-95), hace una relación prolija de diferencias anatómicas externas por él observadas entre los diferentes individuos estudiados y así en la denominada "diferencia 11" (op. cit. 94), incluye siete individuos

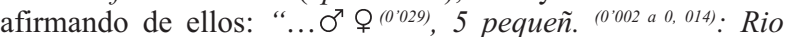
Grande do Sul." (indicando como superíndice y entre paréntesis las longitudes totales de los individuos estudiados). Nosotros consideramos que estos ejemplares son a los que hace referencia la ficha antigua $\mathrm{n}^{\circ} 170$, cuyos datos son: "nombre cientifico, Paludicota Bibroni (Tschudi); localidad, Río Grande do Sul (Brasil); colector, Espada; Clasificador, Espada, Zulueta reviso 1911; modo de adquisición, Viaje al Pacifico; 7 ejemplares". Localizados por Zulueta en 1911 pero no por Martínez- Rica en 1980. Lamentablemente, tampoco hemos localizado estos ejemplares.
Pleurodema thaul (Lesson, 1826)

Bufo thaul Lesson, 1826, In DuPerry (ed.), Voy. Coquille, Zool.: 64. Pleurodema bibroni Tschudi, 1838, Classif. Batr: 85.

Pleurodema darwinii Bell, 1843, Zool. Voy. Beagle, Pt. 5 (Rept.): 36. Pleurodema elegans Bell, 1843, Zool. Voy. Beagle: 37.

Cystignathus bibroni, Duméril \& Bibron, 1841, Erp. Gén., 8: 410. Cystignathus elegans, Guichenot, 1848, in Gay, Hist. Chile, Zool.: 101. Bufo thaul Lesson, 1826, In DuPerry (ed.), Voy. Coquille, Zool.: 64.

Pleurodema bibroni, Jiménez de la Espada, 1875, Vert. Viaje Pacifico, Batr: 87.

Jiménez de la Espada en su trabajo comentado en el caso anterior (1875a: 92-95) y más contretamente en la página 93, dentro de las "diferencias $5^{a}, 6^{a}$ y $9^{a}$ " encontradas entre los diferentes $P$. bibroni estudiados por él, incluye un total de cinco individuos: “... $Q^{\left(0^{\prime} 04\right)}$ : Santiago de Chile. ", "... $Q^{\left(0^{\prime} 03\right)}, Q^{\left(0^{\prime} 035\right)}$ :

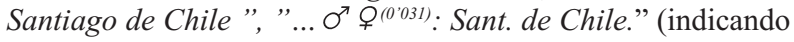
como superíndice y entre paréntesis las longitudes totales de los individuos estudiados). Nosotros consideramos que una parte de estos ejemplares es a lo que hace referencia la ficha antigua $\mathrm{n}^{0} 168$, cuyos datos son: "nombre científico, Paludicota Bibroni (Tschudi); localidad, Santiago (Chile); colector, Espada; Clasificador, Espada, Zulueta reviso 1911; modo de adquisición, Viaje al Pacífico; 4 ejemplares". Localizados por Zulueta en 1911 pero no por Martínez- Rica en 1980. En este caso tampoco hemos podido localizar los ejemplares en cuestión. 
Apéndice 5.- Relación por taxones del número de anfibios colectados por la CCP que se conservan actualmente en el MNCN. E (Especie extinta), T (Taxones con ejemplares tipo descritos por Jiménez de la Espada), JE (denominación propuesta por Jiménez de la Espada); NC (especies No Citadas con anterioridad como colectadas por la CCP).

Appendix 5.- Number of specimens collected by the $C C P$ preserved currently at the MNCN ordered by taxa. E (extinct specie) T (Taxa with tipe specimen drescribed by Jiménez de la Espada), JE (names proponed by Jiménez de la Espada); NC (especies do not cited as collected by CCP previously ).

TAXON

\section{CLASE AMPHIBIA}

Orden ANURA

Familia Amphignathodontidae

NC Gastrotheca riobambae

$\mathbf{T}+\mathbf{J E}$ Gastrotheca testudinea

Familia Batrachophrynidae

Caudiverbera caudiverbera

Familia Brachycephalidae

Eleutherodactylus $s p$.

NC Eleutherodactylus conspicillatus

Eleutherodactylus cornutus

$\mathbf{T}+\mathbf{J E} \quad$ (Limnophys napaeus)

$\mathbf{T}+\mathbf{J E} \quad$ Eleutherodactylus galdi

NC Eleutherodactylus unistrigatus

$\mathbf{T}+\mathbf{J E} \quad$ Oreobates quixensis

$\mathbf{T}+\mathbf{J E} \quad$ (Hylodes philippi)

$\mathbf{T}+\mathbf{J E} \quad$ (Hylodes verrucosus)

Familia Bufonidae

NC Atelopus sp. (1 especie)

$\mathbf{E}+\mathbf{N C}$ Atelopus guanujo

E Atelopus ignescens

$\mathbf{T}+\mathbf{J E}$ Atelopus planispina Chaunus arenarum

$\mathbf{T}+\mathbf{J E} \quad$ (Bufo marinus platensis)

Chaunus arunco

Chaunus crucifer

Chaunus fernandezae

Chaunus marinus

$\mathbf{T}+\mathbf{J E} \quad$ (Bufo m. fluminensis \& napensis)

NC Chaunus schneideri

Rhaebo guttatus

$\mathbf{T}+\mathbf{J E}$ Rhinella iserni

Rhinella margaritifer

Rhinella proboscidea

Familia Centrolenidae

$\mathbf{T}+\mathbf{J E}$ Centrolene geckoideum

Familia Ceratophryidae

Batrachyla taeniata

$\mathbf{T}+\mathbf{J E} \quad$ (Cystignathus hidalgoi)

Ceratophrys cornuta

Familia Cycloramphidae

NC Alsodes nodosus

NC Eupsophus roseus

Hylorina sylvatica

Odontophrynus americanus

Rhinodema darwini

Familia Dendrobatidae

$\mathbf{T}+\mathbf{J E}$ Hyloxalus bocagei

$\mathbf{T}+\mathbf{J E}$ Hyloxalus fuliginosus

\section{$\underline{N^{0} \text { ejemplares }} \quad \underline{\text { TAXON }}$}

$\underline{N^{0} \text { ejemplares }}$

643 Familia Hemiphractidae

$\mathbf{T}+\mathbf{J E}$ Hemiphractus bubalus

JE (Cerathyla braconieri)

JE (Cerathyla palmarum)

$\mathbf{T}+\mathbf{J E}$ Hemiphractus proboscideus

Hemiphractus scutatus

8 Familia Hylidae

NC Dendropsophus leucophyllatus

Dendropsophus triangulum

$\mathbf{T}+\mathbf{J E} \quad$ (Hyla reticulata)

Hypsiboas $s p$.

NC Hypsiboas albomarginata

NC Hypsiboas fasciatus

NC Hypsiboas pulchellus

NC Scinax ruber

NC Sphaenorhynchus lacteus

Familia Hylodidae

NC Hylodes nasus

1

26

4

2

Familia Leiuperidae

$\mathbf{T}+\mathbf{J E}$ Edalorhina perezi

Pleurodema bibroni

JE (Pleurodema granulosum)

Pleurodema thaul

Familia Leptodactylidae

Leptodactylus gracilis

$\mathbf{T}+\mathbf{J E} \quad$ Leptodactylus labrosus

Leptodactylus labyrinthicus

$\mathbf{T}+\mathbf{J E} \quad$ (Leptodactylus wuchereri)

$\mathbf{T}+\mathbf{J E}$ Leptodactylus latinasus

N Leptodactylus lineatus

Leptodactylus ocellatus

Leptodactylus pentadactylus

$\mathbf{T}+\mathbf{J E} \quad$ (Leptodactylus goliath)

$\mathbf{T}+\mathbf{J E}$ Leptodactylus stenodema

NC Leptodactylus wagneri

Orden CAUDATA

Familia Plethodontidae

$\mathbf{T}+\mathbf{J E}$ Ensatina eschscholtzii platensis

Orden GYMNOPHIONA

Familia Caecilidae

NC Caecilia gracilis

NC Caecilia tentaculata

NC Siphonops annulatus 
Apéndice 6.- Breve reseña sobre los miembros, desarrollo del viaje y avatares sufridos por las colecciones realizadas por la CCP.

Appendix 6.- Short comments about the expedition and its members and vicisitudes occurring in Spain to the collections made by the $C C P$.

\section{(A) La CCP y sus miembros.}

El 26 de marzo de 1860 el Ministro de Estado pasó comunicación al de Marina sobre las poderosas razones que hacían necesario el envío de una escuadra a las costas del Pacífico, iniciándose lo que más tarde se denominaría la Expedición al Pacífico. Así pues se concibió básicamente como una operación militar y política, en un intento de que España recuperara parte del poder e influencia en el mundo americano (Cabodevilla, 1998; www.pacifico.csic.es, 2004). En este contexto, y a última hora, se decide añadir un equipo científico de naturalistas (Barreiro, 1926). Definitivamente la CCP quedo constituida por ocho personas: Patricio Paz y Membiela (presidente), marino retirado y aficionado a la Malacología Fernando Amor y Mayor (vicepresidente), catedrático en Valladolid, era sin duda el científico de mayor categoría y prestigio en el momento de la partida y como tal, director científico de la misma. Francisco de Paula Martínez y Sáez (primer ayudante y secretario), y al cual nos referiremos a lo largo del texto sólo por su primer apellido: Martínez. Ayudante en el entonces denominado Real Museo de Historia Natural (actual $\mathrm{MNCN}$ ), su nombramiento provocó cierta polémica al tener su cargo más categoría que el asignado a Marcos Jiménez de la Espada (segundo ayudante), que por aquel entonces tenía más experiencia y categoría al ser desde 1859 Ayudante Primero del Museo. Los dramáticos acontecimientos acaecidos durante el viaje de la CCP, y a su regreso, propiciaron sin embargo que Martínez y Jiménez de la Espada consolidaran una gran amistad y pasaran a la historia como los miembros más destacados de la misma. Juan Isern Batlló (botánico), colector infatigable, desde 1857 era ayudante de la cátedra de Fitografía y Geografía botánicas en la Universidad Central de Madrid. Manuel Almagro Vega (antropólogo), doctor en Medicina por la Sorbona de París, acababa de ingresar en el Cuerpo de Sanidad Militar cuando se incorporó a la CCP. Bartolomé Puig Galup (ayudante disecador), en el momento de su incorporación a la CCP era disecador y preparador del gabinete de Historia Natural de la Universidad de Barcelona. Rafael Castro Ordóñez actuó como fotógrafo y dibujante, y su valiosa colección de fotografías se conserva en gran parte en el MNCN. Es digna de mención, la labor complementaria de cronista de la CCP realizada por Castro, mediante una serie de artículos periodísticos publicados en El Museo Ilustrado entre 1863 y 1866. Referencias biográficas de estos comisionados pueden encontarse en: Castro (1863), Olmedilla \& Puig (1872), Jiménez de la Espada (1875c), Osorio \& Bernard (1875), Martínez (1898), Gogorza (1908), Barreiro (1925, 1926, 1927, 1992), Cuatrecasas (1935), Miller (1983), Puig-Samper (1988), De la Riva (2000), González-Fernández (2000, 2004), López Ocón \& Pérez Montes (2000) y Álvarez (2004).

\section{(B) Síntesis del Viaje de la CCP desde el punto de vista batracológico.}

Como consecuencia de su acelerada e improvisada constitución, las instrucciones científicas recibidas por los comisio- nados fueron breves y genéricas: “... para la resolución de dificiles problemas cientificos; ... recoger ... para enriquecer con nuevas especies nuestras colecciones..." Barreiro (1926). Partiendo de Cádiz el 10 de agosto de 1862, durante los siguientes tres años y medio (hasta diciembre de 1865) iban a recorrer más de $17000 \mathrm{~km}$ (Gogorza, 1908). Durante su viaje recorrieron prácticamente toda la costa atlántica sudamericana, la pacífica desde Cabo de Hornos hasta California y atravesaron el continente sudamericano en dos ocasiones: la primera por el paralelo $33^{\circ}$ y la segunda por el paralelo $2^{\circ}$. Viajaron en barco, vapor, canoa, ferrocarril, carro, diligencia, a lomos de mula y a pie. Aunque no procede detallar aquí todo el itinerario de la $\mathrm{CCP}$, es necesario reseñar los lugares que batracológicamente fueron más relevantes, con objeto de documentar espacial y temporalmente la colecta de los ejemplares objeto de este estudio.

- La primera escala del 14 al 16 de Agosto de 1862 fue en Tenerife, pero no se han localizado ejemplares de anfibios de esa isla canaria asociados a la CCP.

- San Vicente de Cabo Verde (22 al 24 de agosto de 1862). Tampoco se conserva material batracológico asociado.

- Bahía de Todos los Santos, Brasil (9 al 30 de septiembre de 1862). Durante la estancia en Bahía, Jiménez de la Espada colecta el ejemplar MNCN 3073, uno de los sintipos de Bufo marinus fluminensis. En la visita a la Isla de Itaparica, se colecta una de las pocas cecilias traídas por la CCP, un Siphonops annulatus (MNCN 1235).

- Río de Janeiro (5 de octubre al 6 de noviembre de 1862). Jiménez de la Espada visita el monte Corcovado y colecta ejemplares de Hylodes nasus (MNCN 1597-1598). También visita varias veces la «Facenda Imperial de Santa Cruz", coto de caza que el emperador Pedro II de Brasil poseía en la localidad de Santa Cruz, a unos $70 \mathrm{~km}$. de Río de Janeiro, donde colecta seis Leptodactylus ocellatus (MNCN 40634068) y varios de los sintipos de Bufo marinus fluminensis (MNCN 3135-3143).

- Desterro, Brasil (8 al 24 de noviembre de 1862). No hay constancia de la colecta de anfibios.

- Río Grande do Sul, Brasil (27 de octubre al 4 de diciembre de 1862). Jiménez de la Espada colecta entre otros los ejemplares MNCN 3101-3113 y 3145-3150, sintipos de Bufo marinus platensis, y ejemplares de la especie Chaunus fernandezae (MNCN 3087-3093), así como dos Leptodactylus ocellatus (MNCN 1699-1700).

- Montevideo, Uruguay (4 de diciembre de 1862 a 16 de enero de 1863). En los alrededores de la propia capital colecta Jiménez de la Espada ejemplares de Chaunus fernandezae (MNCN 3082-3083), de Leptodactylus ocellatus (MNCN 1702) y los sintipos de Pleurodema granulosum (MNCN 1685-1686). En Playa Ramírez colecta el holotipo de Litopleura maritimum (MNCN 3529). En las excursiones a los cerros de Betete y Las Ánimas, Jiménez de la Espada colecta un ejemplar de Leptodactylus gracilis (MNCN 1689). Además, 
algunos sintipos de Bufo marinus platensis, como los MNCN 3131-3134, debieron ser colectados también en Uruguay.

- La CCP se divide en Uruguay en dos grupos; el primero formado por Paz, Amor, Martínez y Almagro parte de Montevideo por vía terrestre el 26 de diciembre. En este grupo es Amor quien a sus muchas tareas añade la de colectar anfibios. Así se obtienen sintipos de Bufo marinus platensis (MNCN 3144 y 15982), un ejemplar de Chaunus fernandezae (MNCN 3079) y representantes de Hypsiboas pulchellus (MNCN 3246- 3250). También a la labor de Amor se debe el ejemplar MNCN 1694, holotipo de Leptodactylus wuchereri. La falta de concreción en los datos de algunos de estos ejemplares no debería extrañarnos, dada la dificultad de la etapa: ascender y descender el río Uruguay, atravesar toda la pampa Argentina y cruzar la cordillera de los Andes a lomos de caballería. Durante 76 días recorren más de $1500 \mathrm{~km}$ atravesando todo el continente sudamericano por el paralelo $33^{\circ}$ (Almagro, 1866). El segundo grupo, formado por Martínez, Espada, Puig y Castro, embarca en la escuadra y rodea el continente por mar. Se reúnen en Valparaíso en mayo de 1863.

- Durante los siguientes 12 meses recorren las repúblicas de Chile, Bolivia, Perú y Ecuador. Jiménez de la Espada viaja también por Centroamérica, y en la Isla de Taboga (Panamá) colecta dos ejemplares que le sirvieron (Jiménez de la Espada, 1872a) para describir Engystomops stentor. Estos ejemplares desaparecieron entre 1913 y 1980 . En Chile es abundante el material colectado por Jiménez de la Espada, como los sintipos de Cystignathus hidalgoi (MNCN 3528 y 3531-3532), o el holotipo de Ceratophrys leyboldi, hoy en día Bufo spinulosus, también desaparecido entre 1913 y 1980. También, entre otros, colecta ejemplares de Chaunus arunco (MNCN 3123-3126), o Alsodes nodosus (MNCN 4057-4062). Por su parte Isern, además de herborizar de forma incansable todos los territorios que visitaba (Miller, 1983), colectó en los Andes de Chanchamayo (Perú) el holotipo de Rhinella iserni (MNCN 3057), especie tipo del género Oxyrhinchus. Por su parte Amor, Martínez, Puig y Castro viajan desde Panamá hasta California por mar. Martínez visita la reserva de "Big Trees" donde colecta el ejemplar MNCN 1256, holotipo de Urotropis platensis y especie tipo del género Urotropis, actualmente admitida como Ensatina eschscholtzii platensis. Este último ejemplar sufrió una catalogación geográfica errónea, pues pasó como procedente de la cuenca del Río de la Plata y colectado por Amor, como figura en la descripción original (Jiménez de la Espada, 1875b) en lugar de sus datos correctos (Big Trees, California, colectado por Martínez). El viaje de regreso a Valparaíso se realiza sin escalas, en 74 días de navegación continuada.

Independizados de la escuadra a mediados de 1864, comienza sin duda la etapa más fructífera del viaje. Así, de los 653 anfibios colectados por la CCP que aún se conservan en el MNCN, más de 400, muchos de ellos ejemplares tipo, fueron colectados durante esta etapa que los comisionados denominaron "El Gran Viaje" y que les llevó desde Guayaquil en la costa pacífica de Ecuador, hasta Belem de Pará en la costa atlántica de Brasil.

El 5 de abril de 1864 recibe Martínez, presidente accidental de la CCP, un oficio del almirante de la escuadra comunicándole la obligación inmediata de desembarcar pertrechos, pertenencias y personas, y su inmediato regreso a España (Calatayud-Arinero, 1994). Los naturalistas son desembarcados en Valparaíso y abandonados literalmente a su suerte. Tras meses de tozudas negativas de volver a España, solicitando permiso para continuar la expedición, el 29 de julio reciben comunicación del Ministerio de Fomento autorizándoles a atravesar el continente americano por la cuenca del Amazonas (Calatayud-Arinero, 1994).

En los meses anteriores a abril de 1864 se habían producido una serie de acontecimientos que alteran la CCP. Por un lado, Patricio Paz, enfrentado definitivamente al mando militar y a sus propios compañeros de expedición, dimite y regresa a España (Miller, 1983). Por ello debe Martínez Sáez hacerse cargo también de la Presidencia de la CCP. Fernando Amor fallece en San Francisco de California, aquejado de una dolencia contraída mientras colectaba en el desierto de Copiapó. Rafael Castro, ante las poco halagüeñas perspectivas del viaje, decide abandonar la CCP y regresar a España. Por su parte Bartolomé Puig, que se había casado en Chile unos meses antes, alega una enfermedad (en la que el resto de sus compañeros no creen demasiado) y abandona igualmente la CCP, regresando a España poco después.

El 11 de Agosto de 1864 parten Martínez y Castro hacia Guayaquil, donde el Gobierno Español haría efectivos los 200.000 reales con los que pensaba financiar el proyecto del gran viaje. Días después lo hace Almagro. Jiménez de la Espada e Isern lo hacen el 11 de octubre, tras enviar a España la ultima remesa de material y ejemplares vivos para el Jardín de Fieras del Retiro. De Guayaquil pasan a Quito, donde el 7 de diciembre de 1864 se reúnen de nuevo los cuatro supervivientes de la CCP.

- La envergadura de la empresa de organizar la siguiente etapa (entre Quito y el río Napo), implica transportar a pie todo el material en su poder (colecciones, equipaje, instrumental, etc.) al menos durante dos semanas. Esto supone contar con un total de unos 200 porteadores y hace que los preparativos se demoren durante dos meses. La imposibilidad final de disponer de tantas personas juntas motiva que Martínez decida dividir la expedición e ir enviando la carga según se disponga de porteadores (Miller, 1983). Durante los dos meses que dura la preparación y organización del viaje, los comisionados siguen prospectando. Así, con base en Quito, se realizan varias expediciones de colecta a distintos lugares de Ecuador. Algunas de éstas fueron: a) En los alrededores y valles próximos a Quito, donde por ejemplo Jiménez de la Espada captura ejemplares de Gastrotheca riobambae (MNCN 34903502 y 3508- 3509) y de Atelopus ignescens (MMCN 14181492 y 1521-1582) especie hoy en día extinta (Ron et al., 2002). b). La expedición de Martínez a Otávalo, donde colecta ejemplares de Gastrotheca riobambae (MNCN 3495, 3503 y 3504-3505) y Eleutherodactylus unistrigatus (MNCN 1607-1636). En el Páramo y lagunas de Mojanda, colecta ejemplares de Atelopus ignescens perdidos en el MNCN entre 1913 y 1980. c) El viaje de Jiménez de la Espada, Almagro y Martínez al volcán Antisana y a la laguna de la Mica, donde en sus alrededores Jiménez de la Espada colecta otros ejemplares de Atelopus ignescens (MNCN: 1494, 1499-1512 y 3164- 3245). También adquieren materiales a otros naturalistas, como Caecilia tentaculata (MNCN 12361237) comprados al Dr. Manuel Villavicencio.

- Finalmente el 18 de febrero de 1865 comienza la segunda parte de este viaje transcontinental, con destino al río Napo. 
Una semana tardan en atravesar los Andes y llegar a Baeza, a través de la provincia de Quijos. Pese a la precariedad del viaje, Jiménez de la Espada colecta Rhaebo guttatus (MNCN 3095-3096). Aunque permanece en Baeza más de un mes, Jiménez de la Espada no colecta anfibios, pero si aves y mamíferos que se conservan en las colecciones del MNCN, sobre todo colibríes (Barreiro, 1928).

- La salida de Baeza se produce entre el 30 de marzo y el 20 de abril de 1865, destino Archidona, un viaje de una semana. Mientras atraviesa la sierra de Guacamayos, Jiménez de la Espada colecta el ejemplar MNCN 1697, uno de los sintipos de Leptodactylus goliath, designado paralectotipo por Heyer \& Peters (1971). En Archidona Jiménez de la Espada permanece algo más de un mes y en ese tiempo colecta numerosos anfibios, de los cuales 35 (incluyendo 20 ejemplares tipo) se conservan en el MNCN. Entre ellos obtiene sintipos de Leptodactylus goliath (MNCN 1690-1691, 30583060), un sintipo de Bufo marinus napensis (MNCN 1736), el holotipo de Hemiphractus bubalus (especie tipo del género Cerathyla), el holotipo de Cerathyla braconnieri, (MNCN 1735), y otros muchos ejemplares, como los MNCN 1637-1640 (Lithodytes lineatus) o los MNCN 30473056 (Rhinella proboscidea).

- A mediados de mayo de 1865 llegan al río Napo y a la localidad de igual nombre. En los alrededores de esta localidad, Jiménez de la Espada colecta entre otros el ejemplar MNCN 1733, holotipo de Edalorhina perezi, especie tipo del género Edalorhina.

Se reúnen en Ahuano, a orillas del río Napo el 21 de mayo de 1865. Mientras se realizan los preparativos de la tercera etapa, el descenso en balsa por el río Napo hasta su confluencia con el río Amazonas, Martínez permanece en Santa Rosa prospectando sus alrededores y verificando la construcción de las balsas. Almagro viaja a Canelos y Jiménez de la Espada e Isern realizan una expedición al volcán Sumaco.

- El 22 de mayo de 1865 parten Isern y Jiménez de la Espada en canoa. Siguiendo el curso del río Napo llegan a Santa Rosa de Otas, donde Jiménez de la Espada visita los ríos y alrededores de esta población. El día 29 se internan en la selva con dirección al volcán Sumaco. Tras atravesar innumerables ríos, valles y quebradas, el 14 de junio llegan a San José y el 16 inician la exploración del volcán Sumaco. Desgraciadamente deben volver sin culminar la exploración, ante la negativa de los guías a seguir a causa del mal tiempo reinante.

Llegados a este punto, debemos hacer un breve inciso, para intentar aclarar una cuestión importante. Aunque durante todo este viaje de exploración Jiménez de la Espada colecta en los lugares visitados, es en San José donde realiza, bajo el punto de vista batracológico una colecta importantísima. De todos los anfibios colectados por la CCP que se conservan en el MNCN, unos cien de un total de 653 (de ellos 42 tipos) se colectan allí. Los diarios conservados de Jiménez de la Espada terminan justamente el día 16 de junio, cuando se dirigía al Sumaco. Probablemente los diarios que recogieron los acontecimientos posteriores se perdieron durante el azaroso final del viaje. Ya hemos comentado ampliamente este aspecto al final catálogo. Algunos de los ejemplares colectados aquí son los sintipos de Atelopus planispina (MNCN 1390-1417), los sintipos de Bufo marinus napensis (MNCN 3074-3075), el lectotipo (MNCN 1583) y el paralectotipo
(MNCN 1584) de Hyloxalus bocagei, el paralectotipo (MNCN 1585) y el lectotipo (MNCN 1586) de Hyloxalus fuliginosus, (especie tipo del género Hyloxalus), y el holotipo (MNCN 1604) de Limnophys napaeus.

- Reunidos finalmente en Santa Rosa del Coca (actualmente Puerto Francisco de Orellana) el 17 de julio de 1865, inician el descenso del río Napo. Cinco semanas más tarde (el 24 de agosto) llegan a Tabatinga, frontera entre Perú y Brasil. Por el camino han visitado las orillas, afluentes y ciudades de los márgenes, sufrido la zozobra y hundimiento de alguna canoa y balsa con pertrechos y colecciones, y por supuesto, también han colectado anfibios como el holotipo (MNCN 3474) de Hyla reticulata, y ejemplares de Ceratophrys cornuta (MNCN 1730), Dendropsophus leucophyllatus (MNCN 3473) y Scinax ruber (MNCN: 3477-3480).

- Al llegar a Tabatinga pierden el vapor de enlace con Manaos y deben esperar hasta el 18 de septiembre la llegada de otro, en circunstancias extremadamente precarias. Almagro (1866: 137) nos comenta: “... teníamos que esperar hasta el 18 de septiembre... pasamos alli más hambre que durante todo el viaje anterior... "Aquí fue también donde Isern notó los primeros síntomas de la enfermedad que habría de llevarle a la tumba. No obstante, Jiménez de la Espada colecta los ejemplares MNCN 3061 y 3076, sintipos de Bufo marinus napensis, y MNCN 3475, una Hypsiboas fasciata.

- El 19 de septiembre de 1865 abandonan Tabatinga en dirección a Manaos, con pasajes de ínfima categoría, dada su falta de recursos económicos. Coinciden con una bien preparada expedición de la Universidad de Harvard dirigida por el propio profesor Agassiz (Puig-Samper, 1988). Durante la travesía, el vapor vara y el retraso provocado hace que lleguen a Manaos cuando ha partido el enlace para Belem de Pará. Se ven obligados a permanecer en Manaos hasta el 7 de octubre y a empeñar sus objetos personales para sobrevivir. No colectan y procuran sin éxito pasar desapercibidos (Almagro, 1866).

- El 7 de octubre de 1865 y otra vez sin fondos, parten de Manaos con pasajes de la peor clase, llegando a Belem de Pará el 12 y a Pernambuco (actual Recife) el 24. Aquí, tras no pocas gestiones, Martínez Sáez, Jiménez de la Espada e Isern (éste gravemente enfermo), consiguen el dinero para embarcar con las colecciones rumbo a España. Llegan a Madrid el 21 de diciembre de 1865. Almagro lo hace el 15 de Enero de 1866 (Calatayud-Arinero, 1994). Reunidos en junta de naturalistas el día 18 de enero de 1866, dan por concluída la CCP. Cinco días después (el 23 de enero) fallece Juan Isern a causa de la enfermedad contraída durante el viaje (Barreiro, 1926).

Respecto a pérdidas documentales, la desaparición con el hundimiento de la fragata Triunfo ( 25 de noviembre de 1865 ) del diario oficial de la expedición que Amor confeccionaba, y del que habla en su carta dirigida a Pérez Arcas en noviembre de 1862 ( "... me ocupo de un diario extensísimo ... lo cual [no] me hace dormir ninguna noche más de tres horas...", Barreiro, 1926: 439). fue probablemente la mayor pérdida de información científica de todo de lo ocurrido hasta el 23 de octubre de 1863, fecha del fallecimiento de Amor. También el extravío de los últimos diarios de Jiménez de la Espada y de Martínez, que recogían los meses finales de viaje, tuvo una enorme importancia como ya hemos comentado. 
Una versión ilustrada y más detallada del viaje, puede consultarse en González-Fernández (2004).

\section{(C) Avatares de las colecciones de la CCP en España}

Hemos tratado anteriormente algunas de las vicisitudes por las que pasó la CCP durante su viaje exploratorio, con el objeto de explicar las circunstancias que de alguna forma influyeron en la colecta, conservación y obtención de la información asociada a los ejemplares. Seguidamente comentaremos algunas circunstancias posteriores que son importantes para explicar la pérdida y deterioro de los anfibios colectados por la CCP una vez ya en España.

Desgraciadamente, en lo que respecta a la conservación de los ejemplares colectados y de su información, la llegada a España de este material tan trabajosamente obtenido no aseguró su correcto mantenimiento.

A los pocos meses de su regreso, antes incluso de poder realizar ningún tipo de estudio de los materiales traídos por la $\mathrm{CCP}$, el interés propagandístico del Gobierno hizo que el 6 de marzo se comunicara a los tres comisionados supervivientes (Martínez, Jiménez de la Espada y Almagro) el deseo del Gobierno de organizar urgentemente una exposición pública, en el Real Jardín Botánico, con los materiales colectados en América. En contra de la opinión de los naturalistas, el 15 de mayo se inaugura la "Exposición del Pacífico", con gran éxito de público, abierta hasta primeros de julio. Los cambios gubernamentales y de régimen acaecidos entonces, y en los años posteriores, provocaron que la exposición no volviera ha reabrirse, como estaba previsto, en septiembre de $1866 \mathrm{y}$, que hasta 1880 no volvieran las colecciones al Museo Nacional de Ciencias Naturales (Barreiro, 1926).

En el plano administrativo, por su parte, se suspenden gubernativamente los trabajos de la Comisión de Estudio de las Colecciones del Pacífico entre 1866 y 1868. Además, en 1868 se decide que, dada la abundancia de ejemplares en muchas colecciones, éstas se repartan por Universidades e Institutos, antes incluso de poder ser estudiadas completamente. Aunque se reactiva dicha Comisión de Estudio en 1868, en 1872 por Real Orden se disuelve en cambio la Comisión Científica Receptora del Pacífico. En mayo de 1873 el recién constituido gobierno de la República ordena la continuación de los estudios emprendidos por la CCP hasta junio de 1875.
De todos estos avatares administrativos, el único gran resultado científicamente sólido es la publicación de la primera (y última) parte de los "Vertebrados del Viaje al Pacífico", tomo dedicado a los batracios, por parte de Jiménez de la Espada (1875a). Es ésta una monografía a todas luces incompleta, pues también incluye dibujos que ilustran especies nuevas, no descritas en el texto bien por falta de tiempo o de presupuesto. Desafortunadamente para la Herpetología española, Jiménez de la Espada inicia en 1873 su etapa como americanista, historiador y geógrafo, y tras no solicitar en 1872, fundamentalmente por motivos económicos (el sueldo de Ayudante de cátedra más los complementos que Jiménez de la Espada cobraba por su participación en la CCP, y alos que debería renunciar, eran mayores que el sueldo que cobraría como catedrático, almenos durante unos cuantos años) la cátedra de vertebrados de la Universidad Central, parece evidente que abandonó el estudio de la colección de anfibios de la CCP. Este material inicia así el camino hacia el olvido y el deterioro.

Los ejemplares colectados por la CCP retornan al Museo en 1880, tras 14 años de deterioro en inadecuados locales del Jardín Botánico (Barreiro, 1926). En 1895 se decide ampliar las dependencias del Ministerio de Hacienda a costa del MNCN, y éste es trasladado a los húmedos sótanos de la Biblioteca Nacional y a las dependencias del Museo Velasco, cerrándose al público hasta 1902 (Barreiro, 1992). En 1906 se trasladan al emplazamiento actual del MNCN desde el Museo Velasco (Barreiro, 1992). Entre 1911 y 1913 se produce la revisión ya comentada de la colección de anfibios y reptiles por parte de Zulueta, y es de suponer que ello supondría, además de la revisión de fichas y etiquetas, un cambio de los líquidos conservantes y por tanto un freno al deterioro producido.

Aunque la Guerra Civil (1936-1939) afortunadamente no afectó físicamente a las colecciones del MNCN, el posterior exilio de una parte importante de su personal técnico y científico contribuyó no poco a que todas las colecciones, incluidos los anfibios de la CCP, sufrieran un largo periodo de desidia y abandono, Como consecuencia de ello una parte de los ejemplares que Zulueta revisó en 1911 no se han conservado hasta nuestros días. 